\title{
The Role of Misrule in the Practice of Performance
}

\author{
Gregor Cameron
}

198272670

February 2012

Supervised by John Downie

Theatre Programme

Thesis submitted in partial fulfilment for the degree of Master of Arts in Theatre

School of English, Film, Theatre and Media Studies

Victoria University of Wellington 


\begin{abstract}
In the theatre we are familiar with how rehearsal and collaboration can lead to a number of unintended discoveries that can cause a production to change tack. At the heart of this thesis is discovery- of oneself as an artist, as part of community collaboration and as part of a story told on stage.
\end{abstract}

Using carnival as a frame for the space we work in, accepting that the 'trickster' cultural figure can be a manifestation of the carnival, it should be possible for the role of trickster to be taken on by someone in the rehearsal process. This is often but not always the director. These 'happy accidents' can in fact arise through the director's deliberate disruption of the community. At times, problems that raise their heads are solved through this creative process. Misrule is my definition of this and I offer my experience of this within the process of bringing Saint Punch, a carnivalesque/ Grand Guignol show, to the stage. I compare this with some other practitioners' experience of this process of disruptive imagination as defense of my position. By recognizing it in both theory and practice through a critical analysis my aim is to seek a synthesis intended to enrich the theatrical experience of the audience. 
MA Thesis: The Role of Misrule in the practice of Performance

\section{Acknowledgements}

First and foremost for being such a provocateur in my life for over twenty years,

My Supervisor: John Downie,

My Cast and Crew, without whom nothing would have reached playing on the floor, you know who you are and hopefully also know how grateful I am, My Mentors: Alex Funke and Horst Sarubin, Annie Forbes and Tim Denton, Damien Brell, and especially Tom McCrory, My co-conspirators for their generous advice: Kerry Glamsch, Chris Ryan, Ralph Johnson, Sean Redmond, Doug Van Belle, and Matthew Wagner Friends and Staff who stepped up to help: Dawa Devereaux, Paul Wolffram, Jim Davenport, William Franco, and Bernard Blackburn

Family \& Friends always: Shane Roberts, Roc Travers, Morna Lorden, Claire O'Loughlin and the rest of the academic and general staff of SEFTMS, Martin Payne and the Payne Whanau, Joan and Robbie Cameron (Our little group of three). 


\section{Table of Contents}

$\begin{array}{lr}\text { Abstract } & 2\end{array}$

$\begin{array}{ll}\text { Acknowledgements } & 3\end{array}$

Table of Contents $\quad 4$

$\begin{array}{lr}\text { List of Figures } & 6\end{array}$

$\begin{array}{lr}\text { Introduction. } & 7\end{array}$

$\begin{array}{lr}\text { Part One: Inspiration } & 14\end{array}$

$\begin{array}{lr}\text { The Script } & 25\end{array}$

Part Two: The Path to Performance; an exegesis $\quad 85$

$\begin{array}{lr}\text { Context } & 85\end{array}$

$\begin{array}{ll}\text { Workshops } & 87\end{array}$

$\begin{array}{lr}\text { Thoughts } & 90\end{array}$

$\begin{array}{lr}\text { Pre-Production } & 91\end{array}$

$\begin{array}{lr}\text { Casting } & 92\end{array}$

$\begin{array}{lr}\text { Rehearsals } & 94\end{array}$

$\begin{array}{lr}\text { Thoughts } & 107\end{array}$

$\begin{array}{ll}\text { Mentors } & 108\end{array}$

$\begin{array}{ll}\text { Design } & 116\end{array}$

$\begin{array}{ll}\text { Show and Tell } & 123\end{array}$

$\begin{array}{ll}\text { Thoughts } & 124\end{array}$

Part Three: Critical Analysis of Misrule and its part in the performance of Saint

$\begin{array}{lr}\text { Punch } & 126\end{array}$ 
MA Thesis: The Role of Misrule in the practice of Performance

Bakhtin and the Carnivalesque.

The Grotesque Body and the Simulacra.

The Dark Clown and the Trickster

Circling the Question of Misrule

Sacred/Profane

184

Conclusion

Works Cited.

Appendix One

Appendix Two

Appendix Three

Appendix Four 


\section{List of Figures}

$\begin{array}{ll}\text { Figure 1. Gilles de Rais- Des Morgan } & 7\end{array}$

Figure 2. Saint Punch Finale: Punch hangs the Hangman 85

Figure 3. Elliott and Adnan; discussion of The Whipping of the Quaker Women 86

Figure 4. Patrick, Patricia and Thomas, with Toy Soldiers and Barbies, playing out The Whipping of the Quaker Women. 88

Figure 5. Audrey begins to bring her puppet, Judith, to life 93

Figure 6. Judith, Audrey's Puppet, threatens to open the forbidden cabinet 98

Figure 7. In rehearsal the Inquisitor condemns Gilles to death 104

Figure 8. The television, showing the climax of the Bluebeard story, in a kitchen. 115

Figure 9. The Stage: TV Screen, Curtain, Punch Booth and Grille. 118

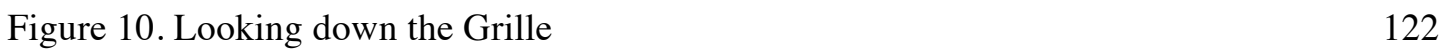

$\begin{array}{ll}\text { Figure 11. The image in front of the rape } & 175\end{array}$

All photos by Gregor Cameron or Maria Becerro Casero, 2011, used with permission. 
MA Thesis: The Role of Misrule in the practice of Performance

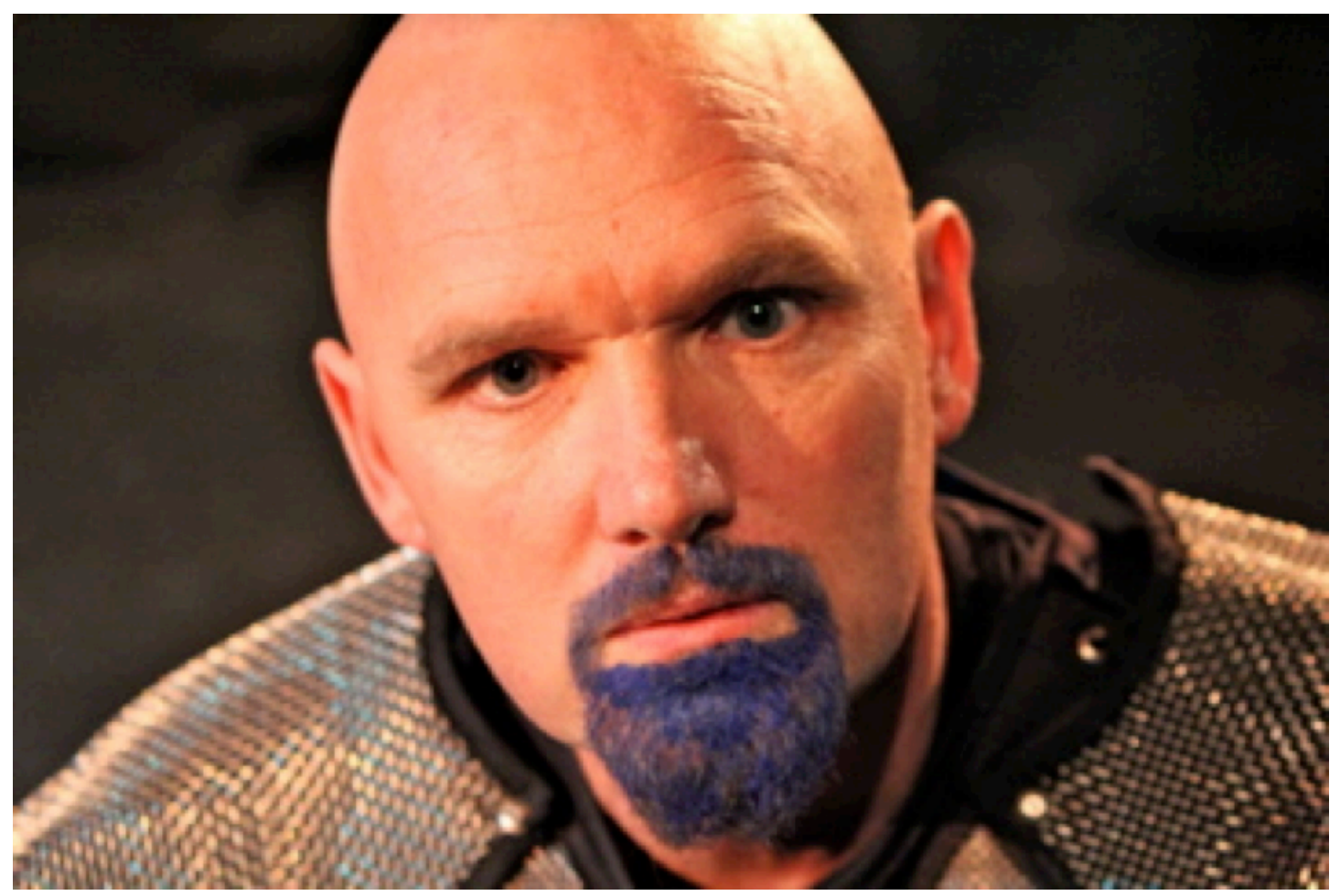

Figure 1. Gilles de Rais- Des Morgan

\section{Introduction.}

How often have I experienced that creative moment when everything can change? Not as much as I would like, as this process is rare and needs careful nurture as it arises out of a collaborative community. Certainly when this has arisen it has managed to provide a solution to a problem, which has been very helpful. I have realised that the theatre space we work in is not unlike the Carnivalesque space described by Mikhail Bakhtin. It occurs that the trickster figure that engages so many differing cultures also belongs to this space. As well as appearing in our stories I wonder whether it can also become a role in the practice of theatre and performance. Certainly I can see how, as a director, I sometimes use a trickster-like presence to inspire the rest of our community, hopefully bringing them into a creative space that allows them to dream, Gregor Cameron 198272670 
engage and adventure. These 'happy accidents' have, in my experience, brought solutions where there were only problems and inspiration where there was a block. In bringing Saint Punch to performance I have tried to map out both the physical journey of the process with the theoretical frame of the carnival and its use of the trickster. I have chosen to call this misrule.

In order to investigate this I have thought about the cultural theory frame, both in its "constative" and its "performative" forms ${ }^{1}$. Matt Hills (2005) describes how the constative refers to words that make statements and tend towards an observation and report position on cultural theory. The performative position acknowledges the constative but also demands that theory produce or has an affect upon the observed object or behaviour. In fact Hills suggests that even in its constative form cultural theory can have an affect upon those interacting with it. In a sense reporting about the workshop performance is a constative position while the work on the play itself can be observed to be performative, the cultural object as representative of the carnivalesque culture it belongs in. Thus, since my work is in itself misrulic, it demands a link between what can be seen/ experienced in the performance and then in the work that surrounded bringing it to the stage. I will introduce a series of elements that will trace this idea in a large historical frame through popular culture in order to try and define the concept of misrule and its purpose in the social spectacle of the theatre.

\footnotetext{
${ }^{1}$ Matt Hills cites J.L. Austin's work, How to do things with words (1976) as source for the terms 'constative' and 'performative'.
} 
MA Thesis: The Role of Misrule in the practice of Performance

In order to do this I have split this thesis into three parts. In the first part I offer some insight into where the project came from, its inspiration. I describe its literary and historical origin and how the three stories may be linked. There are a number of texts that contributed to my thinking. Then there is a consideration of how one's own experience contributes to the work. Misrule as a project sprang from some of these experiences and the knowledge gained. After this comes an examination of the cultural frame of the Carnival. This, in turn, leads to the dark clown and how this icon fits within the history and performance of Saint Punch. Finally I pose the question whether our consideration of this ritual space also belongs to the 'trickster' figure. Then I have included the final performance script of Saint Punch.

Secondly an exegesis of the development of the system of rehearsal, design, mentorship and performance of Saint Punch is included. I discuss the summer workshops and the difficulties that were imposed upon the process by both my own lack of confidence and the external limitations that arose. Then I move on to the pre-production and casting process where this difficult stage of opportunity and challenge collide and how the casting decisions were made. Then the rehearsals begin and the show begins to take form. I describe the system I wanted to maintain and the offers to the cast for them to participate and contribute to the formation of the play. The three differing stage environments are discussed and described, as the three stories contained in the play are each given an environment; Punch his booth, Bluebeard upon the masked stage and Gilles de Rais and Joan D'Arc the television screen. To 
further disrupt this, the characters exchange their native environments and play upon, within the particular constrains of their story, the other two environments as well. Thus, for instance, the audience meets not just the puppet Punch but also his mask and his 'real' self as mediated through visual media. An example of a moment of misrule is introduced as scene four is described and its development discussed. I then offer some thoughts on the way the rehearsal proceeded and my reflection upon them.

The mentors that I interacted with are introduced with a particular focus on how a conversation with Tom McCrory influenced my thinking on Saint Punch and, in fact, my whole approach to my work within the performance area. As the production nears its performance dates I consider the implications rehearsals and the venue had upon the design that developed and how talking with my mentors offered opportunities that were introduced into the design. Part two concludes with some insights into the show and tell performances and my thoughts about how it felt to successfully bring the text to stage.

In the final part of the thesis I bring, I hope, a more conventional academic eye to the critical theory surrounding my object, the text of Saint Punch. I frame this part with an introduction that suggests that in order to beget misrule, one must be operating within a system, using Stanislavski as my first practitioner exemplar. Then I begin with a consideration of the work of Mikhail Bakhtin and his description of the carnivalesque. As his work concentrates around the 
MA Thesis: The Role of Misrule in the practice of Performance

novel I use a number of thinkers that have followed his lead and expanded his work into the performative art arena. Of particular interest is the suggestion that the carnival exists within a liminal state, a borderland where things may and can change. I begin to find a number of contemporary examples before applying this frame to Saint Punch. This leads to a discussion of the context of the play and what I am attempting to do.

The discussion continues with the elements of the grotesque body and its role in producing a simulacrum of the reality it is critiquing. I consider the Grand Guignol of the early twentieth century. I then turn to a consideration of Brecht and his dialogue with the problem of empathy and alienation. In turn this leads back to the carnivalesque and how system and misrule can both be present on the 'stage' or classroom. A number of thinkers raise their heads here as the nature of the reality we encounter in the theatre is considered. The hoodie is offered as an example of how an object can be perceived in a number of ways depending on one's cultural and real experience. Then the figures of the Commedia Dell'Arte are connected to Mr. Punch, and out of this arises the dark clown of the present era. The simulacra of the text are then described and some sense of their significance is discussed in terms of the different mediated images that the play offers. The context of the various stories is also interrogated for the reasons that the stories are offered onstage.

As the Dark Clown is introduced it is also compared with the role the trickster has played in the cultural literacy that many societies share. Clowns are also linked into the work of Bakhtin. This trickster can be seen to play a very 
significant role in stories but more importantly Lewis Hyde (2008) argues that the trickster is a role that artists and creatives take up in order to spark the disruptive imagination that jumps their art into something new- a moment I would argue is a manifestation of misrule. Harlequin and, in turn, Punch provide something of this disruptive spirit which still exists within our modern culture. To illustrate this I choose to use a television performance that features a 'modern' trickster. Matt Hills contributes to the picture of the Doctor in the BBC series Doctor Who (1963- ) as a manifestation of the trickster figure.

Punch's presence as a trickster figure is examined and this leads to a discussion of how artists can inhabit this role. The trickster I will illustrate to be a figure that does not so much do, as one that causes or offers opportunity for things to change- a role that can also be present in the carnival. Theatre is described as a community of collaborators and within this context an example is drawn from the rehearsal process of Saint Punch of how misrule manifested itself.

Finally in part three the question of a link between theory, story and practice is explored. Using contemporary practitioners such as Anne Bogart, Mike Alfreds, Baldwin and Bicât, Judith Weston and thinkers such as Bella Merlin and Alison Hodge who comment on a range of twentieth century practitioners I attempt to draw together a number of 'moments' where I think the misrulic is observable. Using the writing of Jacque Lecoq I try to signal how this practice 
MA Thesis: The Role of Misrule in the practice of Performance

is also tied to the trickster figure and what it can offer in the project of performance.

In this way, rather than be exhaustive upon the topic, I wish to set in motion a project of thinking, a drawing together of history and culture that captures an essence of anarchy within the spirit of social spectacle. I have deliberately set my tonal approach towards the work with an eye both to the subjectivity of the artist's relationship with his work, and as I move outside into critical theory and practice I have chosen to foreground a more neutral position in the writing. In this sense to draw the constative closer to the performative and suggest that object and practice are much closer in co-existence than I previously thought. 


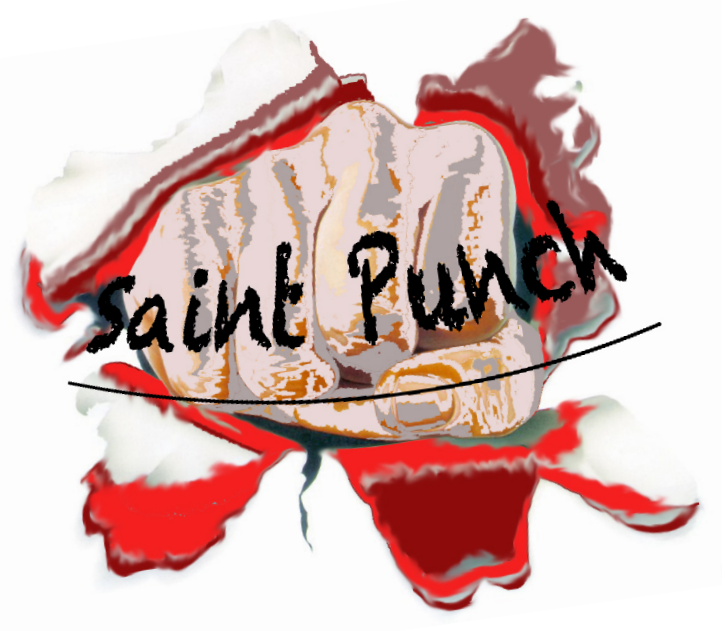

\section{Part One: Inspiration}

Saint Punch has its beginnings with a book that fell into my path some years ago, at the Wellington Public Library. For some forgotten reason I was seeking information about Joan of Arc and the catalogue pointed out this book, The Saint and the Devil by Frances Winwar. Published in 1948 it seemed too old to be relevant and yet I took it home. From that moment my path was forever changed (said in a melodramatic but ironic way). The book compared the journey of Joan to sainthood with that of her Companion-at-Arms, Gilles de Rais, towards a life of devilry and death. It pointed out the travesty of Joan being put to death for the crime of wearing men's clothing with that of Gilles, about ten years later for the crime of conjuring demons. The irony was underlined by the fact that de Rais was also known to have raped and murdered over 144 children after his mission with Joan at Orleans and her 
MA Thesis: The Role of Misrule in the practice of Performance

subsequent death, but for which crimes he was not condemned. In fact reports came out that he would do these things purely for pleasure and often at evenings of entertainment for his noble neighbours. He took as his mandate the difference between noble and peasant as permission to do as he pleased. Grimly enough his being a noble allowed him to ask for a mercy denied Joan, that he would be suffocated before the fires were lit so that no naked flame should touch his still living body. I was aware however that there are a number of different versions and that the 'history' was open to some negotiation about what may or may not have happened. It is not my purpose to debate these arguments here, but it was this first forage that fed the imagination.

This story/ 'historical' event was to stay within me for some time. It came up again when I was flicking my way through a friend's edition of Women Who Run With The Wolves by Clarissa Pinkola Estes (1992). I found myself taken by the reference to the story of Bluebeard. Subsequent reading would connect these two narratives as one, Bluebeard serving as a mediated, through folk tale, version of Gilles de Rais, who reportedly did colour his beard blue. Estes used this particular story to allow an exploration of a woman's rise into her sacred power- spotting predators, trusting instincts, seeing through the appearance to a truth beyond and thus navigating the path of her life under her own direction. Bluebeard offers the external threat that Estes later is able to compare with the internal. Much later, in the midst of rehearsal, I discovered Angela Carter's version, The Bloody Chamber (1979), where the young protagonist is attracted to the cunning 'Bluebeard'. She also acknowledges her inner complicity in this descent into the pit. Carter has been aligned with the 
feminist-centred readings of Perrault and de Sade, however she has disputed such a simplistic labeling preferring to see the work as deeply rooted within the subconscious $^{2}$. Food for thought perhaps, but not essential to my point. Not only are these stories popular but also offer a gateway into cultural significance. Bluebeard can be found as a reference or a topic in cultural artifacts as diverse as opera (Bartok's Bluebeard's Castle) to Heavy Metal (Cradle of Filth's 2008 Godspeed on the Devil's Thunder) through to appearances in plays (Shaw's Saint Joan) to movies. Most close to home is Jane Campion's The Piano (1993) where his story is being played out as the children's shadow puppets.

Which is a good place to start looking at why Saint Punch revolved around the characters of the traditional Punch and Judy of English seaside holiday fun of the Victorian and early to mid-Twentieth century eras. Of course the tradition is much older than that. Some indication has been given that it may have connection to the trickster traditions that many cultures share. In 1994 Neil Gaiman followed up his success in The Sandman series of comics and graphic novels with The Tragical Comedy or Comical Tragedy of Mr. Punch. Rogue Artists Ensemble mounted a stage adaptation of the graphic novel in $2007^{3}$. In this graphic novel the nature of loneliness and dreams are interrogated and exposed using the character of Mr. Punch as provocateur. I was reading

\footnotetext{
${ }^{2}$ Helen Simpson on Angela Carter's Bloody Chamber | Books | The Guardian Helen Simpson on Angela Carter's Bloody Chamber | Books | The Guardian http://www.guardian.co.uk/books/2006/jun/24/classics.angelacarter accessed Tue. 19 July 2011

3 http://www.rogueartists.org/index.php?option=com_content\&task=view\&id=34\&Itemid=92 accessed Wed 24 Aug 2011
} 
MA Thesis: The Role of Misrule in the practice of Performance

Annalisa Di Liddo (2009) who, in writing about the work of Alan Moore

(Watchmen, Lost Girls and other graphic novels), makes the argument to look at these objects not only as literature but also as a form of performative text. Following her logic it is not surprising how easily these texts adapt to film, television or the stage considering their similarity to the storyboarding technique used in these industries at times. She also uses Bakhtin's terms including the chronotope, to describe these forms. Moore like Gaiman uses a wide knowledge of history, mythology and culture to bring his works to life.

I was fascinated to read this innovative use of the Punch character and began to find out more about him. On May 9, 1662, Samuel Pepys notes that he is 'mighty pleased' by an Italian puppet show encountered near St Paul's Church in London's Covent Garden. ${ }^{4}$ It is likely that Pepys' Punch was a marionette rather than a hand puppet and probably named Punchinello which allies with the names Polichinella, Pollicinello, Polichinelle, and the commedia import, Pulcinella. Hence then a link to the Commedia Dell'Arte companies traveling Europe and Mr. Punch, as the name became, would in all likelihood have offered a harlequinade relief to even the most serious of stories, in much the same way as clowns were used in the plays of Shakespeare. This dark clown, it seems, was introduced to England with the restoration of Charles II, the Merry Monarch.

In terms of my work I was amazed to find out that in the eighteenth century Mr. Punch had acquired a wife to fight and bicker with. At that time she was called,

${ }^{4}$ http://www.punchandjudy.org/mainframesethistory.htm accessed 24/8/11 http://www.punchandjudy.comwho.htm accessed 24/8/11 
significantly, Joan. While it is conjecture to link the other two stories with that of Mr. Punch one cannot but see how allied they seem to be when considering the dark underlying motif of violence that they provide. In the nineteenth century the more familiar Judy emerged. During this century the characters and tragical story evolved even as the string puppets lost ground with the upper classes and the glove puppet gained ground with those lower down. It was this lower class version that was recorded in London Labour and the London Poor by Henry Mayhew, published in 1851. By this time the Joey clown and the hangman Jack Ketch are still part of the company of puppets but the Negro servant, or Darkie as he was known have been supplanted by the crocodile (perhaps there is a link with the one in Peter Pan by J. M. Barrie). ${ }^{5}$ Also the Devil no longer features in the cast, possibly also replaced by the crocodile. Judy is now playing the Ghost and it is she who is first resurrected as the cycle reconstitutes itself. J.R. Cleland writing in 1948 likens Mr. Punch to the morality plays of the mediaeval era. ${ }^{6}$ He suggests that by considering the characters as allegories one might see Mr. Punch as an Everyman seeking to travel from his baser earth-bound existence to one more closely allied with God- a carnivalesque journey. He acknowledges that truly tracking Punch's origins is always going to involve a certain amount of conjecture but I think there is certainly worth in entertaining the idea that

\footnotetext{
${ }^{5}$ http://www.punchandjudy.comwho.htm accessed 24/8/11

${ }^{6}$ Puppet Master Volume 2, No 3 pp. 65-68 accessed from http://www.puppetguild.org.uk/digivendpmarchive.htm 2011-09-12 16:27:00
} 
MA Thesis: The Role of Misrule in the practice of Performance

Punch represents a spirit of some consequence rather than just being dismissed as a puppet.

Two further interruptions in my life were to influence the birth of Saint Punch. Firstly I was hospitalised with appendicitis and spent over three weeks in a drug-induced nightmare of visions and delusions, often involving giant, mansized, and, for some reason, yellow ants. These nightmares were probably an indication of how hard my body was trying to fight the post-operative infection that had necessitated the doctors to give me what they described as a toxic level of antibiotics. On my recovery the first draft of Saint Punch was born.

Secondly came the impression left on me of my travels the following year, where my passion for theatre was reborn. In circling the world I was able to seek out and experience many different theatrical styles that are not normally available here in New Zealand. In particular was a commedia show called Carnivale I encountered in Venice, which brought together a number of commedia characters and a formidable audio-visual component to tell the history of Venice. With the easy humour of the clowns offsetting the more documentary feel of the slides and music this was one of the best examples of how theatre can engage in educating and entertaining that I have ever seen. A few days later I was in Berlin and took a day trip to Sachsenhausen Concentration Camp (see appendix 4). This stark reminder of the atrocities of the Nazis was very affecting. Particularly when I saw a picture of Harlequin on the wall of victims. A young gay dancer, who had loved playing this role, had been incarcerated in the camp and there met his end. It occurred to me that 
only the rigidity of the Nazi rule could have killed the misrule of Harlequin/Arlecchino. Also of import was the poem by prisoner/ Pastor Martin Niemöller ${ }^{7}$. This is where I am first aware that my mind had begun to engage in the problem of misrule.

Misrule, it seemed to me, was a process or an opportunity. It was not the opposite of rule and didn't quite fit with ideas of order and chaos since to my mind order at its most extreme would tend to exclude the possibility of misrule. If misrule was some sort of opportunity then how did it manifest itself, what affect might it produce and how could one both observe it and exploit it in creative practice. My thinking began to be influenced by readings about the frame of the carnivalesque. I began looking at Mikhail Bakhtin's work, which centres on the novel. That brought me to the writings on the carnivalesque that have expanded his work to include the theatre. Added to this is the consideration that Mr Punch has some aspects of the dark clown and that sent me looking at the development and history of the Buffo/ Bouffon.

The Dark Clown is a very interesting alternative to the white-faced/ sad/ angry Clown and the red-nosed/glad/ foolish clown which Eric Idle writes about in The Road to Mars (1999). Idle writes this post-modern novel as an 'academic's' attempt to reconstruct a thesis of an android who in turn is trying to serve his comedian owners while researching into the nature of comedy. 
MA Thesis: The Role of Misrule in the practice of Performance

Idle seems to be saying that in order to be funny one has to be disturbed, that the funniest comedians are also the saddest personalities on the planet. He cites such pairings as Laurel and Hardy or Martin and Lewis. Oliver Hardy and Dean Martin are examples of the white face clown and are often the instigators of self-serving action- possibly action that is at odds with what society would consider acceptable. In counterpoint Stan Laurel and Jerry Lewis are examples of the red nose Clown, the fool whose innocence and naïveté constantly complicates and defeats the white face clown's efforts to control things. Other partnerships (which I have added to) fit these descriptions: Abbot and Costello, Penn and Teller, French and Saunders \& Flight of the Conchords

Bakhtin acknowledges these two forms of clown- the rogue and the fool. He also adds a third category simply known as the clown- which can be seen in dramatic terms as the clown in some of Shakespeare's plays who is able to comment upon high and low alike. This 'dark' clown however has a very different agenda. Often allied with the 'killer clown' genre the dark clown is more likely to be looking outward into the world than these two inward reflecting clowns. In carnivalesque terms these clowns have a relationship to both high culture and the low. They are often located within the low culture but through their vision, as the Fool in Shakespeare's King Lear, may be located quite close to the centre of power. Set as commentators upon these cultural centres they either observe or participate. The clowns seem to be assuming very specific roles. Bakhtin, according to Vice, sees the three behaving according to these roles thus:

The rogue parodies high languages; the fool is 'naively in-comprehending' of the high languages s/he comes into contact with; the [dark] clown Gregor Cameron 198272670 
'unmasks' high languages and has license to utter the otherwise unacceptable.

(Vice, 1997:69)

The appellation 'dark' is appended to the Bakhtin description to differentiate this clown from the others. This clown most closely combines the elements of carnival within their appearance and behavior. Puck in A Midsummer Night's Dream might be an essence of this misrulic ${ }^{8}$ clown- it is not chaotic since that would necessitate no regard for the rules- Puck is subversive of the rules but not transgressive. The Joker out of the Batman comic mythos is perhaps a more chaotic clown. However both these examples are emblematic of the Dark Clown through which the status quo, the normative might be interrogated and judged. They challenge the way things are -one through magic and the other through acts of insanity and crime.

Thus, Mr. Punch can be viewed through the lens of the dark clown. He upsets the status quo and holds no respect for high or low within his grasp. He is the grotesque body alive and laughs in the face of consequence. He is reborn within each story as are the other characters. We, as audience, may be shocked at his behaviour and yet is he not acting, as sometimes we ourselves are tempted to do. He brings misrule to the fore so that we may seek, through reflection, that which is good within the actions of the bad.

\footnotetext{
${ }^{8} \mathrm{~A}$ term applied to the companions of $\mathrm{Hal}$, who as he becomes Henry V distances himself from them. Quoted as a word on Page 445 of the notes in A New Variorum Edition of Shakespeare see Bibliography. I use it here to connect the concept of misrule with the behaviour of the clowns and to identify the element that needs to enter practice to allow it to exist in the theatrical endeavor.
} 
MA Thesis: The Role of Misrule in the practice of Performance

This ritualism of the sacred and the profane is also a fascinating aspect of the carnivalesque. I wonder if there is not something of the trickster myth embroiled in Mr. Punch and the dark clown. The trickster is often the catalyst of action rather than the 'actor' himself. In Anansi, Coyote, Maui and Loki he, most often, causes something to happen or draws action towards himself that requires others to seek truth, and the power to solve the problem. This action is often transgressive or grotesque, for example Maui trying to capture the Sun or how Coyote stole fire. These figures are often seen as vulgar unfinished types. "Trickster is a creator, a transformer, a joker, a truth teller, a destroyer."9 The exploration of the transgressive and grotesque can offer insight into the sacred and aspirational.

And here I again face my questions. If the carnivalesque exists as a framework for our story telling, is it also a manifestation of our developing work? What is the relationship between the carnivalesque and misrule in terms of creative endeavour? How can we approach a work that is itself an example of the carnivalesque with an open hand to the 'happy accident'?

As you can see with the following script of the workshop performance, some of these questions are very pertinent. It is important to note that the first draft of this text was submitted to the scriptwriting course run by John Downie in 2006. Since that time and especially as rehearsals developed the piece was altered and updated as discoveries were made on the floor. The script is included, not 
as part of the marking, but to acknowledge how important a part of the creative practice it was, and as a way of recording, along with the enclosed DVD, the final shape of the show. 


\section{The Script}

\section{SCENE ONE}

(Punch throws the baby out the window,

Gilles 'rapes' a child and Bluebeard

scares his wife. )

Stage

Preparations for a wedding. An old man, well dressed, the PROFESSOR enters and faces the crowd:

\section{THE PROFESSOR}

Isn't it nice when we gather...(improvise).... I want to tell you a story. It's a story of a young woman, a beautiful woman, constantly chased by the boys, and as she grew she is then chased by the men, in fact, she draws attention from a couple of the women too... heh! One day her father calls her, he wishes....

A phone rings. A At the back is a large Curtain through which the characters come. To the right Punch's stage/ booth is empty except for a large 'brick' phone lying to one side. The Booth is in the classic pseudo-pros arch but larger than a normal punch-man's booth. It includes the flies at the back that allow a change of scene. Centre stage is an open trap with a grille to look through. At the back directly opposed to the booth is a large old-fashioned Television screen where the historical 'real' black and white images appear. The phone continues ringing. A voice is heard from off-stage. Nothing changes on the stage.

\section{THE PROFESSOR}

Mr. Punch?

(Silence)

\section{THE PROFESSOR \\ Mr. Punch?}

(Silence)

\section{THE PROFESSOR}

Punch? Aren't you going to answer the phone?

Silence. The phone continues ringing- more Insistently 
THE PROFESSOR

Mr. Punch! It's time to answer the phone!

PUNCH. (O.S.)

What?

THE PROFESSOR

It's time to answer the phone.

PUNCH. (O.S.)

What phone?

THE PROFESSOR

The one that's ringing.

PUNCH. (O.S.)

What one that's ringing?

The phone gets louder.

THE PROFESSOR

Can't you hear it?

PUNCH. (O.S.)

Can't I hear what?

THE PROFESSOR

The one that's ringing!

$\mathrm{PUNCH}$.

I can't hear it.

THE PROFESSOR

You can't hear it?

PUNCH. (O.S.)

No. I can't hear it.

THE PROFESSOR

Why not?

Booth

Punch appears in the Puppet booth.

PUNCH. 
MA Thesis: The Role of Misrule in the practice of Performance

I've got this awful ringing in my head.

The Professor appears from underneath the stairs.

THE PROFESSOR

Mr. Punch! Answer the phone!!

PUNCH.

Won't

THE PROFESSOR

Oh, come on, Punch, it might be important. All you have to say is "Hello".

Punch begins pacing, putting on a moping face.

PUNCH.

Oh dear. Oh deary, deary me. Oh deary, deary, deary me.

(How annoying can this get?)

THE PROFESSOR

Mr. Punch?

$\mathrm{PUNCH}$.

Yes?

THE PROFESSOR

Answer the phone.

He leaves shaking his head. The phone is now the most annoyingly loud sound. Punch stands on the phone.

PUNCH.

Hello?

Silence. The phone rings again.

$\mathrm{PUNCH}$.

Hello? Hello, hello, hello, hello?

THE PROFESSOR

(Pausing at the exit))

Push the button, Punch.

Punch looks over the audience side of the phone.

PUNCH.

What button? 


\section{THE PROFESSOR}

The one on your side.

Punch looks down at himself. He looks up puzzled.

PUNCH.

I haven't got a button on my side.

THE PROFESSOR

... Of the phone.

PUNCH.

Ohhhhh.

He punches the button. The phone stops ringing.

$\mathrm{PUNCH}$.

Hello, hello, hello, hello.

Judy's voice comes out of the phone.

JUDY.

Now what's all the noise Mr. Punch? You'll wake the baby.

PUNCH.

Hello, Hello, Hello, Hello.

JUDY.

Really Mr. Punch, don't make so much noise. I do believe you've woken the baby.

The PROFESSOR shakes his head and quietly leaves the stage.

PUNCH.

I haven't.

JUDY.

Oh yes you have.

$\mathrm{PUNCH}$.

Oh no I haven't.

JUDY

Oh yes you have, and you'll have to look after him now. 
MA Thesis: The Role of Misrule in the practice of Performance

PUNCH.

Judy.

JUDY.

Yes Mr. Punch.

PUNCH.

Give-us-a-kiss.

JUDY.

What. Over the Phone?

Punch leers down the phone.

$\mathrm{PUNCH}$.

Oo-kay. What are you wearing?

JUDY.

What? Tell you that- out there in front of the audience? You'll not get round me like that.

PUNCH.

Oh yes, I will.

JUDY.

Oh no you won't.

PUNCH.

Oh yes I will- You're wearing a pink dress with a head scarf and sensible shoes.

Silence. Judy enters the stage. She is dressed just as Punch described her. She is talking into a little cell phone of her own.

JUDY.

How did you know that?

PUNCH.

(as though it is obvious)

I sat across from you at breakfast.

JUDY.

You are a rascal Punch. Now I will make you look after the baby.

She exits.

PUNCH. 
Oh lovely baby, nice baby, where's the baby, Judy?

Judy re-enters carrying the baby. She hands him to Punch.

JUDY.

There you are, Punch. Now, look after him, the little darling.

(To audience.)

Now 'boys and girls', I want you to make sure Mr. Punch looks after the baby properly. If he doesn't treat it properly will you all call me? 021 TELL ON PUNCH

She begins to leave. She stops, peers at Punch.

JUDY.

Very well. I'll be back, Mr. Punch!

She leaves and Punch freezes.

FADE IN:

Screen

A glow infuses the screen. Gilles sits. The dissolute warrior. He is drunk. Two women whisper and giggle at the grille as they watch him. Gilles staggers to his feet and unsteadily crosses the stage. He is dressed as though he belongs in a medieval tapestry- 13th Century.

\section{GILLES}

Bring me another one.

THE PROFESSOR (O.S.)

We're running out.

\section{GILLES}

I said- bring me another one!

The two women giggle and peep over to see the scene below. To their consternation they don't see Poitou/Professor. A child/teen is thrown into the room. It is confused and afraid. The two women 
MA Thesis: The Role of Misrule in the practice of Performance

indicate their excitement. Gilles approaches like a snake towards his prey. His eyes rove across the child's body in the most rapacious manner.

GILLES

So what do we have here? A lonely goat boy or the dutiful daughter lost upon her way to Grandmama's. I Cannot tell, it is so dirty and badly dressed. Is this a dress or is it some hand down shirt from older brothers now left home?

He roughly seeks to determine the gender of the child, pulling at the child's clothes- each lunge of which is met by fear and cringing from the child. He works his way around the child. His hands disappear up the back of the shift.

\section{GILLES}

See how it cringes, seeking about for some form of salvation. A little dalliance upon the path to little death. A girl? They were running low. Ah, my lovely- it seems you are a girl!

From behind the child he quickly translates to the front and pulls open the shift, looking down. The women giggle and whisper to each other.

\section{GILLES}

And almost able to suckle a child. A miracle, for such as you would all-too-soon find yourself with sucklings mewling at your ankles, a farmer's too rough hands bruising flesh too soon brought to its age. Never mind, my lovely, tonight we will not worry at such things, we will instead look forward into the distance, we will instead provide the night with calls to entertainment. See, above even now, the crowd does gather, their faces eager, wondering what the nature of the evening is going to bring before them.

The child tries to make herself as small as she can. Gilles runs his hand sinuously down her back. A ripple of excited laughter echoes from above as the women coo and bid their lord to get quickly up to action.

\section{GILLES}

And doesn't all this oh- so soft and yet, so firm flesh excite the hackles of those too jaded by what they may not have, who's only redress is to watch, to revel in 
the pain of one so vulnerable.

He kicks her.

\section{GILLES}

Let that serve as an object lesson. My audience has all too much appetite for such melodrama that to cheat them of it would prove to both our tastes a bitterness.

The child sobs and tries to crawl away.

\section{GILLES}

Ah, I see you misunderstood. It grieves me not to provide another taste.

He kicks her again.

\section{GILLES}

So, now. Upon your knees, peasant, and open up the path. For to me, it matters not whether, a he or a she, you be.

The two women signal their enjoyment of the sport.

Gilles prepares to enter the girl from behind.

Gilles and his victim slow to slow motion as

counterpoint to Punch's song. The girl whimpers

Punch unfreezes and carries the baby to the edge

of his booth.

Booth

PUNCH.

(Sits down and sings to the baby) 'Hush-a-by, baby, upon the tree-top, When the wind blows the cradle will rock, When the bough breaks the cradle will fall, Down comes the baby and cradle and all.'

The Baby cries. Gilles reaches over and takes the throat of the girl in two hands- her whimpering is cut off

PUNCH.

(Shaking it.)

What a cross boy! 
He lays it down on the booth's stage, and rolls it backwards and forwards, as if to rock it to sleep, and sings again.

Punch continues rocking the child. It still cries, and he takes it up in his arms.

PUNCH.

What a cross child! I can't a-bear cross children.

Then he vehemently shakes it, and knocks its head up against the side of the proceedings several times, representing to kill it, and he then throws it out of the booth.

\section{Screen}

Gilles has all but throttled the girl when her face comes up and takes on a strength that throws him off her and across the room. She has transformed into Joan of Arc. Gilles is terrified.

JOAN

So it seems, 'monsieur champion', that the years have set your devilry upon those who in the past you were full sworn to protect with all the strength of both your heart and that of your arm.

Gilles cowers again at the bottom of the stairs.

\section{GILLES}

(terrified beyond reason) Jeanne? La Pucelle?

The screen goes dark.

Stage.

Above the two women turn and cower as a huge man stamps across to them.

\section{BLUEBEARD}

Didn't I tell you not to, didn't I tell you? Didn't I

say to you- all my worldly goods I gift you, if only this one small room belongs to me? And how do you pay me? What have you done? The moment my back is turned, so I fail to see, You break my heart, you take it away, You prove to be, it seems, the very thing I wished you not, 
Judith stands in front of a terrified Clara stands before the other.

CLARA

Judith, Be Careful!

JUDITH

It is not what you think, my love, it is not what you

think it. My sister and I, my love, just wanted to peek. We did no harm, my love, we did no harm- We sport with keys, my love, and we run the house. It wasn't no trouble, my love, no trouble we seek.

The huge man towers over the terrified women, they shriek and run off.

\section{BLUEBEARD}

I'll cut off your heads, I will, I'll cut off your

heads. And I'll feed your bodies, 'my love' to the dogs of the wood. And then you're mine, my love, to do as I've wanted, All bottled up, my love, is all bottled up. Is boiled up, you'll be, and finely pickled. And when you are, my love, all bottled up, Well then, my love, -I'll see you decanted.

The huge man lumbers off to follow the women off.

Booth

Punch unfreezes. He looks out to the audience.

PUNCH.

What a pity, what a pity

JUDY enters.

JUDY.

What's a pity Punch? Where's the baby?

PUNCH.

Gone to bed.

JUDY.

Gone to bed? 
MA Thesis: The Role of Misrule in the practice of Performance

PUNCH.

Yes.

JUDY.

(To audience.)

Is that true?

\section{AUDIENCE}

(responding to her?)

Thrown him out of window, etc.

JUDY.

What? Thrown my beautiful baby out of the window. Oh you cruel man.

PUNCH.

Didn't.

JUDY.

Oh yes you did.

PUNCH.

Oh no I didn't, etc.

JUDY.

Oh you cruel horrid man. How could you?

PUNCH.

(Wheedling.)

Judy.

JUDY.

Yes.

PUNCH.

Give-us-a-kiss.

JUDY.

Yes, I'll give you a kiss.

She bobs below to get slapstick with which she be-labours Punch.

JUDY.

Here's a nice kiss (bang) and here's another (bang) and another. I hope you like my kisses Mr. Punch.

She chases Punch around the stage, beating him, but eventually Punch manages to get hold of the stick. 
PUNCH.

Thank you Judy for your kisses, thank-you (he hits her.)

Thank-you, thank-you.

JUDY.

Enough Mr. Punch. No more kisses.

PUNCH.

Just one more.

He hits her especially hard and she falls motionless on to the booth stage. He pokes her experimentally - then rolls her to one side of booth.

PUNCH.

That's the way to do it. Poor Judy. What-a-pity, what-a-pity:

\section{End OF SCENE ONE}

\section{SCENE TWO}

(Punch and Joey, Joan beats a soldier and Bluebeard seduces Judith. )

\section{Booth}

There is the sound of men's voices. A little group of drunken soldiers appear upon Punch's booth/ stage. They speak in muted 'foreign' voices obviously familiar with each other/ comradely. They begin to gamble. One man seems to be keen to join in but is at the back of the group. He constantly wishes to gamble.

There is the sound of approaching hooves. Joan and Gilles puppets appear in the booth riding small horses. Joan is resplendent in shining white armour and Gilles in darkest matte black.

JOAN

What is it they do here, sirrah?

\section{GILLES}

Come away, girl, these lowlifes offer no succour e'en for such as thee. 
MA Thesis: The Role of Misrule in the practice of Performance

JOAN

Come now, sirrah, you must know what they do.

GILLES

I do know, but little good can come from you

Interfering.

JOAN

Tell me!

GILLES

They gamble...

JOAN

What?

GILLES

They gamble, a game played by drunks for the sole purpose of losing all they have- leaving their families to starve...

JOAN

They gamble?

GILLES

It is oft the way with such as these. Surely you must have come across such fools in that little mud puddle that you hark from.

JOAN

Take care with your impertinence, de Rais, never forget that the Dauphin placed you in MY service.

\section{GILLES}

I never forget that, la pucelle, you never allow me to forget that.

Joan indicates the men gambling

JOAN

And so...

GILLES

They do no harm.

JOAN

But do they not understand that they stand for the Maid's army- the holy army of France! 


\section{GILLES}

The maid's army?

JOAN

Don't fool with me, sirrah, I lead the Dauphin's forces.

Gilles stops as Joan steps forward. If he were human an eyebrow might raise.

GILLES

Indeed.

JOAN

Indeed. Now deal with these sinners.

GILLES

Leave them alone, girl, please, can you not see they do no harm.

JOAN

Harm? I'll show them harm.

Joan leaps off her horse. She draws her sword- a large white version of Punch's stick.

GILLES

La Pucelle, I beg of you, do not provoke these men. It can only lead to trouble

He seeks about as if hoping for some help from others.

JOAN

If you are unwilling to stand up for me - then I guess I must do for myself- they shall rue the day they stepped across the line between grace and sin. I will not leave this alone- the Dauphin's army shall be walking in the eyes of God- they must be ready, sinless. I will drive out the sinners, the whores. These men shall neither gamble nor swear, they shall not steal and they shall look to their brothers as they would look to themselves.

As she says this she approaches the group of men swinging her sword. She begins hitting out at 
MA Thesis: The Role of Misrule in the practice of Performance

anyone near enough to feel the bite of the flat of her sword. Most of the men manage to escape but one poor fellow falls at her feet and she just keeps on hitting him. He screams

GILLES

Enough, girl, enough. Whatever he may have done he does not deserve to die.

JOAN

He does not?

GILLES

No, Jeanne. He does not.

She gives the man one final wallop. He lies there unmoving.

JOAN

Well, at least this way he will serve a purpose, a lesson to others who would dishonour the maid, and thus go against the will of god.

GILLES

(aside)

Some God.

They freeze.

Stage

There is a huge scuffle going on off stage.

Suddenly Judy's body lands on the stage and lies there as if dead. Punch enters fighting a black crocodile. Both are now masques. Punch hits the crocodiles nose with his cudgel. The crocodile reels and turns to Punch.

\section{CROCODILE.}

Why ever did you do dat fer! I dint cause no harm to you. You'll no doubt break ma dose!

PUNCH.

Humbly do I beg your pardon, I did not go to help it.

\section{CROCODILE.}

Nebber yo' mind, Sir Punch, come and sit down, and den we'll hab a song. 
PUNCH.

I'll not sit and sing with you' Sirrah, for the 'notes' within thy smile, do to me, look far too sharp. I'll not be the melody in case it too soon becomes 'harm-to-me'.

The crocodile follows Punch around stage, begging - until turning suddenly Punch comes face to face with it.

\section{CROCODILE.}

In that case will you share my stock of Sausages?

PUNCH.

Sausages? What Kind?

\section{CROCODILE.}

Pork and Garlic?

PUNCH.

With Cheese?

\section{CROCODILE.}

Three kind of Cheeses, tasty, mozzarella , and go-to-church holy cheese!

PUNCH.

Holy cheese? You wouldn't be wanting to Swiss me would you?

CROCODILE.

What, me?

Crocodile grabs Punch's nose and there is a violent tussle. Finally he breaks free and drives the Crocodile off with a shower of blows. He kills the crocodile just beside Judy's body

PUNCH.

Oh dear, Oh dear, my poor nose, my poor beautiful nose. What-a-pity, what-a-pity, ditty-ditty-do.

Punch freezes. 
MA Thesis: The Role of Misrule in the practice of Performance

Screen

Upon the screen as the lights come up a beautifully resplendent man stands. He looks as though he might have stepped out of a child's bedtime story. His beard is dyed blue. Poitou's voice can be heard from off-stage before his head appears.

POITOU (O.S.)

Messire, messire, she comes, she comes.

BLUEBEARD

Of course she does, Poitou, they always come.

POITOU

(his head appears.)

Is she pretty, Messire?

BLUEBEARD

What would be the point otherwise, Poitou.

POITOU

Having children, M'lord?

Bluebeard does not even acknowledge him.

BLUEBEARD

Leave, Poitou. And show the young lady in.

POITOU

M'lord.

He leaves

BLUEBEARD

Thus do my plans come to fruition. How do I look? Beautiful- at least for her eyes. I doubt not she shall see only the stars she wishes to see.

Poitou appears. Judith passes gingerly past him.

POITOU

M'lord- the lady Judith.

JUDITH

I'm no lady, M'lord.

BLUEBEARD 
And Poitou's no judge of character. And yet, tonight I think he may be right. Few ladies would hold a light to the shine I see hovering about your head, the jewels within your eyes and the blush upon your lips. You came here alone?

JUDITH

No, m'lord, my sister, Clara, rode as chaperone, if it please you.

BLUEBEARD

And she waits where?

Judith indicates the entrance she came in from.

JUDITH

Without, m'lord, your man told us she may quietly listen from there and yet give us some privacy.

\section{BLUEBEARD}

Ah, Poitou, where would I be with out him. I shall of course make sure your sister sups as we take our own refreshment.

JUDITH

M'lord, you are too kind.

\section{BLUEBEARD}

Nonsense, your company is fair exchange for any kindness I may show.

Judith flushes and begins to look around for a way to change the subject.

JUDITH

You live here alone, m'lord

\section{BLUEBEARD}

As alone as one can be surrounded by servants, my Judith. Do you appreciate my home, Judith?

JUDITH

It's beautiful, m'lord, it puts my father's house to shame.

\section{BLUEBEARD}


MA Thesis: The Role of Misrule in the practice of Performance

But he is rich in daughters is he not?

JUDITH

Not, m'lord, as much as if we three were sons, m'lord

\section{BLUEBEARD}

Will you not call me Guy, my Judith?

Judith stares at him for a moment. She makes a decision.

JUDITH

Clara! Come here.

Clara enters from the same entrance as Judith

\section{CLARA}

Judith?

JUDITH

Are you there my sister? What think you?

CLARA

He's very forward, this one. Do we feel safe?

JUDITH

I believe we are.

CLARA

Then it will do no harm for you to enjoy a little company, I know that is what you wish. I shall go back to my embroidery.

Judith smiles as Clara leaves.

JUDITH

You do that. But keep an ear out- I know how you can get after eating too much and too well.

Bluebeard smiles.

\section{BLUEBEARD}

Poitou!

The lights dim.

Stage.

Joey the Clown enters. Joey dances round Punch in all directions, and Punch with his cudgel is 
determined to catch him if possible.

JOEY

No bono, allez tooti sweet, Mounseer. Look out sharp!

Make haste! Catch 'em alive! Here we are! How are you?

Good morning! Don't you wish you may get it? Ah!

Coward, strike a white man!

Joey the Clown keeps bobbing up and down, and

Punch tries to hit him all the time till Punch is nearly exhausted. Maybe Punch is fooling so Joey is careful, he's too cunning for him though, and knows him too well. The dance continues.

Eventually falling into a heap laughing the clown turns to Punch and they both shake hands and make it up.

JOEY

Now it's all fair; ain't it, Punch?

PUNCH.

Yes.

Punch devises a bit of business involving getting Joey to hold up his leg so that he might rest. Joey is angry.

JOEY

Now I shall begin again.

They begin trading blows again till it begins to really look like a dance. Finally Joey uses his finger to so insult Punch knocks him down, apparently dead. Punch then begins to count the bodies - Judy, Crocodile and Joey. But the Clown is not dead and every time Punch moves a body to centre stage, the Joey Clown moves it back to the side when Punch is not looking. Punch gets more and more excited. Then the Clown removes bodies one at a time till only he is left. Punch is puzzled and looks very closely - the Clown suddenly comes to life and hits Punch, then runs away.

JOEY

Good! You can't catch me. 
MA Thesis: The Role of Misrule in the practice of Performance

Roaring, Punch follows him off.

Booth

Sounds of battle come from the booth. Gilles and Joan are back on their horses watching the battle.

JOAN

(praying))

Holy lord, heed thy servant, listen to the entreaty of thy humble servant. For surely the battle doth turn away from thy face and towards the English. If this truly be thy will tell me and we may withdraw. But if thy will is for us to carry the day show thy strength, bolster our wills and send us clear sign that your will be done.

\section{GILLES}

How much good will this do, girl, god doesn't seem to be here this day. Keep up your entreaty if you will but until the wind changes the tide of battle will flow with the English.

JOAN

Then the wind must change! Oh Lord hear thy servant! Let the wind turn against the tide of the battle. Let your servant carry her pennant victorious into Orleans this day. Let not the night come before french feet encircle and break the siege before us.

There is a turning in the sounds of the battle as the men begin cheering. Joan turns to Gilles

JOAN

You see? The battle turns with the wind.

GILLES

Some god.

JOAN

I must get down there. My pennant must fly.

She gets off her horse, unfurls her flag and makes for the battle.

\section{GILLES}

La pucelle! Stop, you must not go there! You know not 
what you do.

JOAN

You think me a fool, De Rais? God is with us, we can not be defeated.

She runs off

\section{GILLES}

Aye, but can we not still be killed- I see them e'en now being cut down by the English archers. She acts the fool- running among those whose role is to die, holding her pennant high. A stray arrow is all it would take, a stray- and there it is, she falls.

GET HER OUT OF THERE, YOU FOOLS, IT IS THE MAID, BRING HER HERE, FOR GOD'S SAKE!!!

Some men carry in Joan's body aloft. An arrow sticks out of her shoulder. She does not move as they lay her down. Gilles gets off his horse and moves over to her.

\section{GILLES}

Ah, Jeanne. Too soon taken, foolish girl. All your talk of god and voices avails you nothing- I can not believe in your god if all he does is allow his servants thus to die. I can not believe this- I care. A foolish peasant girl and I care, I feel a sadness that I've never felt before- and this a girl! A girl? Where are your miracles now girl?

Suddenly Joan sits up

JOAN

Right in front of your eyes I suspect, De Rais.

She regains her feet, pulls the arrow from her shoulder, flexes and turns to him

JOAN

My champion! The Maids champion?! Crying like a village girl. Get hard, De Rais, the battle's hardly over. God would not allow the English to be disappointed in their enemy- the Maid of France.

She climbs back up on her horse and gallops off, 
MA Thesis: The Role of Misrule in the practice of Performance pennant high. Gilles peels off and glumly follows her.

\section{GILLES}

Damn girl.

End of Scene two 
SCENE THREE

( Punch's arrest, The Demon's

inquisition and the beginning of the

folk tale. )

Booth

The booth becomes the inside of a forest- there are the sounds of men beating the bush in the distance. Three puppet girls come into the glade singing. They are dressed, very flowery, as simple folk and walk hand in hand as sisters do.

JUDITH

Clara, Esmeralda, look at the flowers, this place is so beautiful.

CLARA

Indeed it is, little sister, indeed it is. Wouldn't it be fine to live within these lands as ladies, free to walk these paths as if they were our own.

\section{ESMERALDA}

But they are not our own, sisters, we must remember we are here without permission. I for one admit to not a little fearfulness.

JUDITH

Oh, stop it Esme, you are forever worrying- look at this day, look at these flowers, can there be a better time to be alive.

\section{ESMERALDA}

I have heard tales, Judith...

JUDITH

And tales are all they are. We can hear the Gamesmen, they are far away, no one will bother us in this part of the wood.

\section{CLARA}

And besides Esme- their lord is never home, he travels constantly on business, trade, whatever it is that men do. We are perfectly safe...

\section{ESMERALDA}


MA Thesis: The Role of Misrule in the practice of Performance

Still, I can not help but think we must be careful...

Clara and Judith round on Esmeralda.

JUDITH

Esme!

CLARA

Esme!

BLUEBEARD (O.S.)

And yet your sister may be right.

They freeze.

Stage

The Inquisitor walks out onto the stage. Gilles is lead out in chains. They follow a stylized grid pattern on the floor which could suggest a 'court'.

INQUISITOR

My Lord, De Rais, You stand accused, you stand accused of crimes so odious, Odious crimes for which you stand condemned. Condemned to die through your own confession, Confessed before these lords so pious.

\section{GILLES}

I tell my tale to you, most pious judges, I tell my tale, I tell it voluntarily, freely and grievously, I committed these crimes, so odious to your ears, according to my imagination and idea, suffering no one's counsel and following my own feelings, solely for my pleasure and it's carnal delight. I had no other intention, nor any other end.

Prelati the "sorcerer" is lead out in chains.

INQUISITOR

And yet, M'lord, you must admit, m'lord, that seems no passing fancy. We have heard, milord, the spoken word, milord, of this thy humble servant.

GILLES

Francois?

PRELATI

My lord. 
INQUISITOR

Your word?

\section{PRELATI}

I came as a mendicant, was made a supplicant, conformed as an applicant, what followed I recant. Milord would have devils, Milord would have demons, as into the children he would go place his semens. I saw him do murder, I saw him take blood, I saw him take pleasure, my witness to god.

They freeze

Screen

As the lights come up on the screen Mr. Punch is seated at a table. He appears to be in a police interview room. A door opened and a detective's shadow stands in the light.

\section{POLICEMAN}

Now then, now then, what's going on here?

$\mathrm{PUNCH}$.

(To camera) The Bill?

\section{POLICEMAN}

Now Mr. Punch, l've a warrant for your arrest.

PUNCH.

You've left your wallet in your vest?

\section{POLICEMAN}

I haven't left my wallet in my vest - I've a warrant

for your arrest

$\mathrm{PUNCH}$.

You want a rest?

\section{POLICEMAN}

No I don't want a rest. I've an order to take you in.

PUNCH.

And I've an order to knock you down.

(Does so.) 
MA Thesis: The Role of Misrule in the practice of Performance

\section{POLICEMAN}

Now then Mr. Punch, striking an officer of the law is a very - serious offense.

He punctuates his remarks with blows from his phone book, he finally pins Punch against the wall.

POLICEMAN (CONT'D)

Can I see your driving license?

PUNCH.

(Wriggles free and biffs Policeman)

Here you are then.

POLICEMAN

(Hits Punch.)

Punch, you are a villain.

PUNCH.

So are you

(hits him.)

POLICEMAN

That's a good'un.

PUNCH.

That's a better.

POLICEMAN

That's a topper.

PUNCH.

That's a whopper.

The fight becomes violent and Punch finally kills the policeman. His blood is covering the table.

PUNCH.

That's the way to do it. Oh what-a-pity, what-a-pity.

Punch leaves.

Stage.

The inquisitor turns to the entrance.

INQUISITOR

Bring in the other prisoner. 
Poitou walks in, chained as the others.

\author{
GILLES \\ Poitou? \\ POITOU \\ M'lord? \\ GILLES \\ Et tu, Brute? \\ POITOU \\ (confused.) \\ I'm sorry, m'lord?
}

The inquisitor raises himself to new heights.

\title{
INQUISITOR
}

The prisoners will remain silent! This servant here has told a tale, a tale told of evil deeds. His deeds do paint a disagreeable picture, a tapestry of vile crime, against man, against god. Throughout the country-side, he tells, of going, he speaks of foul means and base spells, of luring the peasantry into giving up their children. Children gone missing over fourteen years, One hundred and forty-four children used in sacrifice.

\section{POITOU}

M'lord? I say these things not to hurt you, but to save myself.

\section{GILLES}

Ah, Poitou, Would I could just say I forgive you, it must suffice to say that into the next world shall we stride together, hand in hand.

\section{Poitou and Prelati are led off.}

\section{GILLES (CONT'D)}

Goodbye, Francois, my friend! As like never again shall we see each other in this world; I pray that God gives you plenty of patience and understanding, and to be sure, provided you have plenty of patience and trust in God, we shall meet again in the Great Joy of Paradise. And so I face my fate and while I have to face God, to whom I bow my head, I find myself with little to 
regret, with little to forget, except the maid. I admit my fault as I,unbridled, applied myself to whatever pleased me, and pleased myself with every illicit act. I would ask my lords, most humbly, for three boons, first, I would request that I and my two men are taken off together.

Then I ask that, as a noble tween two commons, no naked flame be allowed to touch my living body. And final boon, I humbly ask, as God doth fix the devil, that as I do await my fate no man of god nor man at arms will allow the maid entrance into my cell.

She knocks Gilles to the ground and puts him in the position of acquiescence as she speaks.

\section{INQUISITOR}

I think you mad, m'lord, I think you mad, As for your boons I think to grant you. Your men they shall accompany thee, subject, under pain of torture, to their recantation. Recantation such as yours moves me, thus, I, personally, shall then make sure that as you stand upon the pyre, a rope be placed around your throat, to give respite to your suffering and, as such, will your humble contrition gift you with our mercy. However for the third, I must confess, I do not understand, the Maid is dead, and has been, lo, these past ten years. I can not, as I know not, how to grant you this poor boon, but if it pleases you I shall leave you to your own devices, no visitor to succour you within your cell.

Gilles is left spread eagle on the stage.

Booth

The three girls cower as the sound of hooves is heard. Bluebeard, resplendent on a black roan enters the glade.

\section{BLUEBEARD}

I heard your singing. It brightened up a day when the boars have gone to ground and the deer are too clever by half. Who do I have the pleasure of addressing?

\section{CLARA}

My name is Clara, oldest daughter of the village Miller, these two are my sisters, Esmeralda and the youngest, Judith.

\section{BLUEBEARD}


Clara, whose beauty would tame the heart of the wildest boar.

((Sotto voce))

and bore me stupid, she would methinks, both child and mind.

(She giggles)

Esmeralda, proud keeper of the rules, I see you ready and able to defend your sisters, against all comers.

(Sotto voce)

and holds her maidenhead against all cum-mers- I'll find no pleasure there.

(She harumphs.)

And youngest Judith, the fairest flower, blossoms true all smiles.

(Sotto voce)

If I'm not too mistaken, this one sets herself a manjust as well then, that here, a man sets.

He gets off his horse and saunters over to the women.

BLUEBEARD (CONT'D)

I see you admire the great extent of my lands. That pleases me greatly. Little did I realise that when I left my home to rove about my woods today that instead of the mangy boar I expected, I would be dazzled by the beauty I behold before me. Prithee, am I unlucky? Are all of you married?

JUDITH

No, I...

CLARA

So please your grace, I must report that today you are unlucky- I am not married but am betrothed to a fine blacksmith's apprentice. My sister here is also tak'n, tho' by God rather than by man- she's for a nunnery.

\section{BLUEBEARD}

And Judith.... If I may be so bold to ask.

\section{CLARA}

Alas. M'lord, she is too young- no man has claimed her. My father has been traveling the nearby villages but as yet can find no suitable suitor. 
MA Thesis: The Role of Misrule in the practice of Performance

\section{BLUEBEARD}

No suitor to suit 'er? How sad. I wonder how that might be put right. May I suggest that you pretty ladies

accompany to my home for some refreshment?

\section{ESMERALDA}

Oh, no, sirrah. That would not be right

(she frowns at Judith)

I could not possibly be party to leaving with an

unknown man- who are you, that you feel so willing to be bold?

\section{BLUEBEARD}

My name is Bluebeard, noble of this parish, owner of these woods and all you see around you.

\section{JUDITH}

Sisters! Do you hear? He is the owner of these woods. He can give us leave to enjoy these paths.

\section{CLARA}

And does that mean, sister, that you would go with this man? What would our father say? I think he would little approve of your excitement, however much this man may mean us no harm. Your pardon m'lord.

\section{BLUEBEARD}

No pardon needed, my dear, I would that ev'ry father's daughter could be as faithful. And thus I take my leave- I will be sure to call upon your father, as time arises, so that I may enjoy your company anon.

He jumps upon his horse and rides off. The girls begin to walk off.

JUDITH

Clara!

\section{ESMERALDA}

Judith!

\section{CLARA}

Sisters! We must get home and tell our father of these things, Oh, what news!

\section{ESMERALDA}

It's he I have heard tales of. I like it not.

JUDITH

Oh, Esme! But didn't you think him handsome.... 
FADE OUT

End of Scene three 
MA Thesis: The Role of Misrule in the practice of Performance

\section{SCENE FOUR}

(Punch's grand larceny, the night of Joan's escape and the running game.)

\section{Stage}

The stage features an old time Tavern sign. It is night-time. Punch enters laughing.

PUNCH.

That was a jolly lark, wasn't it?

(Sings,)

'I'd be a butterfly in a bower. Making apple-dumplings without any flour.'

Punch disappears and re-enters with a bell.

$\mathrm{PUNCH}$.

This is my pianner-sixty: it plays fifty tunes all at one time.

He goes up to the public-house painted on the side-scene, or cottage, represented as a tavern, or hotel. Punch plays up a tune and solicits for money. Publican wakes up in a passion through the terrible noise; pokes his head out and tells him to go away.

PUNCH.

Go away? Yes, play away! Oh, you means, O'er the hills and far away.

Punch keeps on ringing his bell violently.

PUBLICAN

(in a violent passion, opens the door, and pushes him away)

Be off with you

PUNCH.

I will not.

(Hits him over the head with the bell.)

You're no judge of music.

(Plays away.)

Publican exits to fetch a cudgel to pay him out. Punch no sooner sees the cudgel than he exits, taking his musical instrument with him. Punch returns again with his bell. Publican pretends, as he stands beside the curtain, to be fast asleep, 
but keeps his eyes wide awake all the while.

\section{PUBLICAN}

If he comes up here, I'll put one upon his tibby.

Punch comes out from behind the opposite side, and rings his bell violently. Publican makes a blow at him with his cudgel, and misses,

\section{PUBLICAN}

How dare you intrude upon my premises with that nasty, noisy bell!

Punch, while publican is watching at this side-scene, appears over at the other, with a artful dodge, and again rings his bell loudly, and again the publican misses him; and while publican is watching at this side-scene, Punch re-enters, and draws up to him very slowly, and rests his pianner-sixty on the board, while he slowly advances to him, and gives him it whack on the head with his fist. Punch then disappears, leaving his bell behind, and the Landlord in possession of his music.

\section{PUBLICAN}

(collaring the bell)

Smuggings! prusession is nine points of the law! So this bell is mine,

((guarding over it with a stick))

Smuggings! This is mine, and when he comes up to take this bell away, I shall have him. Smuggings! It's mine.

Punch re-enters very slowly behind the publican as he is watching the bell, and snatches up the bell.

PUNCH.

That's mine!

He runs away

Publican sadly returns inside to his bed.

Booth

Enter Judith followed by Clara who is puffing. 
MA Thesis: The Role of Misrule in the practice of Performance

They have been chasing about Bluebeard's house and are finally standing before the cupboard they are not allowed to look in.

JUDITH

He loves me, can't you see he loves me. He gives me his keys and the run of his house.

\section{CLARA}

Oh, sister, please, sister, can't you run more slowly. To run about and check things out does not to me seem seemly.

JUDITH

But Clara dear, you heard him dear, Just before he left us, This house is mine dear, all mine dear, to do with as I pleases.

\section{CLARA}

Yes, sister, so I heard, sister, with but one exception. His keys, dear sister, all his keys, sister, will unlock the doors. But, sister, remember, dear sister, all but one are yours.

JUDITH

Yes, sister, no doubt sister, we must do this for our master. But look here Clara, dearest Clara, doesn't it your interest pique?

CLARA

No.

JUDITH

No?

CLARA

No. What you have, dear, is what you have, and this you should not dispute. For ev'ry man, dear, just ev'ry man, will have his little secret.

JUDITH

But why, dear, I ask you why, when he's safely married. For surely, dear, what's yours is his, and should be vice- versa.

\section{CLARA}

What should and what is, dear sister, are almost always diff'rent. A woman's place, dear, is to keep quiet, dear, and in all things acquiescent. 
They Freeze.

Screen.

On the screen a low light fades up with a soundscape that suggests a dungeon, though not a terrible one. Joan sits in the best light hugging her knees close to her. She is dressed on in a sack with a rope too small to actually tie around her waist. The crudely cut head and arm holes display more than they conceal. She weeps. Above her at the top of the steps Gilles appears. He is dressed in a bloodied English soldiers garb. He pauses to check she is alone.

GILLES

Psst! Jeanne? Jeanne D'Arc, La Pucelle? You are there?

JOAN

I am here. Who is this?

GILLES

Tis' I, Gilles de Rais, thy champion and Marshal of France.

JOAN

Go away.

GILLES

I come to rescue you

JOAN

I told you. Go away.

GILLES

But....

He comes down to the bottom of the stairs.

JOAN

Leave me, De Rais, I have nothing left to give.

GILLES

I understand. You have given so much.

JOAN 
MA Thesis: The Role of Misrule in the practice of Performance And yet God has abandoned me. I no longer hear his voice.

GILLES

(aside- sotto voce)

Did you ever...

JOAN

I did

GILLES

What?

JOAN

I heard his voice, Perhaps through his angels but no matter twas His voice.

GILLES

And as such you should not give up. To give in to your enemies....

JOAN

Enemies who sit beside the throne of France as much as live across the channel.

GILLES

Granted and yet you sit here despondent, ready to give in to their demands.

JOAN

I shall not give in to their demands- not while there is life in my body.

GILLES

Then come with me!

JOAN

And how does that help?

GILLES

The people are with you.

JOAN

With me? Here in this cell? Where I am constantly visited by their soldiers and their demands? They have even taken away my clothes, my soldiers garb- the only protection a woman may possess in a place such as this.

\section{GILLES}

Why do they place you here? 
JOAN

Cauchon would have me in whatever state he can. I fear this is no longer about me or in fact about the English, it is about the throne of France- and who controls it

\section{GILLES}

Ah, it was always about that. Nothing changes!

JOAN

But I heard the voice of God.

GILLES

Of course you did. But that means nothing in the ears of men. You must now look to yourself.

JOAN

Myself- look at myself, a peasant in sacking, an easy target to any man who would.

GILLES

You remain the maid of France!

JOAN

And where in this is the King? Did he send you?

\section{GILLES}

No

(he hangs his head)

I came myself, for my own reasons.

JOAN

And what would they be?

\section{GILLES}

You are the maid of France.

JOAN

Enough! De Rais, I think you are lying. Why are you here?

GILLES

Isn't it enough that I am here?

JOAN 
MA Thesis: The Role of Misrule in the practice of Performance

No. Something goes on.

\section{GILLES}

It's just not right. That you should be here. In this prison rather than a place of Nuns. You, who gave so much, who led the army of France to victory. I could not stand still and not act.

JOAN

And that action brings you what, De Rais?

\section{GILLES}

No thanks by the looks of it. We should leave, girl.

JOAN

Ah, its back to 'girl', is it?

\section{GILLES}

I know not what else to call you. La Pucelle? Or have the English already had their way?

JOAN

No. They have attempted but so far respond to the lashing of my tongue- that drives them off almost as well as the two dozen cords that firmly lace and tie together my manly garb. And that Cauchon uses to abuse the law against me.

LA HIRE (O.S.)

M'lord, a soldier comes!

JOAN

That is la Hire?

GILLES

You did not think I would venture this alone?

He calls upstairs

GILLES (CONT'D)

La Hire. Hold them off. Tell them an 'English lord' doth take his pleasure. That should hold off their queries.

LA HIRE (O.S.)

I shall, M'lord. But be quick my Lord.

GILLES

I do the best I can, La Hire. Thank you. 
JOAN

He remains a good man?

\section{GILLES}

As good a man as any. Better for having met you, I believe.

JOAN

I thank God for him then.

GILLES

As do I. But he remains right, Jeanne, We must be quick.

Joan stands and walks over to him.

JOAN

Then indeed, M'lord, take thy pleasure.

\section{GILLES}

What?

JOAN

Take thy pleasure, M'lord, better to give it to a

Frenchman to have it tak'n by an English.

GILLES

No! I intended that we flee! We must get you out of here.

JOAN

I shall not flee, De Rais, I told you that. My voices have told me, back before they abandoned me, that I shall not leave Rouen.

\section{GILLES}

But, as you say, they have abandoned you.

JOAN

Aye, so they have, but I have not abandoned God. So now, to business, allow me to die a french-woman not an English whore. I would you were quick- I care not for your gentility.

They freeze. 
MA Thesis: The Role of Misrule in the practice of Performance

Booth

Judith and Clara stand before the Cupboard. A large Key is in the lock- it is part of a huge key-ring with a multitude of Keys.

JUDITH

This key, sister, so you see, Clara, does fit the lock. And so, sister, all it needs, Clara, is but one small turn. So if you please, Clara, check my arm, Clara, As I fear that it may do so on it's own

\section{CLARA}

Judith! Do not touch it! Do not do this thing you know to be so wrong. For if you do, sister, you lose all, sister, And I can not see it ever coming home.

\section{JUDITH}

But you can see, sister, how unfair, sister, that he should have something I do not.

\section{CLARA}

But is it not, sister, the true nature, sister, of a man to hold back. Where we,sister, in our nature, sister, share with all, that which we have?

\section{JUDITH}

So will he change, sister, will he change,and thus share what he has told me not. Or should I push, sister, for this right, sister, to know all, as I should.

\section{CLARA}

I can not answer, little sister, this fair question, that you pose, for to do so, little sister. Would do more harm than it solves.

\section{JUDITH}

And so it falls, sis, to this move, sis, That I take now, of great size.

She turns the Key. The cupboard opens to reveal seven bottles on two shelves each containing a woman's head.

\section{BLUEBEARD (O.S.)}

And would you stake, love, you're very lives now, I see you have, love, now met my wives.

Blackout The lights come up on the stage. 
Screen

Gilles now kneels astride Joan who lies with her head turned away from him.

\section{GILLES}

I'm not sure about this, It seems not proper.

JOAN

Tis' but a moment's pain or so I am told- a moment twix woman and maid, between longing and belonging.

GILLES

Belonging to whom?

JOAN

That is the question.

\section{GILLES}

I can not do this

(he withdraws away from her)

I feel no desire for you.

JOAN

What? You! Marshall of France. No desire?

\section{GILLES}

No desire for you.

JOAN

Why not?

\section{GILLES}

Your God didn't make me that way.

Silence. Joan sits up.

JOAN

You are saying...

GILLES

Your god chose another way for me.

JOAN

The way of the devil? 
MA Thesis: The Role of Misrule in the practice of Performance

GILLES

Perhaps.... Yes. The devil make me do it.

JOAN

I still wish for you to offer this small mercy to me.

Should I turn this way?

She turns round rising to her knees.

GILLES

No, Jeanne, It is too much. I am not going to do this.

JOAN

You will! I wish it! I would rather die a woman than be wronged by these damned English. Do it!!!

GILLES

Jeanne!

(near tears)

JOAN

De Rais!

He moves behind her, his hand brushing her back.

GILLES

I...I...

JOAN

I already forgive you, de Rais.

He unfastens his trousers. Moves into position.

JOAN (CONT'D)

Forgiveness, De Rais. No more maidenhead.

The Screen begins to fade

JOAN (CONT'D)

Forgiveness.

He thrusts. They freeze.

Stage

The Joey CLOWN re-enters with Punch

JOEY

Oh, Punch, how are you? 
PUNCH.

I'm very glad to see you. Oh, Joey, my friend, how do you do?

JOEY

Here, Punch, are you a mind for a lark?

(Peeping in at the cottage window, represented as a public house.)

Are you hungry, Punch would you like something to eat?

PUNCH.

Yes.

JOEY

What would you like?

PUNCH.

Not peculiar.

JOEY

I'll go up, to the landlord, and see if he's got anything to eat.

(Goes into the tavern, then pokes his head out.)

Here, Punch; here's a lot of sausages hanging up here.

Would you like some for supper, eh, Punch?

PUNCH.

Yes, to be sure.

JOEY

Make a noise; wake the landlord.

PUNCH.

(Whispering)

Hand' em out here.

JOEY

Nay, I have an idea. Do you pretend as I did to be dead over there. Can you do this?

PUNCH.

Maybe.

JOEY 
MA Thesis: The Role of Misrule in the practice of Performance

Would you like something hot, Punch?

PUNCH.

Yes, to be sure.

JOEY

Then do you make like a deadman, sleeping. - Here's a lark - Make haste - Here's the landlord a coming.

Punch lies down and seems to be sleeping. Enter the Publican scratching and yawning

JOEY

Hey now, good man, I would buy a drink for the house!

PUBLICAN

At this hour? away, go to bed!

JOEY

Nay, be more accommodating. A drink I say and something to eat, I have coin.

PUBLICAN

Very well. One drink and that'll be all right.

JOEY

And one for my friend, out here, sleeping.

PUBLICAN

Very well, very well, I'll take one out to him.

JOEY

He sleeps, like as not you'll need to wake him

Joey enters the tavern.

Publican brings a drink for Punch.

PUBLICAN

Heigh-ho, mister, here's your drink.

Punch doesn't move.

PUBLICAN

Heigh ho

(shakes punch as if to wake him. Punch falls over as if a corpse, Publican jumps back in shock.) 
What is this? Dead? Is this a wake?

JOEY

(entering)

Awake? have you given my friend his drink?

PUBLICAN

I-I-I can not. It appears he's dead.

JOEY

Dead? No he was alive mere minutes ago. You're lying (He shakes Punch)

Oh Punch, what has happened, are you dead, has this rascal kilt you?

\section{PUBLICAN}

No, I....

JOEY

You have killed him! I shall have justice. I shall tell all

(shouting)

Help! Murder! Send for the Beadle, my friend is dead!

PUBLICAN

I did not do this. Please ? Do not shout, do not!

JOEY

What should I do, my friend is dead and you were the one nearest him. What am I to do now? How do I see my friend off properly. A wake you say, a wake. I have not coin for that. How am I to feed the mourners?

\section{PUBLICAN}

That I can help with. I have sausages, I have bread, I have both wine and Beer for you to drink, only please be quiet, I did not do this, please don't say I did.

Punch opens one eye. He sees the publican giving Joey the sausages and the beer and begins to giggle. Joey is caught red-handed. Punch and Joey run off leaving the Publican to curse his fate and set off to tell the Beadle.

Screen 
MA Thesis: The Role of Misrule in the practice of Performance

The screen lights up but to blackness. There is just the sound. Gilles resumes thrusting, each one punctuated by a syllable.

\section{GILLES}

For... give.... -ness. For....give.... -ness.

JOAN

Gilles? Is it? Is it supposed to hurt like this?

\section{GILLES}

Only.... A ...moment's.... Hurt.

JOAN

It feels funny

(pause)

I'm not sure.... Gilles? ....I'm not sure that this is right..... Gilles?

GILLES

For.... Give..... -ness. For ....give ....-ness.

JOAN

Gilles! Stop! This isn't right. Gilles!

GILLES

For ....give ....-ness.

FOR........GIVE..........NESS!!!

He withdraws. Breathing.

JOAN

That.... Wasn't what I thought it was. I feel no different. Are you sure that was it- should I feel more?

\section{GILLES}

I.... Beg your forgiveness, maid.

\section{Stage}

Joey and Punch enter puffing, and laughing. They begin to share out there loot

JOEY

That was a lark was it not, Mister Punch, I do believe his face went through three shades of red. 
PUNCH.

Indeed it was, Joey indeed it was. And to end up with all this loot. I do believe I shall eat well tonight.

(He suddenly looks up)

What's that?

He points up and away. Joey turns to look. Punch hits him over the head. Joey collapses dead.

That's-the-way-to-do-it. what-a-pity, what-a-pity.

He smiles at the audience. Mr Punch leaves the stage dragging his body.

Screen

The screen fades up to show Gilles and Joan lying together.

JOAN

Maid no more.

GILLES

Aye- still a maid.

(There is a long pause. They look at each other.)

I could not do it. I could not take it from you, but I could not say nay to you either. I must beg your forgiveness.

JOAN

You...?

GILLES

I stayed with what I know.

JOAN

You stayed..... You buggered me?

GILLES

Aye. To my shame. I gave in to my basest pleasure.

Joan throws herself away from him.

JOAN

You beast! You blackguard! Get away from me! Go, get out! 
MA Thesis: The Role of Misrule in the practice of Performance

GILLES

I beg your forgiveness.

JOAN

To the devil with you. Ask his forgiveness, for you'll get none of mine- nor of my God's.

\section{GILLES}

Jeanne? You offered forgiveness...

JOAN

Not for this.

Gilles stands. He looks at her for a time but she ignores him. With her presence gone he has nothing to do but leave. He begins up the stairs.

JOAN

Gilles.

GILLES

Yes, Jeanne?

JOAN

At least leave me your trousers.

Gilles hesitates and then removes his trousers. He throws them over. Then head down he walks up the stairs. Joan takes the trousers and holds them close.

JOAN

De Rais. Tomorrow I go to my death- we shall not meet again before then. But mark my words- WE WILL MEET AGAIN.

The lights fade down.

End of Scene four 
SCENE FIVE

(Jack Ketch and the Ghost, The burning

of Gilles and Joan and the woodsman's

chimney flue.)

Booth

Punch walks over to the edge of the booth. He sits down for all appearances nonchalantly whistling. He makes a large satisfied burp. The GHOST of Judy appears - Punch doesn't see it - however the audience reacts. The ghost moves about moaning and whipping up the audience as Punch ignores them both.

\section{GHOST}

OOOOooooohhhhhhh! Boooooooo! Ppppppuuuuunnnccchhhh!

(She eggs on the audience to help get

Punch's attention)

\section{AUDIENCE}

Mr Punch, look out behind you! A ghost etc.etc.

PUNCH.

What's the matter? ... You've seen a ghost? I don't believe in ghosts.

Ghost appears again - Punch turns, sees it, is terrified and chased around the stage but eventually he finds his slapstick and beats the ghost.

PUNCH.

That's the way to do it, etc. Diddy-diddy-doo.

Enter the Beadle. Punch and the Ghost still struggling together.

\section{BEADLE.}

(Closing with them.)

$\mathrm{Hi}$, hi! This is him; behold the head of a traitor! Come along! Come to gaol!

PUNCH.

(A-kicking.)

I will not go, help! 
MA Thesis: The Role of Misrule in the practice of Performance

BEADLE.

(Shouting.)

More help! More help! More help! More help! Come along to gaol! Come along! Come along! More help! More help!

More help! Be quick! Be quick!

Alas there is no more help but between them the Beadle and the Ghost haul Punch off to Jail.

Screen

On the screen the table is back, but this time a kitchen scene. Judith runs in screaming. She is alone. Suddenly the door bursts open. She cowers but it is not Bluebeard. Instead there are two people there- Clara stands behind a huge woodsman wielding an Axe.

JUDITH

Clara!

CLARA

Sister Judith!

Judith looks to the big man.

JACK

My name is Ketch, Jack Ketch, they calls me that because I catch'em. I catch'em then dispatch'em.

They share the joke at Jack's cheesiness.

JACK

Excuse me, Ladies, Duty calls. I shall be back.

He heads off up to the booth.

Bluebeard enters

BLUEBEARD

My Love? I come to find you. Come out and play.

Freeze

Booth

Enter Hangman Jack Ketch, or Mr. GRABALL the puppet version. The booth is now the town. As he speaks to Punch, Jack is constructing the gallows. 
JACK

Now, Mr. Punch, you are going to be executed by the British and Foreign laws of this and other countries, and you are to be hung up by the neck until you are dead - dead - dead.

PUNCH.

What, am I to die three times?

JACK

No, no; you're only to die once.

PUNCH.

How is that? You said I was to be hung up by the neck till I was dead - dead - dead? You can't die three times.

JACK

Oh, no; only once.

PUNCH.

Why, you said dead - dead - dead.

JACK

Yes: and when you are dead - dead - dead - you will be quite dead.

PUNCH.

Oh! I never knowed that before.

JACK.

Now, prepare yourself for execution.

PUNCH.

What for?

JACK

For killing your wife, throwing your dear little innocent baby out of the window, for killing a policeman and striking the Beadle unmercifully over the head with a slap-stick. Come on.

Hangman moves behind Scene, and re-enters, leading

Punch slowly forth to the foot of the gallows.

Punch comes most willingly, having no sense. 
MA Thesis: The Role of Misrule in the practice of Performance

JACK

Now, my boy, here is the coffin, and here is the gibbet.

$\mathrm{PUNCH}$.

There's the coffee-shop, there's giblets, and over there St. Paul's.

JACK

Get out, young foolish! Now then, place your head in here.

PUNCH.

What, up here?

JACK

No; a little lower down.

A little comic business

PUNCH.

(Dodging the noose.)

What, here?

JACK

(showing the noose again.)

No, no; in there

PUNCH.

This way?

JACK

No, a little more this way; in there.

Punch falls down, and pretends he's dead. Jack stops looking down at him. He worries for he may not be able to do his job.

JACK

Punch, Are you dead?

They Freeze

Stage.

A pile of wood is centre stage. Gilles enters chained and Joan's ghost enters as if by magic beside him. They appear to be tied to the stakes 
they are to burn on. Gilles has a rope loosely tied around his throat.

GILLES

Tis' you! Will you not leave me alone?

JOAN

You would die alone?

GILLES

Did you not?

JOAN

Aye, I did. I faced my God. As you will face yours.

GILLES

Are they not the same?

JOAN

Do you not know?

GILLES

I do. My lord is far more unforgiving than yours.

JOAN

So, do you really recant your sins?

\section{GILLES}

Do you of yours?

JOAN

Aye, I did. And served my time. As you'll serve yours.

\section{GILLES}

With little hope of redemption.

JOAN

Which little do you deserve.

GILLES

Aye, I know. And yet I have with dignity met my maker.

JOAN

And that makes all the difference?

GILLES 
MA Thesis: The Role of Misrule in the practice of Performance

Do you not know?

JOAN

You'll not find any forgiveness here.

Freeze.

Screen

Bluebeard stands over a black-eyed Judith. Clara lies on the stage where she has been thrown, getting groggily up. Bluebeard is confident and undaunted.

Jack bursts in upon them just in time.

JUDITH

That's him! The monster! The things he's done.

She breaks down in tears.

JACK

Step forward you. I would see the man I'm about to kill.

\section{BLUEBEARD}

Kill, is it? This is the man you would bring before me, Judith, You think he is enough? Perhaps this will change his mind.

He throws some coins onto the stage. Jack ignores them.

JACK

More than enough for the likes of you. Judith, Clara, open the fire.

The two women begin to move to either side of the Fireplace.

\section{BLUEBEARD}

No, don't!

JACK

Ladies, do it!

Clara and Judith hurry over to the fire place to open it. Jack takes up his Axe and begins to close on Bluebeard. $\left({ }^{\star * \star *} A s\right.$ the fireplace opens many blackened skulls fall and roll across the 
floor. $\left.^{* * *}\right)$

JACK

And so the sins of the miscreant stand revealed. Back away, ladies, it seems fitting that he ends up the same way his poor victims met their end.

Bluebeard backs up until he is on the threshold of the fireplace.

JACK

Any last words?

BLUEBEARD

You can't kill me. I must go on. It is for others to....

He backs in amongst the 'skulls', Jack strikes Bluebeard with his axe and the chimney fills with flames. The two women close the door on Bluebeard's screams.

Jack straightens up and gathers Clara up into a kiss. She swoons.

JACK

Excuse me, ladies! I see another opportunity to ply my trade. Fare thee well!

He leaves the two shaken women to stare after him as the screen goes dim.

Stage

Jack enters the stage putting on his executioners mask.

He stands behind Gilles. As he speaks he begins to twist and tighten the rope around Gilles throat.

JACK

The church has spoken, my Lord, the charges found against you do condemn thee to death. However for thy 
MA Thesis: The Role of Misrule in the practice of Performance

true contrition thou art gifted a peaceful death.

Gilles struggles to speak.

GILLES

La Pucelle? La Pucelle? I would still have your forgiveness.

JOAN

I can not give it. It is not within me.

\section{GILLES}

No, it was not any of the other times either. But all in all I must confess...

He dies.

JOAN

Confess to your lord. And wish him greeting from the maid of heaven, for all too soon he may rue...

JACK

Light the fires!

Gilles and Joan's masques are engulfed in flames. Jack heads back up to the booth.

Booth

JACK

Hi! Punch, are you dead? Are you dead? Are you dead?

PUNCH.

(Hitting him with his right hand, Yes. knocking him back.)

JACK

(Rubbing his nose with his hand.)

I never heard a dead man speak before. Punch, you are not dead!

PUNCH.

Oh, yes I am.

JACK

How long have you been dead?

PUNCH.

About six weeks. 
JACK

Get up, you're not dead.

PUNCH.

Oh, yes I am.

JACK

But I say, no.

PUNCH.

Please, sir,

(bowing to the hangman)

Do show me the way, for I never was hung before, and I don't know the way. Please, sir, do show me the way, and I'll feel extremely obliged to you, and return you my most sincere thanks.

JACK

Very well; as you're so kind and condescending, I will certainly oblige you by showing you the way. Here, my boy! Now, place your head in here, like this.

(Jack puts his head in the noose)

This is the right and the proper way; now, you see the rope is placed under my chin; I'll take my head out, and I will place yours in and when your head is in the rope, you must turn round to the ladies and gentlemen, and say - Good-by; fare you well.

Jack speaks very slowly then - a stop between each of the words; for he's not for driving the people out of the world in quick haste without giving 'em time for repentance. He's far too hopeful.

PUNCH.

(Quickly pulling the rope and swinging

the hangman out into space)

Good-bye; fare you well.

(Hangs the hangman.)

Now, I'm free again for frolic and fun.

(yelling off for his wife)

Judy, Judy, here's a man hung hisself

Enter Judy doffing the ghost costume, in quick haste, bobbing up against the gallows. 
MA Thesis: The Role of Misrule in the practice of Performance

JUDY.

Why, dear Mr. Punch, you've hung a man! Do take him down! How came you to do it?

PUNCH.

He got wet through, and I hung him up to dry.

JUDY.

Dear me! Why you've hung him up till he's dried quite dead!

PUNCH.

Poor fellow! Then he won't catch cold with the wet.

Let's put him in this snuff-box.

He Points to the coffin. Judy takes the figure down and gives it to Punch to hold, so as the body does not turn away, and then proceeds to remove the gallows. In doing so she by accident hits Punch on the nose.

PUNCH.

Mind what you are about!

JUDY

Make haste, Mr Punch, everybody's a-waiting!

They hustle his legs and feet in; but they can't get his head in, the undertaker not having made the coffin large enough.

PUNCH.

We'd better double him up, and take the man to the grave, - not the grave, but the brave: 'cos he's been a brave man in his time maybe.

They quickly finish the business checking too see who might be coming. Judy helps but extols Punch to hurry up as they are coming. Finally Punch lifts the coffin with Ketch in it, he checks around him before walking off while with the coffin he bobs Judy on the head. They leave. The Stage is empty. Silence.

End of Scene five.

Curtain call

Then the curtain call. The Professor enters with a long piece of chalk. He walks to the front of the 
stage and draws a line across the front. He goes right up the wall of the booth and across Punch's play- stage. Then he walks back and stands at his door. The other players enter. Punch and Judy enter and stand behind but close to the line. Bluebeard and Judith enter and stand behind the line but not as close as $\mathrm{P} \& \mathrm{~J}$ appear to be.

Finally Gilles and Joan appear, walk to the centre and place their toes over the line. All others appear arranged around them. As a chorus they say the final line and wait to receive the audiences applause. There is no bow.

\section{THE PROFESSOR}

In times to come, mark my words, this story will be told, to entertain the children.

FIN

Acknowledgments.

Various histories of Gilles De Rais and Joan of Arc. Most particularly The Saint and the Devil by Frances Winwar 1948.

The Folk tradition and tale of Bluebeard.

A Punch and Judy Script as it first appeared in London Labour and the London Poor by Henry Mayhew, published in 1851

I appreciate that these three sources gave up major inspiration to the above work which is while somewhat truthful but is in fact complete bollocks. Any truth found herein is completely coincidental and not the intention of the author. 


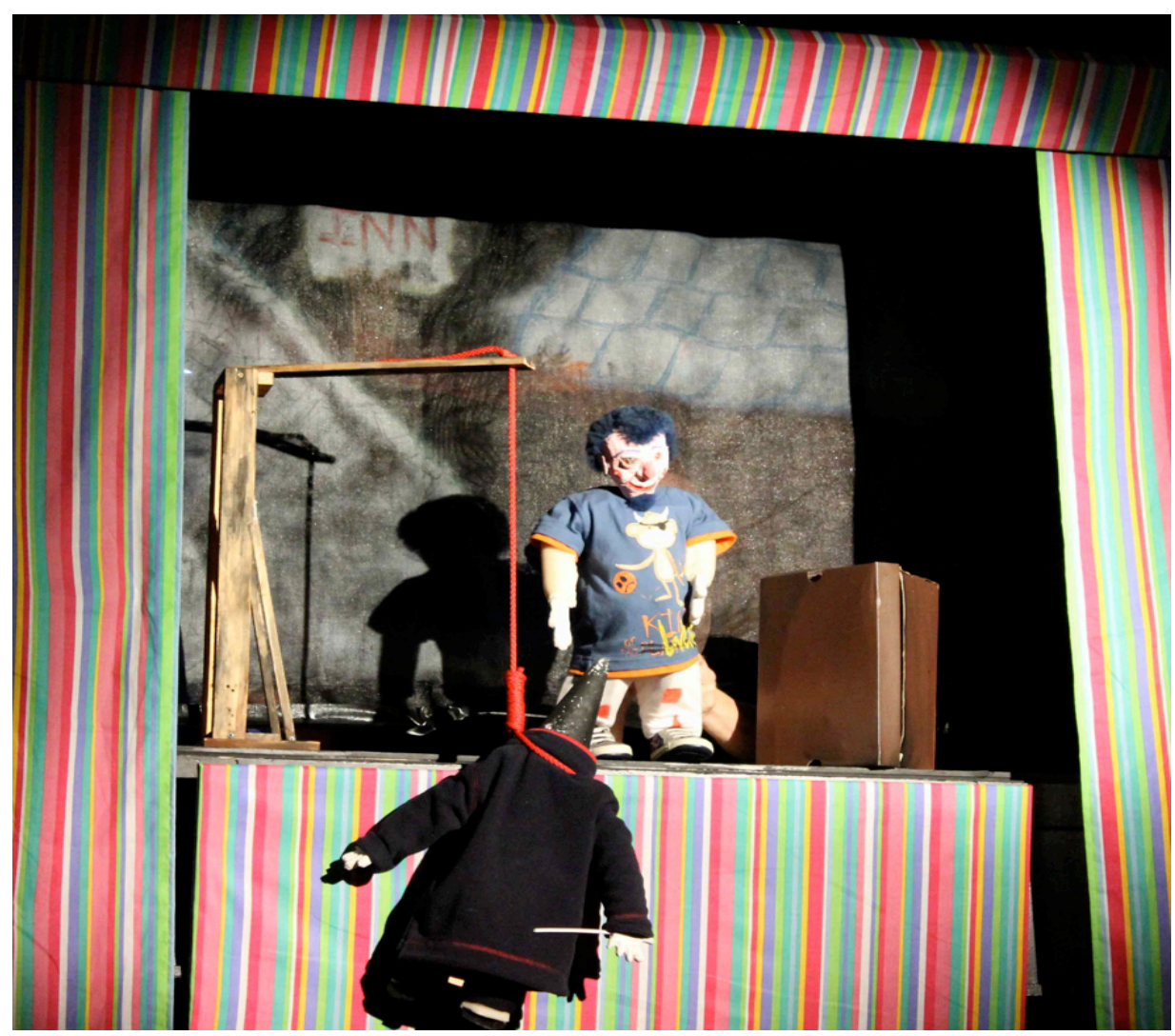

Figure 2. Saint Punch Finale, Punch hangs the Hangman.

\section{Part Two: The Path to Performance; an exegesis}

\section{Context}

The path from page to performance involved a number of elements that interconnected with each other. Although they seem separate elements, it is important to acknowledge that each one has had an affect upon the others. The script of Saint Punch arose from the specific provocation of John Downie's 2006 Honours course in Scriptwriting. As I approached this Creative Practice component of my course, John, now serving as Supervisor, offered a number of provocations that were very helpful (if a little challenging). 2010 had been a 
year of gathering knowledge across a number of theories to form a framework for the creative practice. John suggested trying to utilise the whole space when we had secured 93 Kelburn Parade, Old Drama House as our venue. His provocation was to think in terms of using the whole space. Old Drama House, 93 Kelburn Parade is just that, an old house which has been redesigned to offer a clear stage space on the top floor where chairs can be set up in a number of different ways, with a lighting box in one corner, an alcove opposite and a small backstage area. Downstairs is a green room and a studio space, which can be used for wardrobe/, dressing room. Off that space is a locked wardrobe space and a sunroom that stores furniture and is used as an office. Upstairs and Down are linked by a stairway at the back.

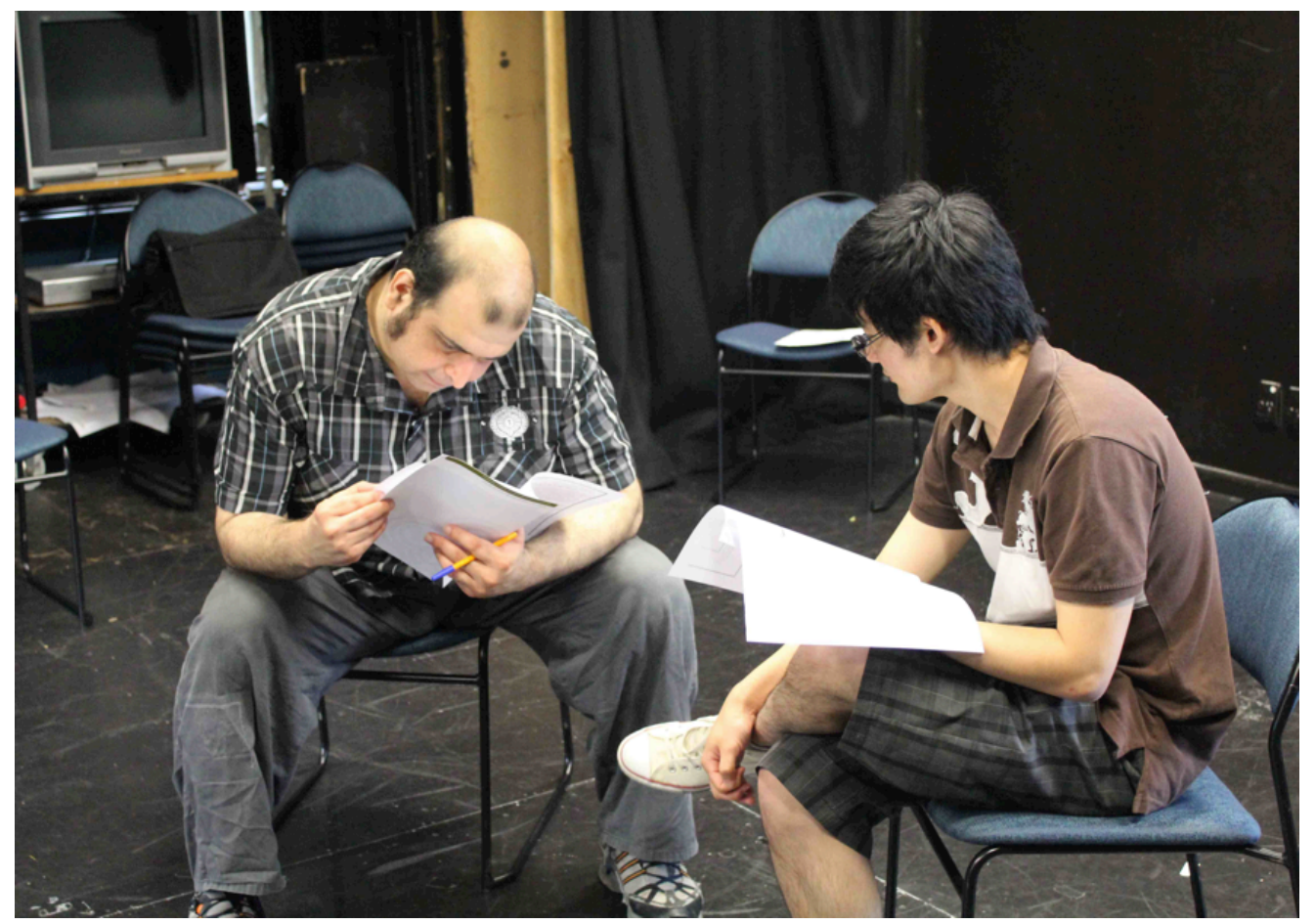

Figure 3. Elliott and Adnan; discussion of The Whipping of the Quaker Women 
MA Thesis: The Role of Misrule in the practice of Performance

\section{Workshops}

The first manifestation of process was in calling together some workshops to investigate choices for the play. One of the first design choices in writing the play had been to choose puppets as a mode of story telling. The first workshop was an opportunity to tell a story using one of John's provocations. He knew that I was considering puppets and encouraged me to think across a wider field, suggesting dolls. I wanted my process to be open and therefore willing to explore offers became an important component in how I would approach this text. I arranged a Saturday workshop and called for collaborators. Several expressed an interest but the challenge here was the timing of the workshop outside of the University term. This limited how many responses I received. This meant a smaller group of people who were not all actors but who brought interesting insight to the process. ${ }^{10}$ I used a story from my Quaker background that seemed to me to reflect some of what I wanted to say in Saint Punch. The story, The Whipping of the Quaker Women ${ }^{11}$, comes from the Dover $(\mathrm{NH})$ Public Library and is a true story of a very young America. It describes three young women on Quaker ministry who were punished by their more puritan neighbours. They were to be paraded through the villages where they had been delivering ministry and there the priest ordered them "to be stripped naked from the middle upwards, and tied to a cart, and after awhile cruelly whipped them, whilst the priest stood and looked and laughed at it." The priest and deputy then travelled with them from Dover to Hampton. However, at Hampton the constable refused to take their clothes off. Further, he would

\footnotetext{
${ }^{10}$ See Appendix One

${ }^{11}$ http://www.dover.lib.nh.us/doverhistory/whippingofthequakerwomen.htm accessed 21/9/11
}

Gregor Cameron 198272670 
have whipped them before day to save their embarrassment. However, the three young women insisted that the punishment be carried out just as it had been set. The constable, unable to find anyone willing to step in for him, set about the execution of his duties, shaking and trembling. He carried them through the other villages, dirt and snow, until in Salisbury he was convinced by a doctor to swear him in as a deputy who cared for their ripped bodies and then turned them over the Picataqua River away from those who would punish them. Such was the strength then of their witness that in time they returned, formed a meeting and over a third of Dover's citizens became Quakers. This subversive use of the puritan punishment seemed to me to be reminiscent of

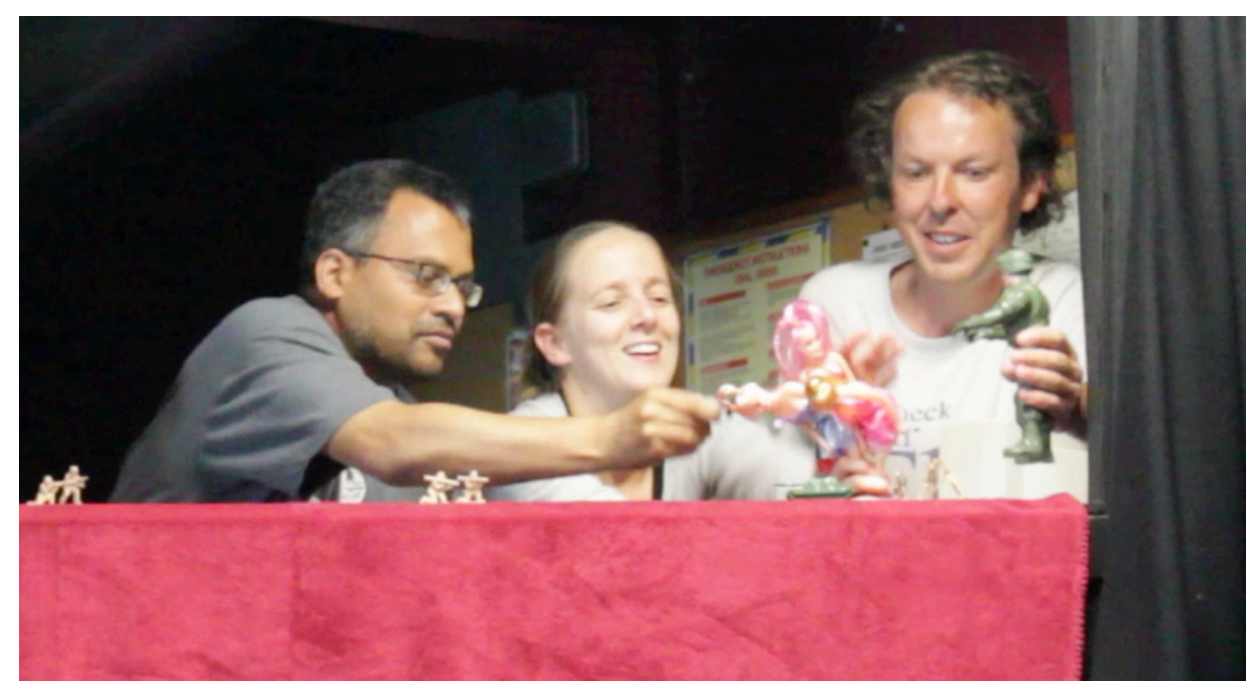

Figure 4. Patrick, Patricia and Thomas, with Toy Soldiers and Barbies, playing out The Whipping of the Quaker Women.

Joan's conundrum at Rouen. This was the text that I wanted to play out during the workshop. Having gathered together we began to explore first the telling of stories and how these become a focus for performance. 
MA Thesis: The Role of Misrule in the practice of Performance

The beginnings of the workshop involved a process of introductory and trust exercises. Together, this diverse group of people split into groups, would be able to work collaboratively. They included musicians and filmmakers, singers and actors, however most had very little experience onstage. This limited how far I could expect the work to develop at this time. However, we decided to have fun together with the exercises and this, for me, was key. I needed to be able to go with the offer, saying yes without expectation and receiving whatever this produced as an opportunity for me to learn.

After a while I introduced the Quaker story and then provided the participants with the objects and dolls they were to use to perform the story. They took the elements and using the toys, dolls and other objects and spent about 30 minutes devising a presentation of the story. They worked generously together however and the stories gave me clear insight into the possibilities of using such props onstage.

A couple of weeks later I put out a call for another workshop but timing got the better of me and I ended up working with a smaller though much more focused group. We decided that as we were such a small group that the most effective way of using the time would be to do a reading of the text of Saint Punch. This allowed me to hear the words for the first time. I loved it. Not perfect but it did give me confidence that I had something to say. If only it were not so hard to find people to play with. 


\section{Thoughts}

Confidence is a key aspect of the creative process. It is at once the most fragile and your strongest ally. If it is not present then there is a great temptation to stall and not move on with a project. The workshops that occurred over the summer break 2010/2011 were a difficult pill to swallow. They seriously challenged my confidence in my own voice. It also felt very depressing as I had to renegotiate my timetable from the beginning of the first semester to the mid year break for putting on the showcase workshop performances.

Confidence is a fragile thing that constantly straddles the edge of too much or too little. Despite putting a number of calls for people to become involved there were simply too many other priorities out there for most of the students I was contacting. They were either rehearsing for Summer Shakespeare or the Fringe Festival, or saving costs by having the summer at home, or working their butts off in one of the decreasing number of summer jobs. None of these things was a reflection on me or upon them but it did mean that only a few close friends became the players at the workshops, and most of them were more interested in crew work rather than acting. Of the people that turned up Thomas would go on to play Punch and Patrick to serve as Bluebeard, Elliott would take over the video studio and Patricia would do sound. It was these peoples faith that held this difficult time together for me. The workshops themselves served to put some ideas on their feet and to give me an 
MA Thesis: The Role of Misrule in the practice of Performance appreciation of what the words sounded like. This was invaluable information and set my mind formatting what worked and what did not. This offered me the stimulus to write the final draft of the play.

\section{Pre-Production}

With some trepidation, I agreed to move my dates to the half-year break and started seeking actors with which to collaborate. This process was quite time consuming and challenging. It was important to me that those who chose to enter into the world of Saint Punch do so with their eyes open and with a sense of what my vision for the play was. I held auditions and interviews and finally ended up with a cast drawn from the university and from outside. They were a mixture of those with solid experience behind them and some who had very little experience of the stage. Fortunately, for the role of Gilles de Rais, I was able to invite an old acquaintance back to the stage after a decade of working professionally in film and television and this collaboration would turn out to be key to Saint Punch's success. I also had at this stage some key collaborators in Sound and Video. There were times however when I experienced some large doses of self- doubt. In discussion with my supervisor, John Downie, and Theatre's Jim Davenport, senior Technical Officer, it was decided to look towards a workshop performance of Saint Punch around Queen's Birthday in the mid Year break of the university. It was also made clear that the main stage at 77 Fairlie Terrace was not the right venue and that I could not finish the performance with real fire. Both of these decisions while they felt like a lack of faith proved to be the right ones and opened up my opportunities rather than closing them down. I spent the rest of the summer making design and look 
decisions. This included beginning work on creating the Mr Punch Puppet. I would have loved to be able to get the cast to have worked upon their own puppets but unfortunately; time and space did not allow this. Rehearsals began on the second week of Trimester One 2011. We were lucky enough to be able to rehearse in the venue itself though this would also present challenges later on in the process.

\section{Casting}

Finding the actors, to fill up the cast proved to be another challenge. The summer had been dry of potential collaborators as people were either working, back at home or in other shows, for example planning for the fringe Festival in March or for the Summer Shakespeare. As the new first trimester began, I had Thomas Pepperell in place for Punch and Patrick Coelho in place for Bluebeard but needed another six or seven actors. I visited the theatre courses, put up notices and created a Facebook page for FatCircus to show up as an activity/production page. I received some response from the first year actors but in meeting them some were unable to commit, some unwilling to engage in the darkness of the piece. Finally I found Rosie Tapsell and Audrey Martin who would turn out to be an absolute gift in the way they wholeheartedly entered into the process. Audrey was perfect to play Judith and Rosie was great for Joan. I was talking to fellow postgrad, Kerry Glamsch, about the difficulty of casting and he was kind enough to promote my show at his Meisner class downtown. Out of that I met with three of his pupils, Emma 
MA Thesis: The Role of Misrule in the practice of Performance

Smith seemed good casting as Judy, Piotr Wołodźko as Joey/The Policeman and Maria Becerro Casero seemed to fit Clara, Judith's sister. Martin Quicke appeared out of the second year theatre class in response to a notice and was keen to take on a number of challenges, Innkeeper, Jack Ketch, Poitou and the Professor/old man. Crucially I still did not have casting for Gilles de Rais but this is where Facebook came up trumps. Being on the Social Media site had meant that I had been getting back in touch ('friending') with the wider Theatre community. One such person from my wider professional contacts was Des Morgan. Des and I had known each other for over a decade but had been travelling somewhat different roads. Getting back in touch with him served both of us as he was able to return to the stage after a decade mostly

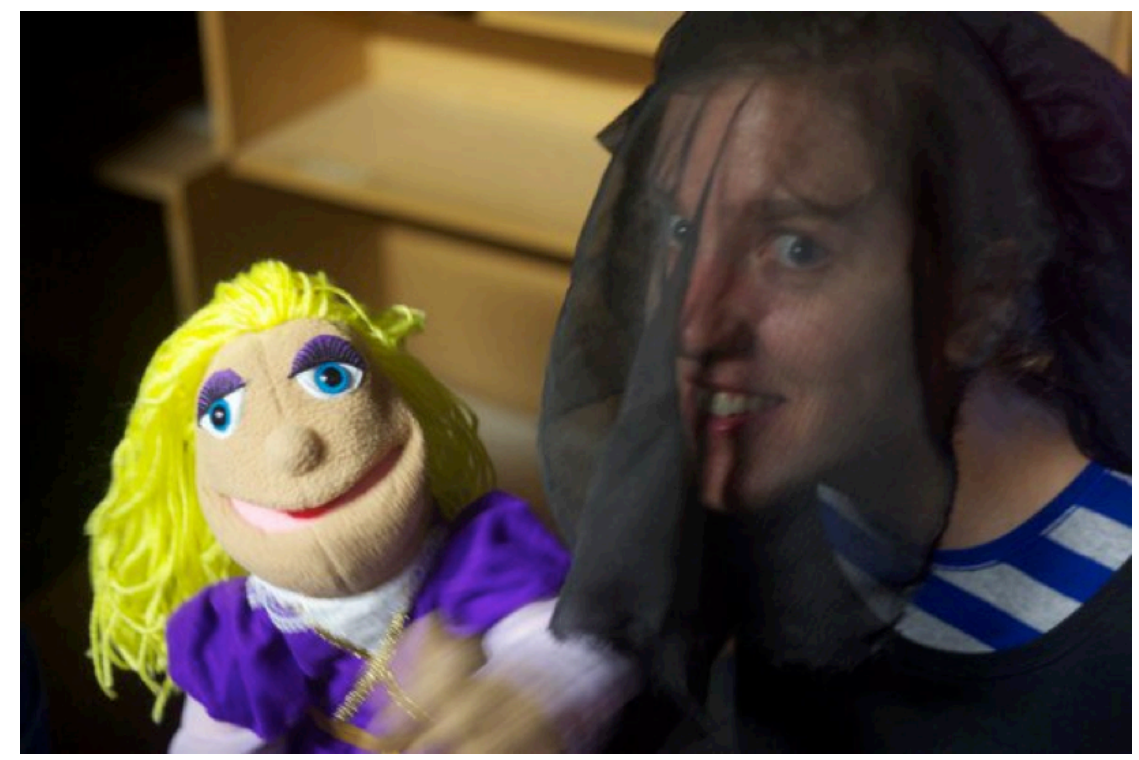

Figure 5. Audrey begins to bring her puppet, Judith, to life

doing film and television and I had a very strong experienced actor to take on the darkness that Gilles de Rais could have been. I finally had a cast that would travel with me generously and competently. 


\section{Rehearsals}

Rehearsals ran on Sunday afternoons (1-3 pm), Wednesday and Thursday evenings (6-8 pm) and a Saturday workshop (1-4 pm). This four-session breakdown was a deliberate choice to allow me to work on each of the three stories separately before bringing the scene together on the Saturday afternoon. It was also informed by the cast's own timetables. Thus Sunday began the week with Punch and Judy, Wednesday became home for the Gilles de Rais/ Joan story, Thursday the Bluebeard story. The first five weeks of rehearsal then allowed us to concentrate on one scene at a time and then begin putting it together on Saturdays.

In order to prepare the soil for the framework I wanted to work within, I, very early on, decided that I would run rehearsals as consistently as I could. Early on in my experience, back in 1984 while studying at Wellington College of Education, I worked in workshop with Dorothy Heathcote, one of the world's leading teachers of role and drama in the classroom, with the patients and staff at Porirua Hospital. Dorothy never seemed to change, each day she appeared exactly as she had the day before. My college tutor, Ralph McAllister, explained that Dorothy believed that in order to build trust and expectation in children and others that she worked with she wished to build into her work an image of who she was and how consistent she could be. To this end, she would only ever wear one outfit during a multi- day workshop, each night 
MA Thesis: The Role of Misrule in the practice of Performance

washing it and then laying it out to dry overnight. Thus, the next day, she would appear to be just as the workshoppers had seen her the day before. She felt this would bring a consistency and a quicker entry into the next phase of the workshop- thereby providing a greater commitment to the creativity each day would bring.

In fact, much of Dorothy's words stayed with me as I incorporated aspects of what she termed Mantle of the Expert work into the rehearsal room. I had decided that as much as I could I would use the 'yes' answer to offers that would come from the cast and that this would include any offer to take over aspects of the rehearsal ritual. I considered that part of the process of them beginning to own their performance. It was important to me that a sense of play arose from the safety of a ritualised rehearsal process. Again being very accepting of how what might arise in the middle of a rehearsal might engender this.

Therefore, rehearsals followed a particular format. They would begin with a 15minute warm up exercise often in the form of a game. I would try to find exercises and games that reflected in some way what I wanted to achieve within the rehearsal. Then there would be a time of discussion (10-15 minutes), arising from the opening exercises, about aspects of the script, frame of the scene or conditions for forming their characters, after which we would put the scene up on the floor through script work, improvisation and role play (90 minutes or so). Week 1 was about the world of the characters. With the Punch and Judy characters I wanted the session to interrogate what the tradition was 
all about- seashores and holidays, murder and mayhem. We discussed some of the comments that exist about Punch, such as from JR Cleland ${ }^{12}$ who notes in 1948 about Punch:

...he is everything that is bad, immoral, subversive, sadistic and cruel, and an even worse influence upon the younger generation than the cinema.

(Cleland 1948:65)

I suggested that this sounds very familiar if we consider that Punch as a personification of the Carnivalesque. Punch serves admirably as the Dark Clown of the theatre and touches many of the essences of the Trickster himself. He serves as an archetype but not one that anyone would wish to emulate but rather serves as an example with which to contrast. Cleland acknowledges this as he goes on to link Punch with the ancient mystery and medieval morality plays. He senses something of the aspiration to the spirit in Punch. Through the physical and through the allegorical ancillary characters, Mr Punch tries to become more than his physical self. Clearly his presence freed from the puppet booth would be both clownish and much more violent. It was important that we talk about permissions and improvisations before we try to tie down what will be the limitations upon what was safe to place on the stage.

\footnotetext{
${ }^{12}$ Some notes on the Punch Play, Puppet Master Vol 2 \#3 July 1948. Published by The British Puppet and Model Theatre Guild
} 
MA Thesis: The Role of Misrule in the practice of Performance

With the historical story, it was all about the differences in power: how the nobility could and did get away with just about anything. How Gilles de Rais was unlikely to have been that different from the other nobles of the time although he was probably one of the most powerful, and how Joan D'Arc represented a new way of thinking. How she brought to the throne some clever ways of proving the veracity of her 'voices' and how that still was not enough to protect her from the betrayals of man's politics. She also thought about her men in a way that was quite alien to Gilles. She demanded of them all the dignity of equals in the faith she placed in them and the standards she held them up to. This serves to further underline the difference in treatment that she and Gilles suffered.

Bluebeard's Tale was introduced as a warning about the folly of trusting that all that glitters is gold. We discussed how folk tales were a sort of short hand way of bringing an awareness of the outside world into the family and/or the village. How Bluebeard has been directly linked to the de Rais of history, how George Bernard Shaw had named de Rais in his play, Saint Joan, Bluebeard, and that perhaps Disney was a useful way to think of folk tales in the present (although very carefully considering the politics of Disney itself). I wanted that sense of a Folk Tale to come across to the audience and so the performances had to be larger than life.

After this discussion, we would put the scene up onto its feet. Asking questions: what comes from the text, what opportunities there were to be found suggested by the directions and what were the prime motivators for the 
characters involved. Clearly, in the first historical scene it is one of horror as Gilles rapes a child. However just before he climaxes, the spirit of Joan D'Arc possesses her and this frightens him terribly. We worked a lot on the simple physicality of the actors, where they could fit together giving a particular vision that the mediation of the camera augments.

For Bluebeard the characters play out of sequence to contrast with the Puppets. We looked at the signification of power between Judith and Bluebeard at this point in their story. Bluebeard appears as this unstoppable physical presence that can throw her around like a rag doll. Posture and presence demanded a lot of time, and how such a loss of control affects the characters. As their first scene involved throwing Audrey around we also began talking about the choreography of stage combat and how we keep everyone safe. I wanted to use this scene to establish the brokenness of the bond between Judith and Bluebeard, his manic disposition and how strong consequently the bond between Clara and Judith would need to be.

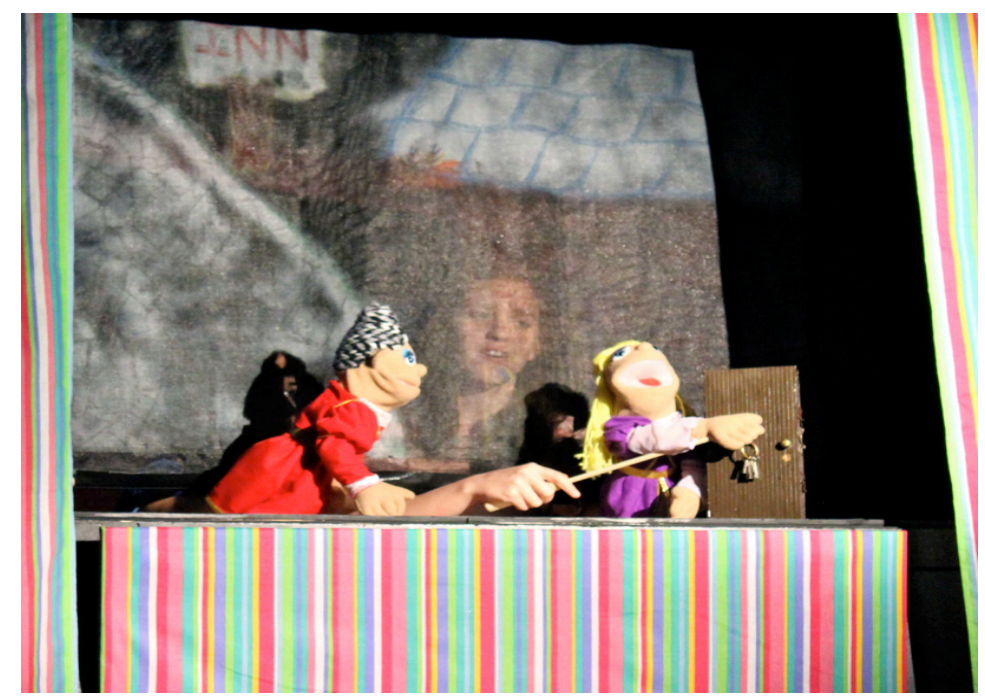

Figure 6. Judith, Audrey's Puppet, threatens to open the forbidden cabinet 
MA Thesis: The Role of Misrule in the practice of Performance

With Mr Punch, the story is in the traditional timeline sequence with the first scene being the one where Punch speaks to his wife Judy and then while looking after the baby, throws it out of the booth. He then covers his crime by killing Judy. In terms of rehearsal, this generated a conversation on tradition. We looked at some examples that included seeing a Punch and Judy man perform in a booth at the Kilbirnie Fair. We were able to talk to him for a few minutes afterwards. He was helpful, particularly in terms of not using the Swazzle, a mechanism for the mouth that produces Punch's voice. During rehearsals, I would work individually with Thomas in order that he not damage his voice by overdoing the falsetto that he adopted. The actors began using substitutes for the puppets right away as we had both the Mr Punch puppet that I had made over the summer and a doll about the same size for Judy. It was during this time that we also improvised around the frame of the play, which was to be a wedding- allowing us to bring in both the idea of a ritual gathering and a place where storytelling would happen.

In this way, a ritual was set up for the rehearsal room, which would continue throughout the rehearsal process. Rather than detail how these rehearsals continued through this pattern, I will highlight several important moments where the vision was challenged and, through collaboration and rehearsal, changed. Each of the stories reached this stage so it is appropriate to offer these in turn. 
With Bluebeard, it arose out of a design decision. Early on, I wanted the actors to construct their own puppets but this became impossible due to the time constrains of the project. Thinking about the connection with Disney I thought that puppets that looked like Muppet characters might serve quite well so I started looking through the Internet to source them. After a New Zealand site let me down, I purchased them from Amazon.co.uk ${ }^{13}$. This, of course, meant that they arrived later than I might have desired. However by letting drips and drops of imagery and hints out to the actors I was able to build their anticipation quite high and they began playing the scene with their hands. By the time they did get their hands on the puppets, they leapt at the opportunity to play up the 'Disney-ness' of the scene. Perhaps it was the familiarity of these types of puppets, which helped raise the level of performance. Perhaps it was the permissions that such a 'mask' offers that made the difference. However, we also talked about where these tales stand in a modern world. Out of this came a discussion of the article that accuses Disney of being a Nazi. By referencing Matt Roth's polemic article which, in seeking to define The Lion King, as Disney-fascism suggests that an illustration of the Nazi Regime can be found in the animated version of Pinocchio ${ }^{14}$. In turn this lead us to the discovery of The Bloody Chamber by Angela Carter that some writers claim presents a feminist reading of the traditional story. The actors therefore were encouraged to explore this story not only as the old folk tale but also through

\footnotetext{
${ }^{13} \mathrm{http}: / / w w w . a m a z o n . c o . u k / s / r e f=n b \_s b \_n o s s ? u r l=s e a r c h-a l i a s \% 3 D a p s \& f i e l d-$ keywords $=$ Doug + and + Melissa + puppets $\& \mathrm{x}=0 \& \mathrm{y}=0$

${ }^{14}$ http://www.ejumpcut.org/archive/onlinessays/JC40folder/LionKing.html last accessed 16/10/11
} 
MA Thesis: The Role of Misrule in the practice of Performance

this subversive retelling. This proved a wonderful example of how being prepared and doing homework can allow something innovative to exist upon the stage. For Mr Punch's story, I think the moment that we started really looking critically at what the script was suggesting allowed for a moment of Misrule. When they left the puppet booth and entered into the other two environments the puppet business became quite limiting. This difficulty arose because the original puppets are not very articulated, being limited to movement one hand can achieve. Business ${ }^{15}$ then must be broad and physical with none of the subtlety that a clown onstage can bring. Once they were downstairs I had a clear vision of what I wanted to reference- the Joker in the interview room from The Dark Knight (Nolan, 2008), not that we were going to be able to use the language of cuts and close ups that Christopher Nolan has to play with. However, it was a start and a clear pointer to what I wanted to get out of the scene.

The challenge of this came to a head for me during the rehearsal of the Publican business in scene 4. While the re introduction of the Joey clown goes along the traditional line, the business later in the scene became complicated. In using the booth, the traditional show is limited to only having two characters on stage at any one time (most professors having only two hands of course). So with Punch and Joey and the Publican available to all be onstage this limitation wasn't really natural. We worked with the original scene however for some time before it was clear that it just was not working.

\footnotetext{
${ }^{15}$ Business in this sense being the physical and visual humour a performance can offer that does not rely upon the spoken word, in for instance the Commedia dell'Arte performance of Lazzi.
} 
There were also problems relating to props that would need to designed and made, such as heads that thrust through bottoms of frying pans and red-hot pokers that poked into noses. Considering this and with a wish to be balancing the other stories that were in Scene 4 I felt that the Punch story needed to be lighter and more comedic. In the end, it seemed that I would need to leave behind the director for a time and become the writer to resolve this.

As it happened, I was reading Neil Gaiman's Anansi Boys (2005). ${ }^{16}$ I have already mentioned that Gaiman's work is a huge influence. In the novel, he tells a variation of a traditional Anansi story. Anansi is the spider version of the trickster stories that appear through many early cultures. In this version, Anansi cons some food from a local shopkeeper and then fools his adversary Tiger into killing his grandmother ${ }^{17}$. It seemed to me that Punch and Anansi had much in common and that perhaps I could adapt this story to fit the scene we were having trouble with. Thus at the next rehearsal I had a new scene for the actors to work with. Punch would pretend to be dead and Joey would thus con food and drink from the hapless Publican.

This frame gave the clowns quite a bit of freedom to express their own ideas on what is funny and became one of my favourite scenes in the performance. For it to arise through the coincidence of my personal reading should not be thought of as an accident unless one, as I do, subscribes to the idea of the

\footnotetext{
${ }^{16}$ http://www.neilgaiman.com/works/Books/Anansi+Boys/ accessed 22/10/11 
MA Thesis: The Role of Misrule in the practice of Performance

'happy accident' and the opportunity this provides. I agree with Anne Bogart

when she suggests that all influences in one's life contribute to the process of being an artist.

As a result of a partnership with memory and the consequent journeys through the past, I feel nourished, encouraged and energized. I feel more profoundly connected to and inspired by those who came before. I feel the courage to articulate for my profession because of the shoulders upon which I'm standing feel sturdy.

(Bogart, 2001:40)

Scene 4 also provided a moment of inspiration in the rehearsing of the Gilles De Rais /Joan of Arc story. However, before that there had also been a moment of difficulty in scene three that had switched how we thought of the stage floor environment. I did not want this story to be clownish even though we had established this as the basis of both the Punch and the Bluebeard story. This scene required the trial of Gilles de Rais to be centre stage. However there was a risk that the audience may not read this as a serious scene because of the rhythmic poetry of the words, I did not want them to be waiting for a joke that would never come, it being one of the wordiest scenes in the play. I wanted to have them listen with as little interference as possible. Earlier we had been using grid-work ${ }^{18}$ to help define the relationships between the characters. I suggested that perhaps having the court defined as a number of straight lines might stylise it so that once used to the convention the audience would listen to the nuances of the words.

\footnotetext{
${ }^{18}$ This gridwork was introduced to me by Annie Ruth while I was a student at Toi Whakaari: New Zealand Drama School. Whether it arose out of Annie's knowledge of Keith Johnstone's work or Ann Bogart's I am unsure. 


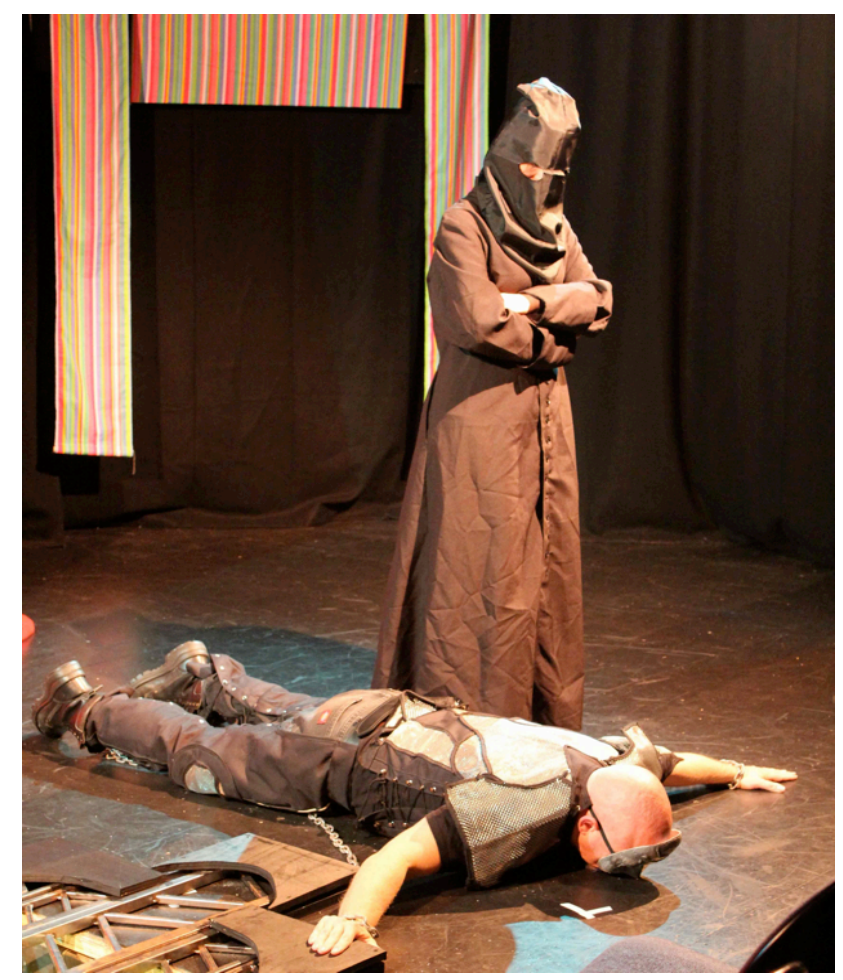

Figure 7. In rehearsal the Inquisitor condemns Gilles to death

Emma dressed as the Inquisitor began what turned out to be mesmerizing approach to Des (as Gilles). For me it called up images of cats playing with prey, the hopeless captives trapped within the confines of the court. It culminated with Gilles prostrate on the stage, having begged for forgiveness, confesses his crimes and wins some boons from his condemners. He seemed from the audience's point of view to be crucified upside down- a satanic image. This somewhat expressionistic approach made all the moves on stage seem deliberate and clean. It allowed the audience to hear the words without the expectation of anything physically surprising and yet still conveyed the form of the Court to shine through. This expression also helped as we found ourselves with one more character than there were actors to fill. Working with Martin, who turned out to be one of the busiest actors on stage, filling a number of 
MA Thesis: The Role of Misrule in the practice of Performance shoes, we experimented with the idea of a Janus Mask- a face on both the front and the back of his head and through this he was able to play both of Gilles' servants.

There is a rape in Scene 4 that mirrors the one in scene 1. However, this rape was a far more difficult one for the actors to get their heads around, as it is quite complex in the way that, in a sense, both the characters are raped. I had a number of quite intimate conversations with Des, and Rosie was encouraged and supported by other members of the cast, especially the female cast members. I felt it important to not approach this material too quickly but with the sense that we were making sure each of us was safe in dealing with the intensity of the act. My original vision was to expose this moment as much as possible -to encourage the actors to choreograph and perform this with as much reality as the camera would allow. I hoped that placing it behind a glass would somehow make the actors safe and at the same time provide enough distance for the audience to be witnesses but not implied participants, as documentary can sometimes make us.

I remember from my childhood a film shown at high school where a camera implacably focused on a nest of baby birds as a grass fire flowed through their meadow. I remember us being at once fascinated and disgusted as we realised that the film makers could have, if they had wished to, rescued the baby birds at any time and placed them in a place of safety. Instead, the camera holds upon the burning brood until the fire has swept through its gaze and continued its tidal wave way across the meadow. We found ourselves 
caught up in the thought that we did not act. I did not want this to be the experience of our audience. I did however want the video feed to be read as a seeming documentary view, which would make the environment of naturalism that, much more affecting. A very difficult balance to find.

However, as we approached the scene and talked about the context it served it was clear that Rosie was having difficulties with the subject matter. Often this would manifest as physical pain and blockages. Des became both concerned and frustrated. I think both he and I were also concerned because Rosie had just turned eighteen and we felt that possibly we were taking her to a place that could potentially prove damaging. This was something that no one intended. However, it appeared that this moment would prove to be the point upon which the show would succeed or fail.

Then in one rehearsal we were talking about how the camera affects what it is that the audience is allowed to see. I was explaining how the camera was a way of distancing the actors from the audience and in a way that this paralleled the affect that arose from the Puppet booth- after all the figures were approximately the same size. At some point the offer arrived from the actors of what would happen if we were to not allow the audience to see anything. They would still be able to hear everything. So we explored what it would be like, in effect, turning off the camera. Suddenly the audience is forced to experience 
MA Thesis: The Role of Misrule in the practice of Performance

the rape from a very different perspective. In fact in rehearsal I found myself having the hair on the back of my neck standing on end.

We solved this issue with what I consider to be one of the clearest examples of how misrule provides the spark for creativity and how this can often offer the solution to a real problem that comes up in rehearsal. In this case it involved masking the act of rape from the audiences eyes, something I will go into in more depth in the critical part of thesis

Thus did rehearsals proceed, often falling into the pattern described, and sometimes breaking open to allow creative moments to appear. Later, rehearsals would be held to solidify our findings, to link the scenes together and to strengthen any moments that needed a deeper understanding or revision to make the best impression upon our audience- nothing very unfamiliar about this composition, which is why I choose to highlight a few key moments that affected the vision. I will talk in more detail about the production week as I talk about the design and tech used just before performance.

\section{Thoughts}

Rehearsals are both a joy and a chore. Both these feelings colour my recall of them. Working with a group that varied in experience so much, I look back at the moments that were difficult with different eyes. One thing that stands clearly in my mind is the need to temper the requirements of the group performing the play against the differing needs of the players as individualsbringing their own strengths and weaknesses to bear upon the text. To be able 
to share a vocabulary, you first have to identify the points shared in common, and then form from that beginning a shared experience which can serve to find a pace that all can share. There is a delicate balance between intellect and instinct. It becomes unbalanced if one or the other is not entertained.

Generally, I found that if $15-20$ minutes spent in the head then $60-90$ minutes needed to be up on our feet.

I would, perhaps, have approached the work differently if I had more experienced actors. However, the work proceeded and I am comfortable that we explored as much as we possibly could during the rehearsal period. By the time our dress rehearsals began to come together, we were able to seek and appreciate the advice of some of my mentors that attended the Tech week.

\section{Mentors}

I was very lucky with the mentors who gave of their time and expertise both before and over the term of the production. John Downie, my Supervisor, of course was shepherding me through this exploration and offered sage advice and useful provocation. James Davenport as technical officer of the Theatre Programme opened some doors for me and, in turn, presented some challenges. Willie Franco who assists Jim at the theatre programme generously gave of his time and advice to Elliot with the video work. I also want to acknowledge the support I have received from the other theatre academic staff. While some came to the performance and offered me feedback, others 
MA Thesis: The Role of Misrule in the practice of Performance

have been there to talk over issues as they have arisen. I have always felt that they have my back.

However, some people outside of the institution have also made significant contribution to my work. During a visit to Melbourne in 2010, AboutFace Productions creatives Tim Denton and Annie Forbes ${ }^{19}$ gave me some time to talk Puppets. They helped me think about the form and function of my puppets and what differing puppets bring to a situation. They also offered direct advice on construction that proved instrumental in being able to make the Punch and Judy community of puppets. Tim and Annie also spent time with me after their production, Boxes, which ran at Capital E in Wellington. During this meeting, I was able to report back to them and get some comments on my completed performances of Saint Punch.

Alex Funke ${ }^{20}$, who is a cinematographer with the miniatures and visual effects company out at Miramar, that serves Peter Jackson's movies, offered some great support when I was asking about using a compositing effect on the stage. He had been doing some work at Victoria University with the honours video production course. I also worked with him on a $16 \mathrm{~mm}$ filmmaking and cinematography course which he and Paul Wolfram facilitated. As well as offering advice, he provided the green screen paint that surrounded the actors as they travelled from castle to dungeon, police interrogation room to kitchen. I was very touched when, after attending the

${ }_{20}^{19} \frac{\mathrm{http}: / / \text { www.aboutfaceproductions.com.au/Site/Home.html accessed 25/10/11 }}{\text { http://www.imdb.com/name/nm0298754/ accessed 25/10/11 }}$

Gregor Cameron 198272670 
performance, he shook my hand and simply said, "It did exactly what you said it would." He offered this with a big smile.

Perhaps the most potent mentor interaction occurred with Tom McCrory ${ }^{21}$. Perhaps that is the reason that I want to report it in such detail, as it underlined, defined and turned my process upside down. Certainly he very clearly set the signposts for connecting my practice with theory better than anyone else had. Therefore I include a fairly detailed report of our meeting.

Friday the thirteenth was a resonant day to begin a conversation with the dark side as a focus. Tom McCrory is a performer and tutor in movement at Toi Whakaari/ New Zealand Drama School. He attended Jacques Lecoq's school in Paris for two years working on the Bouffon, the fool as performer/provocateur. With his wife he leads The Conch a New Zealand based Pacific Theatre Company. Very generously he gave his time to speak with me at Toi Whakaari, Friday the thirteenth of August 2010.

New Zealand being such a small place our conversation began by recognition of the people and places we shared in common. Jonathan Hendry, head of Acting, had told him that I was an ex-student of Toi Whakaari and so we already shared people in common. He also knew John Downie, now a lecturer at Victoria University of Wellington's Theatre and Film

\footnotetext{
${ }^{21}$ http://www.theconch.co.nz/index.html accessed 25/10/11
} 
MA Thesis: The Role of Misrule in the practice of Performance programmes, from back in 1989 at the University of Bristol- a year before I first knew and worked with him in the final year of my undergraduate degree. Then we were talking about his journey to Lecoq's school when he mentioned his wife whom he met in Europe. Something in Nina's name rang bells with me and I asked if she had worked with Rob Bennett when she was at Wellington Teachers' College- again a connection as we had been at college at the same time.

While none of this knowledge was immediately obviously meaningful I hope it will become clear how relevant this very human process becomes within the frame of our conversation. Being human underpinned all that was said that morning. As Tom was to say it all depends on communication- that which is common, the commune, communicated.

Tom spoke of his early fascination in fine art, particularly his introduction to sculpture through his grandfather. His university work began in this area but then developed into the form of theatre design which in turn lead to his awareness that the finest expression of what he wanted was to be found within his own bodies ability to perform and be- a fascination with the movement of the body. A timely workshop brought Lecoq's work to his attention and thus he found himself in Paris- an enervating competitive environment where he faced enormous success and dismal failure in the process that Lecoq has developed. He spoke of the student body being decimated after the first term and then again at the end of the first year. This 
competition spurred those like Tom to perform intensively to survive and honed a sharp sense of finding the truth, the new, and the essence.

So from this beginning we began to look at what it is to be a performer and a teacher. Tom's experience at Jacques Lecoq's school has given him a fine sense of connection with craft and tradition, how the apprentice looks to the master through to the position of journeyman and finally to a masterate of his own. We discussed this particularly with reference to the journeys of Monika Pagneux and Phillippe Gaulier, who after studying and teaching with Lecoq formed their own schools. In a sense carrying the essence into further work and discovery. I was interested to hear him talk of craft rather than art; as for me this is a key discretion in the work of a professional. Craft is the set of tools, which support the professional through the rigors of a career. Art tends to be the enthusiast's collection of experiments- both the success and the failures that inform the path of discovery. However taking the step beyond the norm means that the process of craft invites a level of risk that may be unsustainable. Tom commented that the traditions that are passed to the apprentice form the basis of the tools used within the craft- a way of managing such risk.

From there the conversation turned to the specifics of how Tom's work related to my own. Spotting my Punch and Judy graphic novel Tom suggested seeing the cover image as a mirror. Gregor as Punch is quite a 
MA Thesis: The Role of Misrule in the practice of Performance provocation! How does the illustration relate to the inner image of Gregor? What is frightening about this revelation? What is the impulse to engage in this genre and them? And that is how much of the following discussion wentbringing up more questions than answers. However if the answers were there then the creative journey probably does not need to be taken.

The impulse to explore the 'dark clown' comes from within. According to Tom, Lecoq said that we all wear three masks: What we think we are, what we share in common with others and what we really are. Lecoq's work was all involved with paring these masks down to the essential story, moving from the mask constructed by our egos in combination with our society to the nature we should be living in conjunction with and finally through to the essential sacred image, an expression of the spirit.

Practice, for Lecoq, was an invitation to examine the impulse, come to terms with it and discern the difference between the ego driven destructive face of the dark impulse and the sacred call, which seeks to deliver light by defining the darkness. In short, using the energy of the fool to unpick the destruction, which often goes hand-in-hand with the constructed ego. Tom drew the analogy of the binary nature of the constructed ego- either things are good or they're bad, black or white. He suggested this forms much of the basis of much Christian practice, not all, but enough to have a profound affect upon the way most of us operate in society. The difficulty this produces as part of the way our egos are constructed is that it creates the very blocks that prevent us from experiencing simply being human. 
This, of course, risks becoming a happy chappy new age trip so it is important to see this work within the theatrical context. Bouffon is a methodology of stripping the baggage away from the performer and stopping the three masks from interfering with the possibility of the essential story. Tom suggests this central story; the essential sacred story is one of transformation, involving the path of destruction leading to rebirth. The human, as and with nature.

Bouffon, with the invitation to play, identifies those separations of ego and essence. Again Tom poses a question: Once I, as the fool/performer, touch upon the essential spirit how do I share that with others? How do I reveal the essence/spirit? Bouffon also offers 'otherness' as a connection to the divine. In effect the fool is a tool for offering transgression as a path to the sacred. It describes the way otherness as dealt with by societies other than European as perhaps offering examples. For instance the apaches dressed as women who are given a special place within the tribe or the fa'afine in Samoan society, the fools invited into the sacred places who in their disrespect move laughter into a re-appreciation of their sacred-ness. In essence it requires an attunement to the profane that offers a moment to reflect upon and brings the spectator back to the sacred. Therefore the process of destruction is always about bringing about the rebirth, creative reconstruction, responsive not reactive. This process draws a number of similarities to Bakhtin's writing 
MA Thesis: The Role of Misrule in the practice of Performance

about the carnival. It is always the intention of the carnival to use transgression as a mode of reflection upon the status quo. The fool or the clown therefore both innocent and rogue is about providing a mirror held up to the audience. "Devils may step where angels fear to tread," says Tom.

So it is with this new image of the sacred and the profane that I stepped more confidently on my journey. Tom's words had changed my perception of what I was doing but in some way had also changed me, myself. It was this passion and excitement that drove me through the more difficult times and laid down a pattern of what it was I wanted my audience to experience.

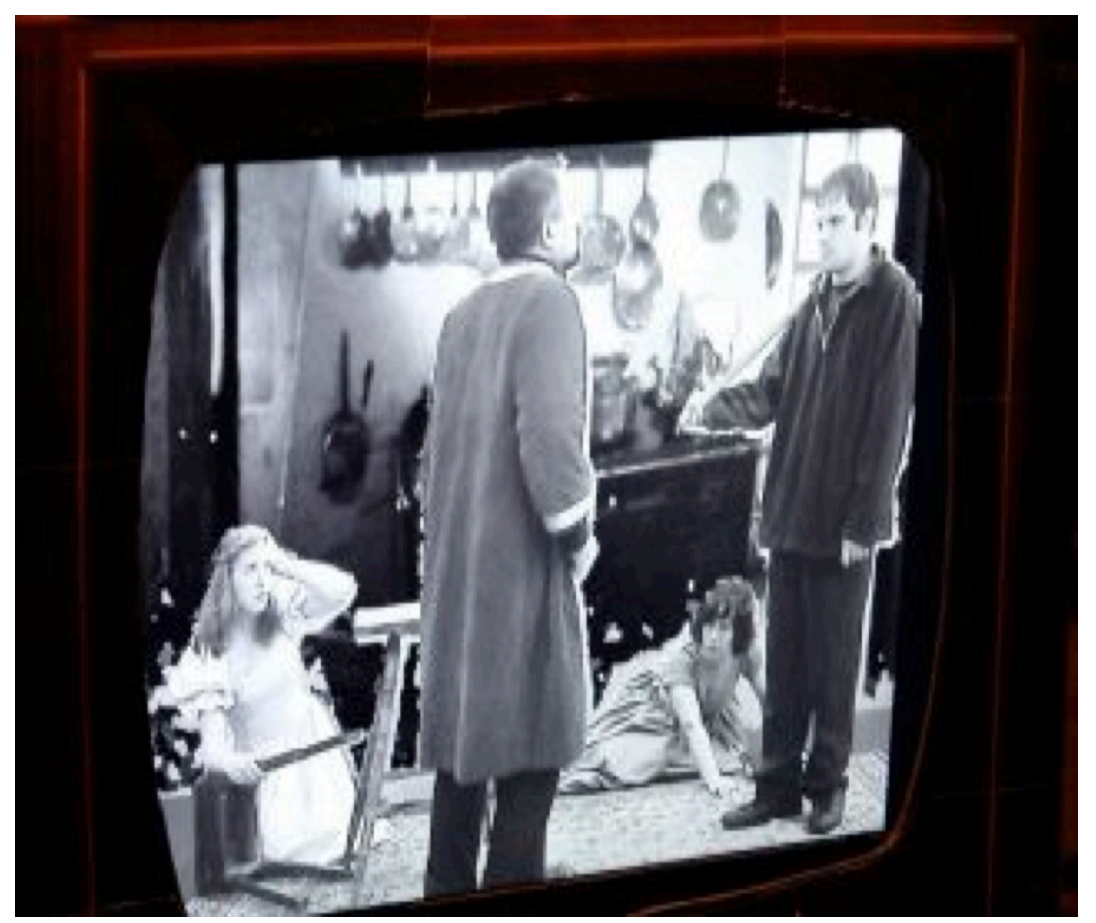

Figure 8. The television, showing the climax of the Bluebeard story, in a kitchen. 


\section{Design}

While I had a clear sense of the three environments, that the script suggested, in the theatre, I was hoping that a designer would bring something else to the performance. Unfortunately, despite a few invitations to collaborate, I found myself doing more and more of the planning. As time went on a great team of stage management and technical crew did emerge but I felt very much stretched in coming up with the staging that we used. The play required three clear environments. Originally, I had intended them to be a punch booth, a masque space and a naturalistic stage space between them. I had some sense of placing the actors on to three levels. I had planned for the highest level to be a place of large almost operatic masques and constructs- huge to contrast with the puppets that were closest to the audience. This intention was just not practical in Old Drama House. Given this space and Downie's challenge I needed to rethink the design. I am quite interested in how these three stories are somewhat a shadow of each other. A process of mediation has clearly drawn one through another. This mediation is fascinating and it seemed inevitable that I capitalise on it. Therefore, my thoughts turned to making the naturalist/realist space into a reflection of both mediation and significance by using a camera. I decided that I wanted the audience to read the screen as a source of historical reality or at least some sort of recognisable claim to veracity. I also wanted to 
MA Thesis: The Role of Misrule in the practice of Performance

explore how I could bring in the outside and make the supposed space that much bigger. Thus formed the plan to use the downstairs room as a green screen studio and use the sunroom as a space that could hold a miniature set and control for the four video cameras that would allow two angles on the actors, one high and one more directly at eye level. I took advice from video developer Cameron Mackechnie at this point as to how such a set up could work but this proved too expensive. Thus working on a very small budget I relied on advice from Willie Franco to use the facilities that the theatre programme already had. By using a video mixer with the four cameras Elliot Lim, who had followed this project through the summer, was able to switch from one angle to the other, live editing as he went.

The second major design was the Punch booth, which I decided needed to be more flexible than just the traditional one had been. As it happened, the Lighting box was about the right size and shape to be the Puppet Booth. By framing this in striped material and backing the booth with gauze I wanted to suggest tradition but also provide room for my actors to perform and 'see' their performance as well. This would also expose the illusion somewhat to the audience but not intrusively. I had been working on Punch's community of Puppets over the summer and they were just the right size to feature in this space. In designing the puppets I decided to not go traditional completely. In fact, I wanted the Punch puppet to reflect a more modern urban look. Thus, I dressed him in a hoodie, this being a form of dress that is rich with signification in modern stories. At times then, it can represent a morally 
ambivalent figure ${ }^{22}$. Kevin Braddock in the Guardian sums up the Hoodie's role in the recent riots in Britain. Moreover, having made this choice I followed it through with the other Punch community puppets using a range of Baby sized clothes.

When Des came on-board, I discovered he had a passion for modelling and this strength definitely deepened our collaboration together and helped putting together the show. I had purchased from the $\$ 2$ shop some eight-inch toy soldiers and Barbie clones. Des was able to work on these and adapt them to our needs. He painted and subtly changed how they looked before

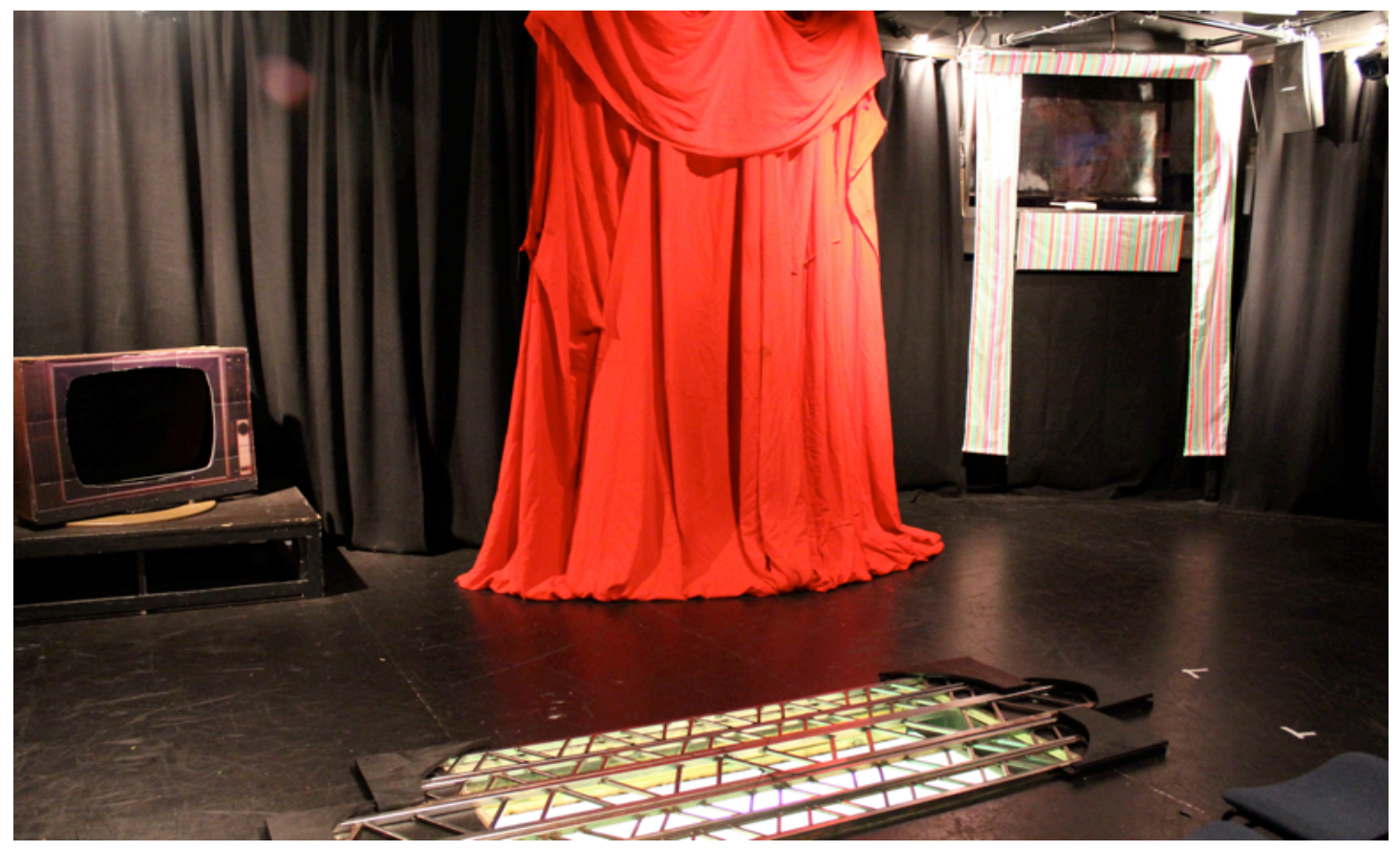

Figure 9. The Stage: TV Screen, Curtain, Punch Booth and Grille.

${ }^{22}$ http://www.guardian.co.uk/uk/2011/aug/09/power-of-the-hoodie accessed 29/10/11 
MA Thesis: The Role of Misrule in the practice of Performance

adding handles so that he and Rosie were able to play their puppet scene in the Booth. Des also made the circular mini-set that Elliot as able to combine with the green screen work. The Barbie clones became headless later on, as we needed to produce a cabinet for the Bluebeard story.

With the Bluebeard story, I was having some trouble choosing an image for them. As I worked with the actors, a form became evident, so I began to search the net for suitable puppets. Very soon, I came upon a company called Melissa and Doug. ${ }^{23}$ These hand puppets call up a reference to The Muppets, a Disney property that would have a resonance for both actors and audience. Having purchased these off Amazon.co.uk I began to see a real growth in how the actors began to see their story on the stage. Des offered to make the cabinet in which Judith would find the heads of Bluebeards former wives. Finding the heads up in the booth was easier to design, and allowed Gilles and Joan's scene to be on the video.

The Video Studio consisted of a raised floor and four flats, painted with green screen paint. Elliot placed a camera in the top corner of the room for a wide shot and another closer to the stage for close-ups. He then mirrored this with the circular miniature stage, allowing us to place photos on the walls, which would change as the action moved from one venue to another. We used photos and no furniture as this was about as far as time and resources would allow but it would have been interesting to go much further if possible. Up on the stage I built a frame for the large LCD screen that we were using and

\footnotetext{
${ }^{23}$ http://www.melissaanddoug.com/hand-puppets-animal-puppets accessed 29/10/11 
made it look more like a large console Television from the 1960's. Elliot would then pull the colour out of the image so that we were showing the audience a Black and White image. This was entirely deliberate as it was not my intention that they should not be aware of the conceit of the green screen, but rather see the image as a representation of how the docudrama image was produced back then. I wanted the audience to read the image as representing 'truth' without forgetting that the image was entirely false. This playing with representation was entirely deliberate as one of the main objectives of the show was to encourage the audience to question the mediated images presented through the Media.

Finally, the stage should connect these environments together. I wanted the stage, now the domain of the masks, to bring together the two others. All the actors on the stage would wear a mask although only the old man who bookends the play would be wearing a Commedia Dell'Arte mask for real. By presenting in mask, the actors declare a place of unreality in which the fantastic and the grotesque might exist. I wanted also to signal that presence of the circus or the carnival by placing centre stage a large red curtain, which would be the major entry and exit for the action.

Downstage, but off centre, a trap lead down to the video studio. I wanted to raise this so that a connection would be established that could prove that our video was still live performance. This was a difficult sell to Jim Davenport for 
MA Thesis: The Role of Misrule in the practice of Performance very good Health and Safety reasons. However, it was always my intention to somehow block the open space with a grille that would allow a view down but stop anybody from falling through. Eventually Jim agreed to this. He provided the steel grille that we used for this purpose. While this setting was sparse in some regards, it all signalled my intention for the final performances. As the play itself neared, I began to collect more Technical crewmembers. Shannon Friday, Courtney Leggett, Kate Norquay, Bop Murdoch came on-board as stage management crew lead by Rose Kynoch (MK). They assisted greatly in realising the design. Jim provided two of his scenography students, Stephen Keen and Andy Friedland to help complete the Video Studio. Andy went on to setting the lights and running the lighting board. Patricia Hetherington and Elliot Lim followed the project from the summer workshops and now ran the sound and video design. Finally, for my last illusion I had help from Dawa Devereaux, a friend who had collaborated with me when we were both students in 2006, who produced the flame circles I needed to burn Gilles and Joan in the show's final scene. These were placed in a pile of wood that opened up for the actors to enter. The illusion meant that as the actors stepped onto the sponge rubber pile of wood, a tube of material with a sort of flame patterning was raised to the mid-riff. Combine this with light and sound and both Gilles and Joan are burnt 
Costumes were intended to be consistent from environment to environment, and where this was not possible for cost reasons they were to be suggestive of a commonality. Thus Gilles wears a kind of costume that suggests armour without actually being armour, Punch wears clothes similar to his puppet but not identical. Most were found costumes or cost very little to put together. It is important to note that this performance was a show and tell and far from what might have been a full production. The budget came out of my pocket, I am grateful for all the infrastructure support I received from the university, and in particular the Theatre programme.

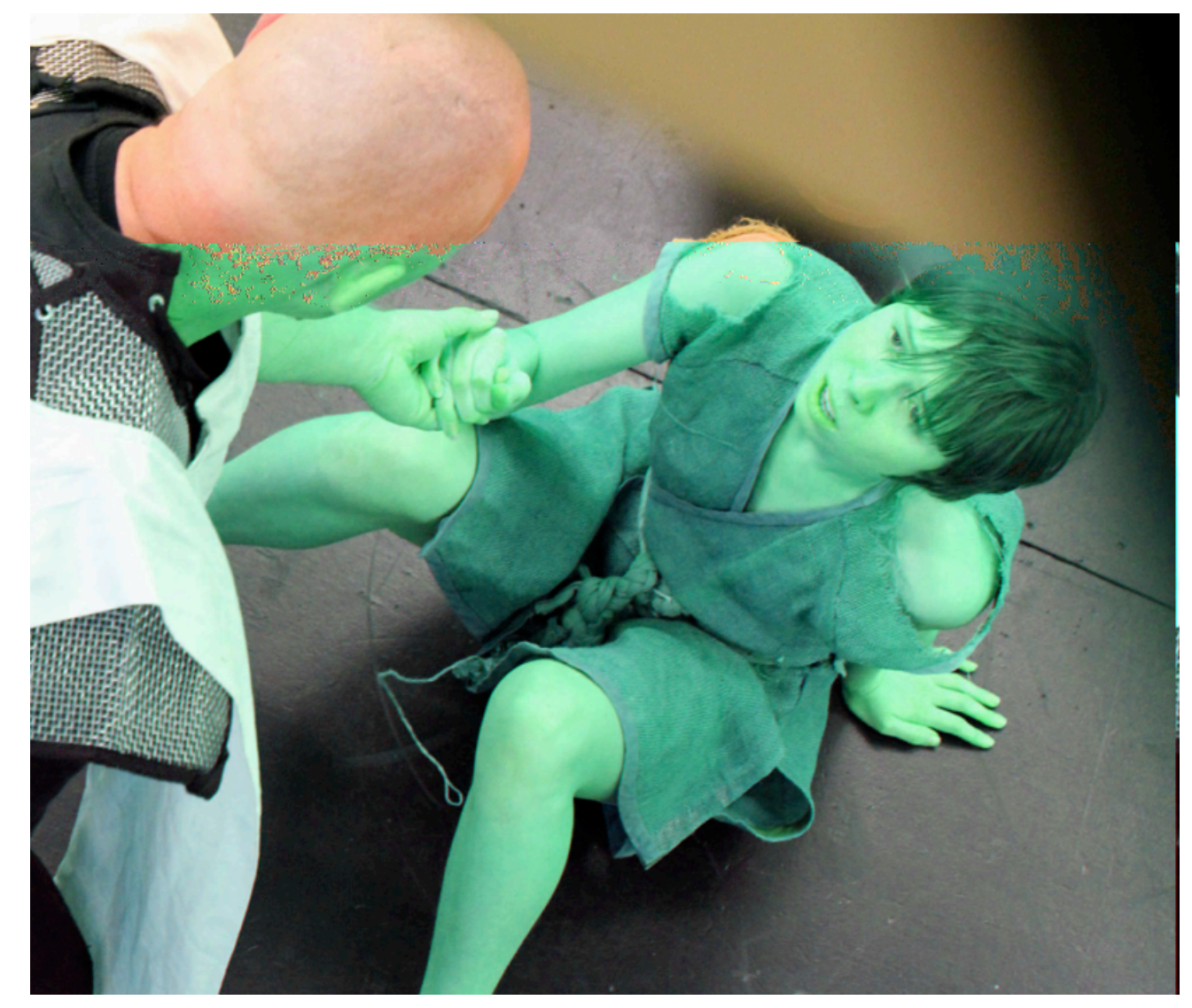

Figure 10. Looking down the Grille 
MA Thesis: The Role of Misrule in the practice of Performance

\section{Show and Tell}

The final week of preproduction was frenetic. While we were able to rehearse in the space in the evenings and on the weekends, it remained a teaching space so any setting of tech and stage needed to await the end of trimester. Added to this pressure were the major productions being done in 77 Fairlie Terrace, the main Theatre, which were using most of the lights and such and had to be cleared before we could access some of the resources of the Theatre Programme. Despite this, we began to construct our playing space. Andy and Stephen painted and put together the studio downstairs. Elliot began to put together the video feed. Patricia began putting together her set of sounds. On Saturday the $4^{\text {th }}$ of June 2011 , we began work on the upstairs five days before the first performance. Shannon, Bop, Courtney, and Kate helped with bringing my stage ideas to fruition with contributions that supported those ideas. Rose MK began taking over from me in organising cast and crew. Far faster than I imagined the stage and show began to look more and more as though it would far exceed my expectations.

We were still rehearsing and it was during this process that a few select people were invited in to have a look at the work thus far. John Downie, Chris Ryan, Kerry Glamsch and Ralph Johnson all gave feedback, both to myself and to the cast that was welcome and very pertinent. Of course, some last minute glitches arose in not having enough time to test and put together with the action the technical aspects of the show. It all looked quite ambitious. 
After a dress and a tech underlined how quick it had been to suddenly make the technical aspects of the show gel with the cast, we were off. Saint Punch ran for four nights, June $8^{\text {th }}$ to $11^{\text {th }}$. The audiences were a mix of staff from Victoria University, invited friends and members of the local theatre and film community.

\section{Thoughts}

During the run Rose MK took on the main concern of running the show. This left me time to film the performance and to gauge what the audience was experiencing. The DVD attached to this thesis includes a recording of the final night that I believe was where everything came together about as nicely as I could ask for. In sitting in with the audience, I was able to listen as they laughed at the comedy and caught themselves laughing at events that perhaps were not quite so funny. It was a queer feeling.

I spent a bit of my time trying to gauge the reactions of my fellow audience members. I realised that most of them were engaged, especially because of the broken narratives and changes of scene made by the characters. They needed to be engaged or risk missing something. This is not to say that every moment was as interesting as every other, but by and large their attention was on the performance. However it would be true to say that direct interpretation like this is a little inaccurate. 
MA Thesis: The Role of Misrule in the practice of Performance

I think that the performance stood on its own merits. I do acknowledge however that it was produced on a shoestring budget and as such suffers in its lack of complete consistency of design. Later I got the opportunity to speak to members of the audience about their experience. By and large the comments I received were positive with a number of them saying that they left the theatre quite engaged and that the play travelled with them for some time. I believe this to be as positive a response as I could want. However there was one exception who, I am told, travelled all the way back to Raumati from Wellington concerned that perhaps I should seek help and wasn't there a chance that I was suicidal and shouldn't they do something? Luckily, friends of mine, who know me all too well, and were unconcerned, had brought her along.

How do I feel? Actually I am very satisfied with the show, warts and all. My intention had been to investigate the carnivalesque, to take the audience on a journey that they perhaps did not expect. However this was leavened with the knowledge that I did not want to leave any of them behind. Thus the trick you play involves planting breadcrumbs, which will be followed through a landscape rich if they will only raise their heads. If they do then all sorts of thought could be excited, but if they don't there is still enough within the breadcrumbs to satiate their imagination's appetite.

I believe that the amount I learned from what went right has been far exceeded by the knowledge gained from what went wrong. I clearly expanded the range of my confidence and belief in my own ability - and also managed to place in front of an audience an intriguing piece of theatre. 


\title{
Part Three: Critical Analysis of Misrule and its part in
}

\section{the performance of Saint Punch}

\author{
On rare and unforeseeable occasions, the Jester would turn the city \\ upside-down by some prank which might be no more than an elaborate \\ practical joke, or which might be a calculated assault on some currently \\ cherished belief or way of life. All things considered, the name "Jester" \\ was a highly appropriate one. There had once been men with very similar \\ duties, operating with the same license, in the days when there were \\ courts and kings.
}

(Clarke, 1956:51)

Let's start with Stanislavsky. As the role of misrule in practice, as well as performance, is what this paper is about it seems sensible to look at one of the masters of twentieth century acting/theatre systems. He offers a clear definition of how a director in the theatrical space is required to act. He suggests, as Bella Merlin (2007:180) tells us, that there are three key points that inform the director's role. Firstly they need to know how to deal with the writer, something he did in his relationship with Chekov, for this relationship defines the creative moment that will move the work, the written text, outside into the light. Secondly, they must know how to work with the actors. Choosing and then provoking the actors into asking the right questions becomes the objective of the director, how to provide enough context to influence the actors own natural curiosities. Finally there is the collaboration they must negotiate with everyone else involved. This ranges from stage management to ticket 
MA Thesis: The Role of Misrule in the practice of Performance

sellers, technicians to designers. In this sense he must be able to effectively communicate the vision, and listen to the reactions to it, to bring together whatever new life is evident in the theatrical experience (Merlin, 2007:181).

These relationships are a key component to producing a moment on the stage that is going to enrich the audience experience within the theatrical space. Even in his use of a fourth wall, Merlin tells us, Stanislavsky was not attempting to close the audience out but instead school his actors to consider the truth on stage rather than, as the tradition had been, to pander to the audience's demand for 'entertainment'. If what is placed onstage is truthful to the actor, irrespective of the system used, then the audience would be drawn into the moment of the theatre (Merlin, 2007:249-50)

You should love your art because it makes it possible to talk to the spectator about the things he cares most for in life, and to make him a more useful member of society by embodying certain definite ideas on the stage in artistically creative characters. If the spectator obtains an answer to what is engaging his thoughts, he will grow fond of the theatre and will look on it as a necessity. But if all we do in the theatre is to entertain him, he will come and have a look at us and then go away.

(Stanislavsky quoted in Merlin, 2007:250)

Richard Schechner cites to entertain and educate as a core constituent of theatre as far back as the Roman poet Horace's Ars poetica (65-68 BCE). He continues to make it clear that this has been a call continuing down through the renaissance to Brecht in the twentieth century (Schechner, 2006:45). This key function, it seems to me, is allied to the carnivalesque. If the audience enters the theatrical space in the clear expectation that something is about to happen, something that they will understand and enjoy, but that will possibly Gregor Cameron 198272670 
open their eyes to a new worldview, then the 'entertain and educate' function continues to be a potent element in the magic of the theatrical ritual.

Schechner also offers a system of seven key functions of performance:

1. To entertain

2. To make something that is beautiful

3. To mark or change identity

4. To make or foster community

5. To heal

6. To teach, persuade, or convince

7. To deal with the sacred and / or the demonic

(Schechner, 2006:46)

System is a key word here, as in order to work towards an idea of creative misrule it is important to understand two key points under which misrule and carnival can occur. There must be a frame of the status quo: the 'real world', a system. In the frame of the carnivalesque, it is everything outside the carnival space and, in misrulic terms, is the system within the carnival from which misrule manifests. As we see with Stanislavsky, the system is the rich bed for encouraging the manifestation of the Carnivalesque. Both of these forms require order, but the misrule of carnival is not chaos.

Art is an act of the spirit. It asks you to be a conduit for something larger than yourself. 
MA Thesis: The Role of Misrule in the practice of Performance

\section{Bakhtin and the Carnivalesque.}

In order to define the carnivalesque it is useful to refer to the writings of the Russian Literary Critic, Mikhail Bakhtin. Lewis Hyde (2008) recognises Bakhtin as correctly interpreting that the Renaissance, as reason and religion grappled with the minds and souls of the people, drove the carnivalesque to seek refuge in the arts. As Protestantism and its insistence on restraint took over the public sphere, the medieval carnival moved from a carnivore's holiday physically enjoyed by the people before Lent into literature and art. (2008:194). According to Sue Vice (1997) Bakhtin considered the existence of the carnivalesque in his studies of the French renaissance writer, Rabelais (c.1494

- 9 April 1553). He categorizes the carnival as having three aspects:

- Ritual Spectacles including comic shows and pageants,

- Comic verbal compositions which feature parodies both in high and low language and,

- Various genres of billingsgate (curses, oaths and popular blazons (1997:151).

Bakhtin goes on to detail this list in his consideration of Russian writer Dostoevsky (1821-1881). Carnival is further refined as inhabiting the novel:

- Without footlights as there is no division between audience and performers, free and familiar,

- Combinations and inversions that arise from apparent binaries (sacred/profane, high/low, wisdom/stupidity, male/female), 
- The body as governed by both high and low natures (grotesque, eliminations, parody),

- Death and renewal,

- Laughter pointed both at and with the participants; the laughing aspect encompassing the sense of community- the town or place which draws the players and spectators together (Vice, 1997:152).

Carnival time (and space) is characterized by '[m]oments of death and revival, of change and renewal [which] always lead to a festive perception of the world' (Bakhtin quoted in Vice, 1997:153). It is important to note that defining things in terms of binaries is problematic and limiting, that in a dialogic world there are many other voices and positions that feed into situations. However in mythological terms they perform a useful function of definition determining limitations about a position. Thus we can use antithetical terms to perform certain positions in a given situation.

Vice makes it clear that Bakhtin had some reservations about whether theatre could be dialogic, a key idea that arose from his work on the carnival. However he did consider the theatre a place that could be carnivalesque in his writings, which include identifying Shakespeare as using the Carnival trope (Vice, 1997:198). It is left to others to debate whether or not Bakhtin's consideration of the theatre was complete or not. Ronald Knowles (1998) notes that Bakhtin believed in the 'unfinalizability' of things- an open-ended dialogue (1998:3). 
MA Thesis: The Role of Misrule in the practice of Performance

Meaning, in language, and in comparison with the work of Saussure, was to be found in the space between, the dialogic. The dialogic is one of the keys to polyphony, the 'many-voicedness' which Bakhtin attributes to the novel, and unlocks the form of the heteroglossic, the 'many-differentness' (Vice, 1997:112). However, it seems reasonable to engage with the theatre as a space in which many points of view can be voiced, experienced and reacted to, at a point of live juncture- a 'live' moment of give and take between writer, performer and spectator. Robert Stam (1989) points out that Bakhtin's writing on the active participation and response of the reader is not at odds with the reception studies that arises out of current cultural approaches of Film and Media scholarship (1989:21). Stam also points to Bakhtin as a "liminal" thinker"on the borders, at the junctures and points of intersection of academic disciplines as traditionally defined and institutionally regulated" (1989:17). Hence Bakhtin appears to be constantly in a state of flux and therefore it is appropriate that his thinking could and should be applied to fields that have developed considerably since he was writing in the first half of the twentieth century $^{24}$. Knowles comments that Bakhtin does form a contrast between the conventions of the 'well made play', where aesthetics, particularly those of the Greek tragedy, were, in the nineteenth century, elevated to 'a monolith of official [high?] culture and the 'whole of Naturalist drama' of Ibsen and his contemporaries becoming 'novelized' (1998:9). In this instance Bakhtin does signal that the emerging theatrical traditions offer a far greater sense of manyvoiced-ness than they have previously. Knowles, in his book, uses Falstaff's comment from Shakespeare's Henry IV Part 2 to illustrate the possibility: "I

\footnotetext{
${ }^{24}$ Bakhtin wrote most of his works in the twenties and thirties in Soviet Russia and did not become known in the west until the sixties.
} 
have a whole school of tongues in this belly of mine" (Knowles, 1998:9) suggesting that this form of dialogic has inhabited theatre even before the rise of the Naturalists. Hence the spectacle of nineteenth century theatre gives way to a representational world which is not bordered by the confines of the theatre but instead suggests a wider world outside, a moment in the stream of these characters lives, illuminated with the 'novel' of the theatre. Knowles notes Bakhtin's recognition of the Carnival in the work of Shakespeare but his hesitation to allow theatre polyphony (1998:8). However Knowles also notes that Bakhtin also seems to ignore the work of Chekov that clearly allows for polyphony within his drama and stories (1998:10)

Mark Fortier (2002) cites Robert Weimann who studied the way in which Shakespeare's plays can be seen to operate in more than one voice. They appear to be able to represent both the official position (ruling class) and that of the people. This can happen as simply as through position on the stageupstage for authority and downstage for an intimate and informal position to address the groundlings and lower class (2002:161). Shakespeare also becomes playful in his placing together clowns and kings, cross-dressing heroes and heroines, and lords that become friars. Thus play becomes identified as a crucial element on the carnivalesque stage. Play and laughter are key elements in the way that an audience is invited to participate, an instant feedback system if you will, in the spectacle of the theatrical space. Michael Bristol (1985) maps how misrule, burlesque, grotesquerie, and other 
MA Thesis: The Role of Misrule in the practice of Performance

inversions travel from countryside to marketplace and from there to the plays

of Jonson and Shakespeare. He notes that people's interaction with

performance and theatre was very common across a wide if not complete array of social groups and communities. As the urban community grew so did the tradition of the development of the organized professional theatre, especially that of London (1983:638). The theatre increasingly becomes a place, a central spot where communities could meet in the expectation of seeing something festive in the spirit of the medieval markets and carnival. It becomes a defined border between the status quo and a space in which something 'other' may happen.

This sense of the difference between inside and outside of the carnivalesque space fits quite well with some modern conceptions of the theatre. Bakhtin does not engage much with the theatre, as his concern is the novel. In the witness of play and laughter, in what can be presented in the theatre, society is offered with an opportunity, an invitation, but, like the proverbial horse, the provision of water does not imply the drink. The social contract that is implicit between spectator and performer allows access across these divides. At entrance and exit, performance and response to the theatrical moment, this community gathering serves to repeal one of Bakhtin's criticisms of the theatre as simply a spectacle ridden de-politicalized space. Marvin Carlson references Julia Kristeva in discussing who the author is in carnivalesque terms. She places the dialogic firmly in the space between the 'author' and the spectators, with the performers acting as a conduit for the variety of voices. In a sense they are "in turn simultaneously both subject and addressee of the discourse. 
The carnival is also the bridge between the two split occurrences as well as the place where each of the terms is acknowledged: the author (actor + spectator) (Carlson, 2004:69). It must be noted, however, that some aspects of the carnivalesque are also apparent in ludic sports arenas. Whether this type of spectacle is able to rise above the 'pressure release' aspect of the carnival is open to debate, take for example the annual sevens tournament played out in the Wellington Stadium (New Zealand). Here is played out a performance not only of the athletes but also in terms of the spectators and their colourful costumes which definitely have a carnival atmosphere but it would be difficult to suggest that any real critique of anything outside the stadium was being played out, a grand example of the social spectacle.

David Danow (2004) places Bakhtin's reading of literature in an apparent binary of "two aspects, seriousness and laughter, [that] coexist and reflect each other, and are indeed whole aspects, not separate serious and comic images as in the usual modern drama" (2004:34). Thus suggested, there is a composite rather than a binary form, which Danow sees in magic realism of the Latin American literary form. In a sense laughter provides a vehicle into some aspects of the world that otherwise would be closed to scrutiny. The Carnivalesque invites both laughter and seriousness into its space in order to offer more than just an entertainment to the participants. After all, the carnival is both a place of letting off steam about, of being reflective, and possibly critical, of the status quo that exists outside. Kenneth Pickering and Mark 
MA Thesis: The Role of Misrule in the practice of Performance

Woolgar (2009) consider carnival as part of the celebratory theatre. They observe its liminal state: " a borderland between two states of being" (2009:99). They discuss Augusto Boal's criticism of Bakhtin's theory. However, while Boal sees Carnival as an agency of the state oppression, his own Forum Theatre is almost a manifesto to the reflexive revolutionary aspect of the Carnival. Pickering and Woolgar invite us to consider the inverse of too much laughter, that "a population fed a constant diet of sport, celebrity or royalty is not equally impotent when it comes to changing the attitudes or policies of the governing elite" (2009:99). With this overt political agenda, and without the component of laughter, it is difficult to see how much fun a Boal production would be. The argument could be made that this very seriousness is counterintuitive to any lasting change being made manifest. In losing the entertainment and educational aspects of the carnival Boal may well limit just how much political enlivenment he can achieve. His work on Legislative theatre however is interesting because of its direct action element- perhaps the intention to turn from allowing the audience to be affected into one which has a direct effect means that the carnival is still present but in a different form ${ }^{25}$.

David Charles (2004), in commenting on Playback Theatre, offers Boal's Invisible theatre, along with Bread and Puppet theatre, the trestle table stages of Rome and Medieval times as example of a transient theatre full of mutability and multiplicities (2004:4). Each offered sign or mimed object displays many possible uses and readings. Improvisation connected by space and time, the here and now, is consistent with Bakhtin's idea of the chronotope. Playback

\footnotetext{
${ }^{25}$ Thompson, S. Leigh. "Essay: Theatre of Change (About Legislative Theatre) I the Forum Project". $<$ http://theforumproject.org/whatisto/what-is-theatre-of-the-oppressed/essay-theatreofchange4/>.
} 
exists in the here and now, "cheerfully.... reflecting and releasing the stories, energies and emotions of its participants" (Charles, 2004:7) The chronotope defines time and space in any literary or performative text, it is the place, the duration that settles the detail of the mise-en-scène, "how fictional time, space and character are constructed in relation to one another". Charles also acknowledges that while improvisation is free it is the 'ritual' or framework under which it operates that allows for this freedom. Transgression that forms in the context of the status quo, understood and then offered up to scrutiny through the improv form. The rules of governance, known, are temporarily suspended (Charles, 2004:16) Thus the frame, while not being ritual, is certainly a form which the theatre may utilise.

Diane Wilson (2006) has offered a useful reading of Buffy the Vampire Slayer ${ }^{26}$ in Bakhtinian terms. She offers many examples of how various modes of the carnivalesque can offer readings of Joss Whedon's work. In particular Whedon is quoted as saying:

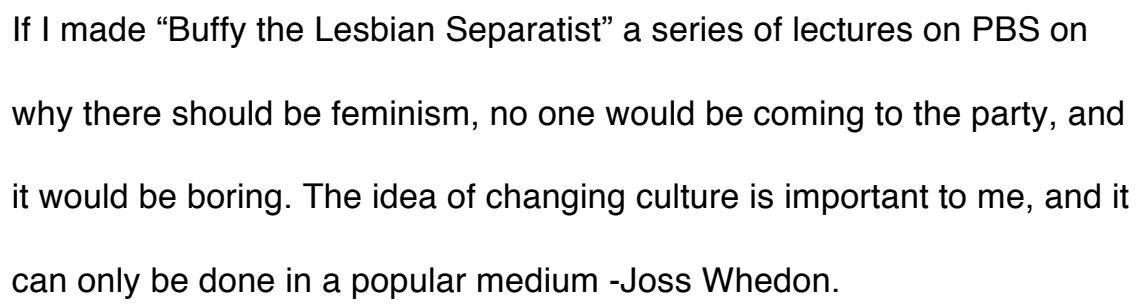

(Quoted from Nussbaum in Wilson 2006)

This is telling in a number of ways. Clearly Whedon knows his audience and directly engages them. He uses humour as a mode of inversion on the horror

\footnotetext{
${ }^{26}$ Whedon, 1992 film, then $1997-2003$ television series
} 
MA Thesis: The Role of Misrule in the practice of Performance trope and from this position, the political nature of what he wishes to foreground, allows for a much greater affect upon his audience.

Farrell Cleary (1995) has argued for a Bakhtinian reading of James K. Baxter's plays. He notes that Baxter observed his own "ineradicable tendency towards vaudeville" (1995:121). Baxter wrote, in a foreword to The Band Rotunda, a warning that the characters should not be identified as "merely comic types or grotesques, though there are grotesque and comic elements in the action and dialogue" (1995:121). Cleary ends his article recalling Baxter's use of earthshaking laughter in the character or Flanagan in The Day Flanagan Died. Cleary suggests that it foregrounds Flanagan's freedom from the rules and that, "for all its hero's untidiness and irresponsibility, the play would have its audience treasure that life [before death] and escape the zombie fate of so many in Baxter's New Zealand (1995:131). Again Stam (1989) underlines the importance of laughter:

\footnotetext{
Carnivalesque laughter can be raucous, subversive, even angry, a laughter that erases old differences and installs new, unstable ones. Laughter is profound, communitarian, erotic, a current passing from self to self in a free and familiar atmosphere. It is the adult memory of the cascading giggles of children, who laugh not necessarily at specific localizable "jokes" but as part of a collective contagion.
}

(Stam, 1989:120)

Saint Punch brings the carnival to the stage. At the beginning the setting of a wedding serves to introduce the characters, as well as set up the frame for the telling of stories - a comfortable place for the audience. The theatre itself is set in a fairly unadventurous design with audience sitting opposite the stage They 
perceive upon the stage the familiar trappings - the puppet booth, the 'circus' curtain and the television. After the procession of characters comes a comedic interlude establishing that the three states are not going to necessarily always be separate, as the Professor speaks with the puppet Punch. Then the first scene is played up in the puppet booth and the audience is encouraged to laugh. The television introduces the historical figures of Gilles de Rais and Joan D'Arc, which puts laughter into question as de Rais rapes the child. Then Bluebeard and Judith appear upon the stage in Mask playing out the accusation of betrayed trust. The audience must decode where in the narrative these two other stories fit, further alienating them from too much empathy with the traditional folk and historical stories. This disruption of the stories timelines is a deliberate dislocation for the audience who, up to now (scene 1), have been in a familiar theatrical frame. This intention is leavened with the knowledge that the audience must not be dislocated to the point of becoming lost- they are encouraged to decode not disengage.

The fourth wall is already porous as Mr Punch and Judy and the Professor directly speak to the audience, the wedding serving as the ritual and the action on stage serving as spectacle in both its horror and its comedy. This pattern of comedy skits between the more violent plays invokes the common strategy of a night at the Grand Guignol, the so-called douche écossaise or hot and cold showers (Freshwater 2007:248). Punch's inversion in his gentle care of Judy and the baby is unnervingly mirrored in the actions of de Rais and Bluebeard. 
MA Thesis: The Role of Misrule in the practice of Performance

However we are also aware that though Punch kills the baby that there will come a renewal of their story as the tradition recognises- all things are forgiven and repeated in Punch's mythology.

The masks of the stage serve to subsume the actor and emphasize their embodiment of their stylized characters. These characters do not represent reality as we understand it, but rather a representation of it. However, as the actors pass through the differing mediated environments, that thought is undermined, the carnival does not allow them to so easily dismiss the images before them- they laugh at Punch and Judy, can enjoy the romance of the puppets representing Judith and her sisters meeting with Bluebeard. Then the characters appear on the screen, acting more naturalistically. The screen itself defines a particular reading of the image, harking back to the sixties social realism docudramas of Peter Watkins ${ }^{27}$ or the American TV series You are There (TV Series 1953-1957) ${ }^{28}$. Suddenly the audience finds itself within the dungeon, the police interview room, the noble's castle. As swiftly, the violence turns real, visceral, and discomforting. The inversion is complete and the audience should question whether what they are experiencing should be laughed at. In a sense the carnivalesque allows for a place where there is an agreed liminal space. It is a space where these characters can be re-mediated as they cross between the three performance spaces. Their basic character and the story they are telling does not change but the space can invade the context of the stories. With Punch's story his entry into the real (Film) environment heightens the sense of his threat. This was the intent. In placing

\footnotetext{
${ }^{27}$ Peter Watkins, director of Culloden (1964), The War Game (1965) and Punishment Park (1971).

${ }^{28}$ You are There. http://www.imdb.com/title/tt0045458/ accessed 28/11/11
} 
and moving the characters from place to place I intended that their stories would be thrown into question.

\title{
The Grotesque Body and the Simulacra.
}

\author{
The grotesque character is a comic figure. It is impossible to sympathize \\ with him, despite his agonies, because we view him from a detached \\ perspective, and when we are not emotionally involved in his suffering, \\ we are amused.... \\ As with the grotesque character the entire technique of the grotesque is \\ also essentially comic, for we always view the grotesque from a vantage \\ point. To be certain, the subject matter of the grotesque- the raw material \\ which creates the vision- is always potentially horrible, but the treatment \\ of this material is comic: this explains the peculiar complexity of tone, \\ combining both horror and the ludicrous, which characterizes the \\ grotesque as an art form.
}

(Gilbert Muller, quoted in Lokke, 1988:9)

With the connotation of the Grand Guignol, the carnival allows the audience to experience an uncomfortable close up encounter with what lies behind the stories. The Grand Guignol is a place of horror and violence, often connected to the fashions of Horror and Action cinema, however in the theatre it was more likely to feature illusion, suggestion and trickery than any actual violence despite its reputation. In fact Grand Guignol is a very good example of how the carnival negotiates with the official system without. The Little Theatre in London in 1920 provoked the censorship function of the Lord Chamberlain when it began a season of Grand Guignol plays. Some plays were banned and 
MA Thesis: The Role of Misrule in the practice of Performance

some played. In response to this threat some other means of licensing needed to be found. The Old Women, was likely to be banned if the authorities knew that it would go on in London. Russell Thorndike, translator of the French Guignol play, put on the application for a license that would only be a showing to a small village. The censor felt it would do no harm there, but instead José Levy, manager of the London Grand Guignol, put it on at the Little Theatre in London as intended (Freshwater, 2007:252). This subversion of the law is interesting in that it suggests the presence of misrule in practice as well as performance.

Michel Foucault, in A Preface to Transgression, notes this system of limit and taboo and suggests that without the limit there can be no transgression, no crime where there is no law (Freshwater, 2007:249). Grand Guignol, as a genre, arose from the Guignol puppet figure, which in France served as a kind of Mr Punch-like character and was emblematic of a shift from the kind of horrific image that might traditionally have stayed off-stage straying onto the stage (2005:38). Pickering also suggests a link to Soap Opera and Melodrama in Movies and TV that feature 'good' or 'bad' characters (2005:39). Thus in content it had clear ancestry with the human corpse count of a Shakespeare or a Ford but, rather than happening offstage and then reported, the characters afflictions and mutilations were performed in front of the audience. Bakhtin may have acknowledged that this entry of the grotesque body onto the stage is clearly an invocation of the carnival. This feature of the carnivalesque is key as it links back to some of the earliest traditions and rituals. The grotesque body 
is primarily concerned with the functions of the lower abdomen, elimination and procreation, shit and sex.

Richard Hand and Michael Wilson trace the line between the Elizabethan and Jacobean stage through the gothic writers of Frankenstein, and Jekyll and Hyde (2007:19). They also state some of the adaptations that the Grand Guignol needed to make in its travel from Paris to London. In particular they point to the fact of its Montmartrean origins- that the sexual component of both humour and horror in the Paris version would need taming for a more conservative London audience. However it was still transgressive enough to provide a hearty dialogue in the papers of the time (2007:20). In part this explains why in most translations the location of the action remains France rather than making it local.

In talking about the style of acting within the London Grand Guignol, Hand and Wilson suggest that its melodramatic core was a deliberate attempt to invite the audience into the moment- what The Times suggested might be "realistically or romantically 'creepy':

There is a point at which horror works best when it is unconvincing, where it revels in its own artifice. If the audience knows that this is not real horror, then it is better to be able to enjoy it and surrender to its emotional intensity.

(Hand and Wilson, 2007:43) 
MA Thesis: The Role of Misrule in the practice of Performance

Either by being victim or by being perpetrator the Actor becomes the grotesque body. As the Tatler called it, "a really wonderful exhibition in the art of making the audience's blood curdle"29 (2007:43). This position as the grotesque allows an audience to place themselves either in opposition or in collusion with the character and the character's political position. Both positions should lead to the audience reflecting upon what they experience within the theatrical space. The experience may still be one that swings from laughter to horror but that very oscillation invites reflection, and possibly change.

The grotesque body also raises some questions about the use of the simulacrum. Puppets of course are the most familiar physical form of simulacra used in the theatre but the same may hold true of the masked performer and in fact of the actor themselves. In the movement of thought from Plato to postmodernism thinkers such as Nietzche, Baudrillaud and Gilles Deleuze have considered the importance of the simulacra. As they define how the simulacra is experienced by each of us they acknowledge that the simulacra, far from being a copy of a copy, plays a role "which is incommensurable with conceptual reason" (Edgar and Sedgwick, 1999:312). This quality of being without comparison means that when the audience accepts a 'stand-in' in the theatre they are signing up to a social contract that includes a degree of willing disbelief. A troubling notion if the theatre piece is reliant upon the audience also being willing to empathize with the characters or situation onstage. 
Berthold Brecht is suspicious of empathy. He accepts that empathy is key to an audience's enjoyment of the night out but is concerned that this may preclude them from thinking critically about the piece. He uses the actor as simulacra deliberately within his A-effect ${ }^{30}$. He says "[o]ur dramatic form is based on the spectator's ability to be carried along, identify himself, feel empathy and understand." (1978:25) Brecht is happy to use the distance between what is and what is being represented to secure an event in the theatre that challenges his audience not just to accept what is before them but invites them to be critical about what they perceive.

Brecht himself co-opted the Finnish folk figure of Mr Puntila in order to use the figure to illuminate the world in which misrule governs. E Speidel argues that Brecht is here illustrating how harmful class division is and how much more humanistic and neatly controlled the social state might be under communisma Marxist position (Speidel, 1970:321). In the play, Mr Puntila and his man, Matti (1940), Brecht offers a character not too far removed from that of Mr Punch, though Speidel makes it clear that Chaplin's Millionaire from City Lights (1931) "who, like Puntila, 'overflows with good humour and kindness when he is drunk, but reverts to a 'reasonable' attitude, mean and businesslike, when he is sober" is a more likely ancestor (Speidel, 1970:319). Brecht is concerned with this split personality and uses it to illustrate how there is clear division between the emotional warm human and the rational Darwinistic capitalist. In

${ }^{30}$ Alienation effect for want of a better translation. 
MA Thesis: The Role of Misrule in the practice of Performance

doing this Brecht is harking back to the picaresque novel "where the main interest lies in the individual episode and not in the development of a coherent story" (Speidel, 1970:320). Here there is clear connection to the traditional structure of the Punch story. Scenes are loosely connected and it is in the episodes the scenes run that should engage the audience. Brecht was conscious however that it should not prove a populist play but be accorded the same respect as a piece of grand theatre. In this he also did not wish to emphasise the romantic, the crude or the farcical; but rather use the humour, charm and disruptive behaviour of the character to engage the audience and invite them to consider the ongoing political meaning of the piece. The audience, able to dismiss the humour as un-affecting, concerned Brecht. How does one place a clown in front of an audience and still engage them in a meaningful dialectic?

His position is one of encouraging dialectic even as here he employs a clownlike figure. In the twenty-fifth paragraph of $A$ short organum for the theatre he explains:

Even the wholly anti-social can be a source of enjoyment to society so long as it is presented forcefully and on the grand scale. It then often proves to have considerable powers of understanding and other unusually valuable capacities, applied admittedly to a destructive end. Even the bursting flood of a vast catastrophe can be appreciated in all its majesty by society, if society knows how to master it; then we make it our own. 
Brecht adds an addendum to this which goes some way towards explaining how he perceives the age of reason coming to terms with the way in which the misrule of humour and surprise contribute to meaning in the theatre:

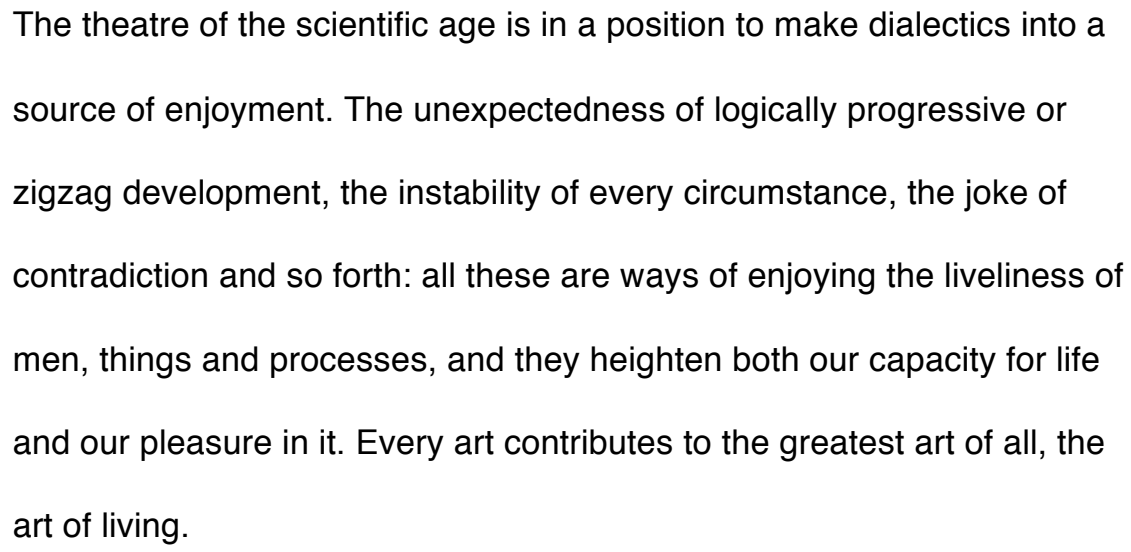

(Brecht, 1978:277)

Brecht seems to be saying that not only is everything in art an artifice but that our too-close identification is a trap that disallows any form of reflexivity. However at the same time he is also describing a location for the theatre that has clear aspects of the carnivalesque. He works in a form that does not attempt to be reality but rather seeks to reflect and be reflected upon. He expects an active critical audience to make meaning out of dramatic texts without the confusion of empathy but with an understanding of it (Franks, 1999:192). Here Brecht enters into a kind of 'what if' territory. Anton Franks and Ken Jones discuss how an educationalist like Dorothy Heathcote might recognise Brecht's intentions. They are unconvinced about some of Heathcote's understandings but acknowledge that she "suggests that the dramatic and theatrical experience is, in Brecht's words, like 'visiting another room', a room which makes the construction of an 'as if' or potential world is possible This other room operates, for Heathcote, as a place where the role 
MA Thesis: The Role of Misrule in the practice of Performance

can be experienced with "the freedom to experiment without the burden of future repercussions" and in "the absence of the chance element of real life." (Heathcote, 1991:104).

Here lies a border, very likely the border of the carnivalesque. Heathcote and Brecht seem to invite their respective students and audience to collaborate in a kind of 'laboratory' in which they remain themselves but at the same time must reflect on what manifests or is presented. Again theory and practice are beginning to reflect each other. Gavin Bolton (1985) recognises that Heathcote and Brecht rely on the "notion of 'distancing' than on verisimilitude." He points to the Greek term Metaxis, the real and the fictional held simultaneously in mind by both performers and spectators allowing an interplay between these worlds that encourages discretion rather than immersion (Bolton 1985: 155). Franks comments on Heathcote's acceptance of:

...the potential for drama and theatre to distance us from everyday life, to see it afresh, to employ Verfremdungsteffekt, to reveal gestic moments, to reveal the potential mutability of both dramatized and everyday life, so that the student, the actor and the spectator can employ their powers of reasoned reflection.

(Franks, 1999:190)

This use of the body as simulacra, as a mediated stand-in for real-life has a number of challenges within the Carnivalesque space. It demands that the representation stand for something or risk losing meaning. In Saint Punch there are a number of simulacra, the most obvious being the puppets, and they need to be dealt with by looking at what is offered to the audience to aid decoding. However Gilles Deleuze is suspicious of representation: "It mediates 
everything, but mobilizes and moves nothing." (May 2005:74). The carnival acts as a frame for representation allowing it to acknowledge its limitations and causing it to be clear about what it intends to represent within the performative text.

... we read and make sense of texts in terms of their cultural contexts or frames. Contexts function as cultural frames within which to make sense of texts, frames which operate through our knowledge of, and literacy in, a variety of other contexts... All texts carry elements, or traces, of context with them. Mikhail Bakhtin, the Russian critic and theorist, coined the term dialogism to refer to the way in which texts, through their relationships with other texts and other contexts become charged with these traces. Any text resonates with the meanings of other text, and other contexts or places in which that text has been.

(Schirato and Yell: 2000:52-52)

Firstly however it is important to acknowledge that writer, director, designer, actors and audience all enter the theatre space carrying with them an intertextual matrix (Hills, 2005:40). Influence lies everywhere. This matrix is the baggage accumulated by any individual moving through the rich cultural landscape that they live within. Tony Schirato and Susan Yell define intertextuality as a "process of making sense of texts in reference to their relations with other texts" (2000:53). In other words, we aggregate our experiences in a way that allows us access to all that we have produced, viewed, read or witnessed. We are aware that there is difference but treat these experiences as the basis by which we make sense of the world. Of course, what makes sense to one may not have resonance for another as 
MA Thesis: The Role of Misrule in the practice of Performance individuals but, in some sense, this is the glue of culture - that we experience enough in common to be able to read at least some commonalities in whatever is placed before us. Jen Webb and Schirato (2003) also reference the work of Bourdieu in how knowledge of a field, or fields, such as the intertextual matrix, contributes to a process of reflexivity. This leads to a process, quoted from Bourdieu and Wacquant (1992), that "disposes its subjects towards 'the systematic exploration of the unthought categories of thought that delimit the thinkable and predetermine the thought"' (2003:545). Matt Hills makes it clear that this intertextual awareness is "by definition unfinishable and nonforecloseable" (2005:40). Adolphe Haberer (2007) argues strongly for the influence of intertextuality throughout the range of cultural artefacts with particular focus on poetry. In the process he challenges Bakhtin's view that poetry is monologic rather than dialogic. He suggests that the intertext is exactly what makes these artefacts dialogic (2007). Thus what we read within the representation on the stage is loaded with a number of both cultural and personal resonances, some deliberate and others accidental or only recognizable through an almost accidental bringing together of these artefacts. This alone argues for a dialogic reading of the stage and strengthens its ties to the carnivalesque. Simulacra and the grotesque body can also have a number of readings and responses.

Punch, the puppet, traditionally sports a bulbous nose and a hump on his back- he is grotesque. In Saint Punch, shaped traditionally, he is not clothed in his traditional garb but wears much more contemporary costume. The reason for this is twofold. One is pragmatic, this is a performance without budget and 
as the puppet he must also be seen as mask and as a figure on 'film'. Thus the costume must be readily available and transferrable. Secondly he must be contemporaneous with the audience to assist them with relating to this older tradition. He wears a hoodie which has become, as Rachael Owen and Anna Sweeting imply with the title of their report for Victim Support, 'Hoodie or goodie?'- an icon for 'falling into the wrong crowd', for youth offending and for the urban culture most at risk (2007). As Gavin Hood says "The hoodie is the uniform of the troublemaker: its wearer may as well be emblazoned with a scarlet letter."31 From the Grim Reaper to Robin Hood the hood stands as a marker for awareness, for moral ambiguity. As such Punch's representation connects him to both tradition and to a more contemporary ambivalent image. The other puppets in his narrative also wear more contemporary clothing even when their spoken language still harks back to their traditional influences. As he leaves the booth and enters the stage his mask connects him clearly to the Commedia Dell'Arte tradition of clowning. Rosalind Crone (2006) chronicles Punch's history and makes it clear how the violence of the domestic mirrors his epoch's ambivalence towards a growing unsettledness about the concept of marriage and domesticity (1079). She points out that Judy arose from "phrases such as 'to make a Judy of yourself' and the label 'Judy' when referring to women who behaved in a disorderly manner."(2006:1081) This was a change from her eighteenth century name, Joan.

\footnotetext{
${ }^{31}$ http://www.guardian.co.uk/politics/2005/may/13/fashion.fashionandstyle accessed 6/12/11
} 
MA Thesis: The Role of Misrule in the practice of Performance

The grossly exaggerated violence and Punch's nonchalant attitude about his wife's death make the scene rather humorous and ridiculous.

Moreover, Punch's disposal of his wife's body objectifies her. Thus, with his re-establishment of his mastery of the household, Punch becomes a hero, while little sympathy is left for his painful and ugly wife.

Extreme violence also characterizes Punch's encounters with other puppets in Piccini's show... when Punch is finally sent to the gallows, he succeeds in tricking the hangman into placing his own neck in the noose...

(Crone, 2006:1063)

His narrative's characters also appear as figures in masks and the tone is one of Clown. As he and the policeman appear on the screen a different, darker moment is illuminated. Here the reference is much more the image of the Joker from the Batman canon, most particularly from the film, The Dark $K_{n i g h t^{32}}$. This is an altogether much more disturbing image, physically much more threatening as Punch beats the Policeman to death.

Similarly when Gilles de Rais and Joan D'Arc appear as themselves on the screen they carry a much heavier presence than in the other environments. De Rais is clothed in a representation of armour and Joan appears in sackcloththere could not be more distance between them. However, between them, the power struggle is much more complex. As they leave the screen and enter the booth, instead of recognizable puppets, dolls- toy soldiers as action figuresplay them. Some remodelling has been done to change the modern toy soldiers into their medieval counterparts but the image is still of two people 'playing' at war. Here the division between de Rais and Joan becomes explicit,

\footnotetext{
${ }^{32}$ The Dark Knight, (2008), Christopher Nolan http://www.imdb.com/title/tt0468569/ accessed 4/12/11 
he a warrior belonging to the dominant hegemony, full of divine right and careless of the lives below him in the social order, she belonging to this lower social order, given divine leading to change things for her beloved France. As they watch the battle the division between their world views becomes wider, she intolerant of her fellow man giving in to his baser impulses (ironic given her behaviour in Scene four) and de Rais shrugging such behaviour off. This 'play' is important as it reads a particular point of view upon these characters, for the older de Rais it is play, whereas for Joan it is so much a symptom of why she acts. Here played out is the division between the renaissance and the medieval. We see this even more explicitly as they move into the stage. The Mask is coupled with a more expressive set of moves upon the stage; de Rais is played almost as a chess piece about to be sacrificed. His life is in the inquisition's hands, and those of his erstwhile friends and confidants. However in contrast to Joan he is given a form of mercy in being promised a quick death before burning. Thus when they return to the stage at the end of the play it is she who mirrors the giving of his 'mercy', not in the sense of forgiveness but perhaps as a way of sharing the sense of his 'punishment'. He dies and is burnt as Joan's ghost screams silently and writhes in agony, terribly alive to all the pain and suffering, almost a reference to a Christ being sacrificed. The representations that the puppets, masks and actors ask us to witness, as audience, do not through their complexity and ambivalent signification allow us to fully empathise with their condition but attempt to lure us into taking a 
MA Thesis: The Role of Misrule in the practice of Performance

position or at least to consider carefully what this mediation of their narratives leave us with.

In contrast Bluebeard has a much softer treatment. The performance in their native stage is deliberately large. This is melodrama, a Disney type fable. Even when they are on the television screen they are playing up the emotions and motivations of their characters. It is during their time in the Puppet Booth that their characters feel truly at home. They are glove puppets not dis-similar to 'The Muppets' of television and cinema fame. Particularly they also hark back to the 'Muppets' beginnings on Sesame Street, an educational show for children in the United States of America (1969-present). They are perhaps therefore the most endearing of the three stories and their simulacra are charming and attractive for the most part, a welcome lightness as a foil to the other stories. However the grotesque body invades their space as well, as the cabinet is illicitly opened to reveal the six heads of Bluebeard's previous wives. Here is an image of true horror, mediated through a mode most commonly associated with children, who are, after all, the intended audience of a tale such as this. The juxtaposition of the childish with the ghoulish is intended to deliver a wonderful moment where the audience does not know whether to laugh or cringe in fear. Such moments can be cathartic or force one into a reflexive-ness that is to be encouraged during the theatrical moment.

Maria Tater tells us that Bluebeard began as adult entertainment but has fallen through "a cultural Black Hole" until it found itself behind the covers of a fairy tale collection (2004:12). She cites both Cunmar of Brittany and Gilles de Rais 
as being claimed as the progenitor of Bluebeard. She is not entirely convinced and adds that there are many comparable stories from many other cultural traditions. However she acknowledges that the common manifestation has been used as a warning to wives against "the fatal effects of curiosity and disobedience", allying it with some of the readings that have been placed upon Punch and Judy (2004:17). Further it explains how the colour Blue became, in the eleventh and twelfth centuries, a signifier for the aristocracy leading to the nomenclature, blueblood (2004:19). However this but part of what is played out in Saint Punch. Feona Attwood (1998) compares Bluebeard's wife to the fate of Ada in Jane Campion's The Piano (1993). A useful comparison underlined by the inclusion of a community play performance of the story within the film (Chumo, 1997:173). Here the wife's curiosity becomes a reading of the dangerous nature of female sexuality (1998:90) Attwood places the film as picking away at patriarchal discourse (1997:95) in a way that empowers the wife. In Campion's film, Peter Chumo tells us, the resonances are clearly visible as the shadow-play chopping of Bluebeard echoes the mutilation of Ada at the end of the film, the commonality of the keys to the chamber and the keys of the piano, and the play of illusion and reality of the cinema is commented on as the Maoris storm the stage to save the wife believing the image before them to be real. Finally art itself is attacked though Stewart and Ada's impossible distance (1997:176). Campion's heroines are at once both innocent and complicit in their fates. Similarly following Angela Carter (1979) Saint Punch seeks to make visible Judith's complicity in her fate, her want for this 
MA Thesis: The Role of Misrule in the practice of Performance

glamorous man, her need to take charge of her own rights despite the possible consequences. Robin Sheets argues for Carter's The Bloody Chamber (a version of Bluebeard) as "writing against the interpretive tradition that emphasises the wife's illicit sexual curiosity" (1991:644). Moreover she recognises its link to the story of Gilles de Rais. Of course the Marquis de Sade is also referenced in Carter's story. Sheets suggests, following Barthes, that as a narrator, the protagonist represents a shift in power through her control of language (1991:649). She is neither Juliette (the bad girl), or Justine (the willing victim) or Judy (the disobedient woman). Rather she is the imperfect woman: "she has the right to act, to experience the consequences of her actions and to learn from error."(1991:650) Her experience with the 'grotesque body' of the Marquis serves as a catalyst for change and selfreflection.

In Kari Lokke's critique of The Bloody Chamber and Max Frisch's Bluebeard there is a strong argument for Bluebeard being grotesque simply because it is the nature of the fairy tale motif (1988:7). She suggests, through Bakhtin, that the Medieval/Renaissance "grotesque had an emancipatory function, for the juxtaposition of opposites broke down false societal and ideological barriers to expose the truth of life's unpredictability and spontaneity and to celebrate the unity and power of that life in all its most corporeal manifestations" (1988:7). Through these two author's works she illustrates how the presentation of the characters environment contribute to the way in which the grotesque is presented. With the character of Felix Schaad, the reader is invited to consider how a buttoned down but fantasy rich life can fall into pieces. Schaad's name, 
significantly, she points out, "is related to both schaden, to harm or to hurt, and schade!, what a pity!, Too Bad!" which harks back to Punch's stock phrase (1988:9).

Given how laden with meaning Bluebeard can be it is ironic that in Saint Punch it is perhaps the piece most lightly provocative. And yet as a counterpoint to the other horror and comedic forms of violence it is, perhaps, a necessary interlude in which the audience may find the pause to reflect upon what their reactions are to the rest of the work. If it is true that a work becomes grotesque by virtue of its characters and its content then Saint Punch manages to provide its audience with a clear context for reflection (should they choose to). What becomes clear is that the grotesque body motif provides a link between these three stories. The puppets, the masks and the actors on screen also are linked in their use of the simulacra as grotesque body, which both distances the audience and makes it safe for them to relate either intellectually or emotionally to differing moments of pathos and jest.

\section{The Dark Clown and the Trickster}

In The Road to Mars (1999), author Eric Idle (late of Monty Python's Flying Circus) offers a breakdown of how humour works using the example of the clown. He particularly cites the white face and the red nose clowns. He locates such pairings as Laurel and Hardy or Martin and Lewis. Oliver Hardy and Dean 
MA Thesis: The Role of Misrule in the practice of Performance

Martin are examples of the white Face Clown and are often the instigators of action- possibly action that is at odds with what society would consider acceptable, often marked by them trying either to perform or attain high status. In counterpoint Stan Laurel and Jerry Lewis are examples of the Red Nose clown, the fool whose innocence and naiveté, and position of low status, constantly complicates and defeats the red nose clown's efforts to subvert things.

Bakhtin also acknowledges these two forms of clown- the rogue and the fool. However he adds a third category simply known as the clown- which can be seen in dramatic terms as the clown/fool, in some of Shakespeare's plays, who is able to comment upon high and low alike. Sue Vice suggests that Bakhtin saw their 'stylistic functions' were 'determined by [their] relationship to heteroglossia', which each one helps to introduce (Vice, 1997:69).

In carnivalesque terms these clowns have a relationship to the high culture and the low, the sacred and the profane. They are often located within the low culture but through their vision, as the Fool in Shakespeare's King Lear, may be placed quite close to the centre of power. Set as commentators upon the cultures they either observe or participate in the clowns can be seen assuming very specific roles. Bakhtin, according to Vice, sees the three behaving according to these roles, thus:

The rogue parodies high languages; the fool is 'naively incomprehending' of the high languages s/he comes into contact with; the [dark] clown 'unmasks' high languages and has license to utter the otherwise unacceptable. Heteroglossia is dialogized by these human figures, as it 
becomes double voiced through being parodied, and revitalized by different viewpoints.

(Vice, 1997:69)

Thus Bakhtin sees that through incomprehension, deception and transgression/subversion the three archetypes contribute a form of organization to the heteroglossic (1997:69). The appellation 'dark' is appended to the Bakhtin description to differentiate this clown from the others. This clown most closely combines the elements of carnival within their appearance and behavior. Puck in A Midsummers Night's Dream might be an essence of this misrulic clown- it is not chaotic since that would necessitate no regard for the rules- Puck is subversive of the rules but not really transgressive. The Joker out of the Batman comic mythos is perhaps a more chaotic clown except that he cannot exist but to balance the Batman, which links him irrevocably to the rules he transgresses. Both these examples are emblematic of the Dark Clown, through which the status quo might be interrogated and judged. Puck and to a lesser extent, the Joker, because he is the alter image of the Batman, challenge the way things are- one through magic and the other through acts of insanity and crime. However, as David Abrams and Brian Sutton- Smith have written the Dark Clown is not synonymous with the growing popular culture image of the psychopath or sociopath as these characters lack the flexibility that is also emblematic of the dark clown/ trickster figure. They tested both the hypothesis of the psychopath and the traditional culture hero with children aged between five to seven and a group eight to eleven, and they used as a 
MA Thesis: The Role of Misrule in the practice of Performance popular culture hero the cartoon character Bugs Bunny ${ }^{33}$ (1977:30). Their conclusion supports the role of the trickster figure in the socialization of children, commenting particularly on the way in which the children's flexibility in defining their social roles and in their explorations of novel responses (1977:47). They then suggest that the variation in Trickster stories arises from the needs of their audiences. The cartoon character is simply one of the modern interpretations of this cultural role. In considering the role Mr. Punch has served in previous centuries it would not be too far from the role Bugs plays for his television audience.

There are also examples of these clowns from the Commedia Dell'Arte tradition. Arlecchino/ Harlequin is the dark clown to Brighella/ II Capitano's rogue and Pierrot/ Pantalone's fool. Of course the classic manifestation of the Commedia clowns that have entered the twentieth century are the Marx Brothers. Harpo is the rogue, Chico the fool and Groucho, of course, is the dark clown who unmasks and subverts the high and the low with considerable license. Robert Stam in Subversive Pleasures (1989) acknowledges their films as fine examples of the carnivalesque. They attack and subvert a number of controlling institutions- such as the racetrack, the opera, the law and even warring nations and their diplomats. Stam notes Bakhtin's words concerning the masks of the clowns:

[which] grant the right not to understand, the right to confuse, to tease, to hyperbolize life; the right to parody others while talking, the right to not be taken literally, not "to be oneself".... the right to rip off masks, the right to rage at others with a primeval (almost cultic) rage- and finally, the right to 
betray to the public a personal life, down to its most private and prurient little secrets.

(Stam, 1989:112-113)

As hinted above, there appears to be a link between the Dark Clown and the Trickster figure that arises in Mythology. Jan Kott, in Theatre Notebook (19471967), describes Harlequin like this:

\begin{abstract}
Harlequin has every possible gesture. He doubles and trebles himself, changes and transforms himself. He is a poor starved servant and a great conjuror. He is all intelligence, elemental, a demon of movement. He puts two flowers in his mouth and, for a dozen seconds, is a beautiful woman. He is neither a clown nor a marionette. It is he who pulls the strings of all the other characters in the comedy. He sets the mechanism of this little world in motion. But at the same time he parodies and mocks it. For he is the only one who knows all the moves.
\end{abstract}

(Jan Kott quoted in Nichols, 2002: 147)

Nichols goes on to describe Arlecchino's ability to change and transform, his one constant quality as liminal (2002:151). Furthermore she links his manifestations prior to his appearance in France in 1571 as "reminiscent of Old Comedy's archetypal trickster (2002:156). She traces his lineage through to his "father" Mercury (Hermes in the Greek) who is the god of deceit, disguise and trickery and most clearly the western world's figure of the trickster. Hermes, Maui, Loki, Anansi, Coyote and Monkey appear all over the globe in various guises but with an abiding similarity, their liminal ability to open doors and create disruption. Klaus-Peter Koepping notes that "two forms of action and thought seem to designate the trickster across all cultural 
MA Thesis: The Role of Misrule in the practice of Performance

variations, namely, his cunning form of intelligence and the grotesqueness on the body imagery used to indicate the inversion of order' (1985:194). Perhaps in Mr. Punch's case the grotesque body serves to hide the cunning intelligence, as he traces his origins through that of Arlecchino. Koepping cites Elisabeth Frenzel who observes that the trickster/ fool figure acts as a mediator between audience and play, " who on the one hand stands apart from the unfolding story but on the other hand is a part with which the audience identifies most closely: one delights in the stupidity of others but is also in the fool himself, which turns means a joke on the alter ego of the listener or viewer (1985:195). This mediation is a similar one to the Trickster as culture hero who mediates between gods and men (1985:206). This view seems intrinsically Carnivalesque, through the laughter underlines "the tension between identification and distancing" (1985:197). Koepping certainly allies himself with some of Bakhtin's theory as he comments about how the grotesque body is somehow similar to the liminal, "the body is always in a state of becoming" (1985:200)

The trickster figure can be, as Barbara Morris suggests, seen in that modern manifestation of the carnivalesque screen in the corner of the living room. The television offers an engagement with the carnival but all too often more likely to be used as a form of pressure release rather than one of fomenting change, simply the anaesthetising spectacle or gossip provider. However Morris offers George Constanza, a character out of the Seinfeld ${ }^{34}$ situational comedy, as a trickster figure appealing to adults rather than children (1999). She suggests 
that "television comedy has immense interest and importance; it is a seasonally fluctuating barometer of public controversies, fantasies, and disillusionments regarding social norms, values and human interests (1999:47). She sees George as a hero/trickster who is among the "unattractive and disturbing outsiders or misfits in their communities, who fumble clumsily and amusingly toward some semblance of control in powerless situations" (1999:49). One of the weaknesses of Morris' argument is the seeming mortality of George Constanza. The trickster figure is an outsider not only of the community but also of humanity itself- sometimes an animal totem, sometimes a god. Even the clown figure separates itself from the human through mask or puppet, the simulacra standing in.

Every time the Doctor gets pal-ly with someone I have this overwhelming urge to notify their next-of-kin.

$$
\text { - Rory (The God Complex) }{ }^{35}
$$

Perhaps a better example of the trickster figure in television is the character known as the Doctor ${ }^{36}$. Doctor Who is a science fiction series that has run in various forms (television, radio plays, audioCD, comics, novels, webisodes and fan fiction) since the day after Kennedy's assassination in 1963. It has lately become one of the BBC's flagship productions, which is winning favour not only at home but also in international markets, including the significant US market. ITunes ${ }^{37}$ recently named the 2011 season as the 'top' most

\footnotetext{
${ }^{35}$ Doctor Who (2005) series six in 2011 episode 11 Original Air Date-17 September 2011

${ }^{36}$ http://www.imdb.com/title/tt0056751/ accessed 10/12/11, http://www.imdb.com/title/tt0436992/ accessed 10/12/11

$37 \mathrm{http}$ ://www.digitalspy.co.uk/ustv/s7/doctor-who/news/a355296/doctor-who-named-most-downloaded-us-itunesshow-over-modern-family.html accessed 10/12/11
} 
MA Thesis: The Role of Misrule in the practice of Performance downloaded show in the United States, beating out a number of US produced shows. The show follows the adventures of a 'Time Lord', an alien who seems to have a preternatural interest in the Planet Earth. He is able to travel about in time and space thanks to his 'TARDIS' (Time And Relative Distance In Space) machine. In 1963 viewers were introduced to a crotchety old man known as 'The Doctor' played by actor William Hartnell. When his ill health threatened to end the series the producers came up with the idea of the Doctor being able to regenerate into a new body. Since then ten other actors have assumed the title role. In some other manner, such as in Cinema, web animation or through charity skits, a number of other actors have also contributed to the Doctor but are not generally considered part of the canon. With a mixture of history, science fiction, fantasy, horror, science and melodrama the show has been a fixture for nearly fifty years.

The Doctor operates as a trickster/ hero because he is an alien and through a number of other aspects in the make up of the show, for instance, over the years there have been times when his control of where his Tardis materialises has been quite random or disordered. He is often shown to have vast knowledge but then also ignorant of the most surprisingly small details that require others to get him out of trouble. However wherever he does appear he becomes a catalyst for some form of action or change. He is almost always travelling with a human companion who becomes essential in the action or change that follows in the Doctor's wake. Again often while the Doctor is capable of messianic saves from danger, he is often shown to be in need of assistance from these companions or in need of action from the people 
populating the environment he finds himself in. Piers Britton (2011) ably traces what he refers to as a Harlequinade motif through both the television series and the various other manifestations of this meta-text - in the sense that the original text is both informed, judged and added to by subsequent texts, something Henry Jenkins covers in his book, Textual Poachers (1992). Jenkins particularly looks at the fan fiction of Doctor Who as meta-text (1992:162).

Britton describes the design of Gallifrey, the Doctor's home planet, which is: a kind of cross between the House of Lords and the most conservative of cathedrals or Oxbridge colleges, its denizens preoccupied with ritual, etiquette and precedence, and correspondingly lacking in sensitivity or imagination. Individual characters' names, too- such as Goth, Spandrell, Hilred and Runcible- suggest either the medieval world or a Trollopian parody of collegiate and Episcopal institutions.

Overtones of British academia and clerisy are carried through into James Acherson's designs for the Time Lords' dress. Their daily fatigues hover in form between cassock, surplice and dalmatic, while their ceremonial robes are grotesquely bloated variants of academic regalia: gowns with voluminous sleeves, skullcaps, and monstrous collars which somehow seem to synthesize aspects of the academic hood and mortarboard, (Britton, 2011:166-167)

Thrown amongst this the Doctor, who has through his various incarnations been dressed as a feisty Victorian man, a Chaplinesque clown, a sixties/seventies Dandy, a cricket player, a Tatterdemalion, a form of cosmic 
MA Thesis: The Role of Misrule in the practice of Performance

Where's Wally, a Northern Comedian, and recently a more familiar sort of New Romantic come nerdy "Bowties are cool" type of rebellious student or disruptive youth, one can see how Britton might connect the Doctor with Harlequin, and thereby make a connection with the Trickster.

In his book, Matt Hills (2010) connects the Doctor to the Bakhtinian concept of the Chronotope. The chronotope, which Hills translates as Time/Space, links time with genre discourses, of which, he suggests, may be in turn seen as a manifestation of what Bakhtin calls 'chivalric romance...'a miraculous world in adventure time' (2010:103). Matt Hills wishes to place the Doctor into this adventure-time, because of the 'fantastical world' that surrounds him. The Doctor is both 'at home' and cut off from his 'home-world' but lives in this space between, the marginal- a characteristic that he shares with the Trickster. The form of the genre of the Doctor's adventures, Hills names as 'intimate epic' (2010). Hills goes on to make a case for the Doctor's meandering around space/time as "impulsive wandering represent[ing] the "normal course of events' rather than an intrusion of disruptive forces" (2010:105). Thus he argues that the Doctor falls into adventure that just happens along rather than seeking trouble. In this he is similar to the trickster who is often reactive rather than pro-active, wanting to change something rather than create. Hills argues that this allows Doctor Who to be multi-generic. Thus it can be science fiction or historical, fantasy or horror, dramatic or melodramatic, social critique or imaginative. Generally stories involve "the intrusion of non-human forces" in Hills opinion and he questions whether Doctor Who ever enters into a political 
agenda (2010:104). However this is the question that Alan McKee asks

(2004). He acknowledges that Doctor Who is basically an Adventure Serial:

The Doctor travels to planets with various forms of social organisation. He then has to choose: either to side with rebels who aim to overthrow that social structure; or to protect that social structure from attack. Usually if a civil war is in progress, he will favour the rebels; if an interplanetary incident is threatened, he will protect the culture he finds.

(McKee, 2004:202)

However McKee, writing about the politics of Doctor Who, notes the Doctor deals only "with the local, and the visible and the immediate" (2004:208). One of McKee's survey respondents commented: "There is something about Doctor Who, which doesn't have connections with particular political persuasions- of the underdog, of cleverness and inventiveness winning out over brute force.... It's so woolly, the program" (2004:214). All this seems to argue for the Doctor as a Trickster figure- uninvolved but disruptive, willing to rebel but also capable of protecting the status quo, acting as a go-between or irritating force, dealing with the immediate with an ambiguous relation with the bigger picture.

In this [uncanny] sense, the Doctor himself also embodies this spectre'the ghost of Christmas past', as he says in "A Christmas Carol" (25 December 2010), and also of the present and of the future- a spirit of moral and actual rebirth, resurrection and regeneration.

(Charles, 2011:20) 
MA Thesis: The Role of Misrule in the practice of Performance

Showrunner and writer Steven Moffat's latest Christmas edition of Doctor Who ${ }^{38}$, The Doctor, the Widow, and the Wardrobe offers a closer look at the Doctor as Trickster. Moffat has in the past written stories that reference other texts but here, as he was last year with A Christmas Carol referencing Dickens, he is clearly honouring the works of C.S. Lewis. During World War Two, the Doctor finds himself caring for a family whose mother he owes a favour to. He appears, and names himself, as Caretaker, one who does not do but rather takes care. The story leads the Doctor to follow the children through a portal; a liminal space but not a wardrobe (the Doctor identifies his TARDIS as a wardrobe when pushed). Instead this portal is through a Christmas present opened too soon, Christmas Eve instead of Day. They find themselves lost in a wintry forest with the Doctor and eventually trapped within a tower. Meanwhile their mother follows them through, her reaction to the threat of danger to her children adds a level of reality and subsequently a situation with more jeopardy- they are on an alien planet of the future about to be harvested. What makes this really interesting is that the Doctor is pretty passive in this episode, taking care but not leading. That is left to Madge, the Mother, who ultimately comes to their rescue in a gigantic transporter tripod ${ }^{39}$, digests the life force of the forest and then leads them all home, rescuing her children, the trees and, in true Who fashion, her dead husband. Thereby making Christmas come true for her family and, by ordering the Doctor to visit Rory and Amy, the Doctor's own Christmas wish. We can see in this that Moffat is not only

\footnotetext{
${ }^{38}$ http://www.imdb.com/title/tt1998643/ accessed 21/1/12

39 Which relates directly with Matt Hills writing on how the humans often use simple tech to rescue themselves and the Doctor.
}

Gregor Cameron 198272670 
referencing Lewis but also, perhaps, James Cameron's Aliens ${ }^{40}$ and Kevin Anderson's Saga of the Seven Suns ${ }^{41}$. The point is that as Caregiver the Doctor is essentially powerless, like the Trickster it is his role to offer pathways to the humans he interacts with- to inspire them and to offer them choices. $\mathrm{He}$ 'cares' but does not lead. He is cut off yet dependent upon both humanity and the gods, in his case the Time Lords. His space/time is liminal, constantly changing. He has no place of his own but belongs everywhere.

The Marginal figure effaces spatial boundaries in several distinct ways:

(1) he is a vagabond who lives beyond all bounded communities and is not confined or linked to any designated space; (2) he lives in cells, caves, ghettos, and other 'underground' areas- like the spider inhabiting the nooks and crannies of social spaces.... He lives above or below ground but not as normal mortals on the earth- ....with places of transition, movement, and license. Temporally and spatially, he tends to confound the distinction between illusion and reality, if not deny it altogether. In fact, he casts doubt on all preconceived and expected systems of distinction between behaviors and representation thereof.

(Babcock-Abrahams, 1975:155)

Trickster is "at one and the same time, creator and destroyer, giver and negator, he who dupes and who is always duped himself" (1975:161). She also links Trickster to the work of Bakhtin and Kristeva with thoughts about how "such coexistence of opposites [are] "dialogic" (1975:161). BabcockAbrahams offers a very good list of Trickster characteristics that are appended

\footnotetext{
${ }^{40}$ http://www.imdb.com/title/tt0090605/ accessed 21/1/12

${ }^{41} \mathrm{http}: / / \mathrm{www}$.wordfire.com/index.php?option=com_content\&view=category\&layout=blog\&id=61\&ltemid=210 accessed $21 / 1 / 12$
} 
MA Thesis: The Role of Misrule in the practice of Performance

to this paper as appendix three. Christopher Vecsey considers Trickster stories as being "entertainment, education, a form of humourous rebellion. They can evaluate, explain and reflect upon realities, thereby making those realities clearer and more profound to the people who tell and hear the tales" (1981:161). Vecsey points out that the story teller in the Akan tradition of Anansi tells his listeners that the story is not true even before he begins (1981:169). Thus he can tell a fanciful story and the listeners will enter into the space of the story recognising that fantastic space- and within it magic can and will happen but that the trickster is not omnipotent for: "Anansi does not teach morals when he is victorious. It is when he fails that the Akan draw ethical conclusions" (1981:173).

This is similar to the tension playing through Doctor Who. The Doctors failures are more telling than his successes, his reliance on the actions of his companions and other humans he comes into contact with is what defines his heroism and his trickster ego. The same can be said of Mr Punch. His tales are always about his failure to deal with the world about him, up to the scene of the hangman. Here is played out Punch's resurrection, his triumph over death itself, but it still comes with the cost of the Jack Ketch's life. With this reversal Judy comes back from the dead (as apparently so do all the other characters Punch has killed) and the story is reset- to be played again another time. The audience witnessing this must appreciate that this means the story is not true, they must decode the moral and ethical states without leaning on Punch as an example. Regeneration and transformation also underpin the Doctor's adventures. Matt Hills talks of this morality behind the Doctor, 
particularly as the Doctor plays out his dealing with some of the monsters that populate his universe. Hills quotes a line from one of the 2009 series "the Poisoned Sky": "I have to give them a choice" (2010:134). This is the Doctor's dilemma. Hills makes the point when talking how the genre of horror is used in Doctor Who. He recognises that instead of reactive horror where the human race is faced with an implacable nemesis that cannot be dealt with in any reasonable manner, the Doctor faces a progressive horror, one that has a whole history behind it to explain why it is set upon this path. The Doctor has to give them a choice; "progressive horror seeks to understand monstrosity, whilst reactionary horror uses stock ideas of good and evil" (2010:133). He cites Russell Davies here who has the word evil crop up in every script: "I send them back and write, 'Come up with a better word'. Words like good and evil stop all interesting debate. There's no such thing. People do terrible things and people do great things. None of it's a disembodied malevolent force." (2010:134). This moral ambiguity, complex though it is, argues for the Doctor being a Trickster rather than simply a hero. Davies again, “...you've got to give the Doctor an appropriate thing to fight- if it's just 'evil', then all you have is a war, and the Doctor isn't much of a warrior." (2010:135). Hills points to Davies' "Doctor Who" as particularly playing the 'persona ex machina' as his companions act, on the Doctors provocation to save the day (2010:39). By driving a lorry, driving a forklift over the bad guy at the cost of their life or by deliberately throwing themselves in front of traffic in order to correct the timeline, it is the human action that saves the day (2010:39). And this is not 
MA Thesis: The Role of Misrule in the practice of Performance limited to the 'new' series as companions such as Adric in the original series made similar sacrifices.

In Saint Punch the carnival finds a personification in the Punch puppet, the trickster onstage. It also has some reading in both the Gilles and Bluebeard stories. Judith courts the trickster and pays the price of the curious.

Somewhere between Gilles and Joan there is a moment of change between the Medieval and the Renaissance, between divine right and righteous divine. But why is this engagement with the trickster of such consequence? Perhaps it is that while Trickster appears all over the globe in any number of guises he is also a role that can be played off the stage. If the trickster has a role within the practice of the performative text, it is in the mediation between sense and nonsense. Todd May asks the question: "What is the relation between sense and nonsense?" (2005:108). He suggests that Deleuze sees it as: "Sense is the paradoxical element that resides in the proposition but is the attribute of things. Nonsense is the paradoxical element that circulates among language and things and brings them together." (2010:108). This seems to be an essence of what Deleuze calls the "state of becoming" which for him is the state that our lives are in, rather than the state of being, which is often cited as the state we live within. For Deleuze living is more like a constant state of difference (2005:60). Difference acknowledges that rather than being in a state of stasis, life is never-ending change. We live in the liminal just as the trickster does. However this state is resisted, there is a clear interest in maintaining the situation, particularly if we see it as beneficial to us to stay put. Deleuze finds this way of thinking troublesome. However this becomes the space of the 
carnival. Bakhtin might have suggested that the carnival and its personification is the place where the tensions between being and becoming can be examined. Trickster is never the same twice because he is so liminal but at the same time he appears so often in the status quo, the state of being, bringing disruption and movement to those who see the status quo as a trap where some are privileged and others placed under a yoke.

I'm no prophet. My job is making windows where there were once walls(Michael Foucault)

(Hyde, 2008:283)

As Artists, there is privilege to be living in the becoming. Artists live in the community, they often reflect or engage that community both from within and without the space of the theatre. Artists must engage with the status quo but challenge its form as a place where nothing can change. Order in its ultimate expression becomes misrulic in that it kills all that seeks to challenge it; art, science, politics and religion all have a line to the state of becoming in their various ways but become barren in the face of ultimate Order. Perhaps this is the fate of the Thousand Year Reich, the Nazis entering a stage of stasis where nobody would be able to change, where stagnation becomes the only possible escape.

Becoming is unfinished, liminal. It is the motivation calling to misrule. But it is not destruction and chaos. Misrule lives beside order as a horse might live in harmony with its reins. When the artist takes on the mantle of the trickster they are calling on their own disruptive imagination. Lewis Hyde's book (2008) links 
MA Thesis: The Role of Misrule in the practice of Performance this disruptive imagination to the trickster. He quotes Carl Andre: "Culture is something that is done to us. Art is something we do to culture" (2008:307). The trap here is for those who do not engage with imagining something different, "who never sense the contradictions of their cultural inheritance run the risk of becoming little more than host bodies for stale gestures, metaphors, and received ideas, all the stereotypic likes and dislikes by which cultures perpetuate themselves." (2008:307). Hyde cites the art and attitude of Marcel Duchamp, praising his "well oiled contradiction- like his use of chance, his addiction to puns, or his turn to mechanical drawing"- as a way of avoiding being finished, as engaging becoming, especially when that becoming is undefined.

However it would be a mistake to say that these artists live outside society, however on the boundaries they might choose to explore. Their art is still firmly grounded in the state of human-ness, exploring what that is, collaborating with members of the society to extend what it is to be becoming human. They find their art by extending what has come before, either by acknowledging and extending or by defining it and turning away from well-established paths. Here the trickster lives, at the crossroads, between states, directing traffic. Here we can acknowledge the benefits enjoyed by those who have gone before and anticipate what might be found as we travel beyond what has gone before. Duchamp, Hyde tells us, acknowledges and explores these shadow-lands, seeking the news but at no time releasing his culturally received knowledge. His knowledge directs the meeting with chance as, for example, he places a canvas on the floor, adds paint to some metre long threads and from a 
deliberate height lets them flutter down to etch a 'random' image upon the canvas. He called this piece Three Standard Stoppages (2008:122). He resisted logic by choosing chance, in the process creating a 'new-ness'. However Duchamp was still an accomplished artist, he understood what it was he was resisting. His art still resonated within a system- canvas, paint, hand with only the fall determining the final result being misrulic. And here we can see a return to the beginning of this paper as a work of art arises out of a system, that without a structure there is no definition, no possibility of a 'new' arising, it needs to know what it is not. Again this seems quite carnivalesque and lies within the realm of the trickster.

In the theatre art is realised by collaboration. This working together is often framed by a vision and most often through the mechanism of a script. In this it shares a form with both Film and Television. The vision is an unfinished idea of what the art might say to its receivers. It should be open-ended so that it can be improved by what is offered by the collaborators. In Saint Punch there was a moment where misrule intrinsically changed what was to be presented and lead to the work being improved. The action of scene four was most challenging for all the people involved. Gilles has broken into Joan's prison in 1431, just prior to her execution. She is nineteen. Joan has recanted and feels abandoned by her voices. Added to that she has had to fight off some attempts to rape her by English soldiers. Gilles' arrival sets her mind on 
MA Thesis: The Role of Misrule in the practice of Performance

another path. She will die a French Woman, her virginity taken by a countryman rather than her captors.

With collaboration there is also the need to manage the group that is approaching the text. Clearly performed rape presents a certain number of problems. It was the intention of the written script that the rapes are played out in front of the audience- quite unflinchingly offering the theatre of cruelty. However that would require quite a lot from the actors who are going to be interpreting this. With this particular performance the actors experience ranged from the professional through to some who had not been on stage before. Of the two directly involved in this scene, one was an experienced professional, and the other a first year theatre student with some experience. In fact she was only just turning eighteen making her younger than the character she was portraying. Naturally this brought up a number of challenges around keeping her safe and yet still gaining from the scene the reaction the piece was looking for from the audience.

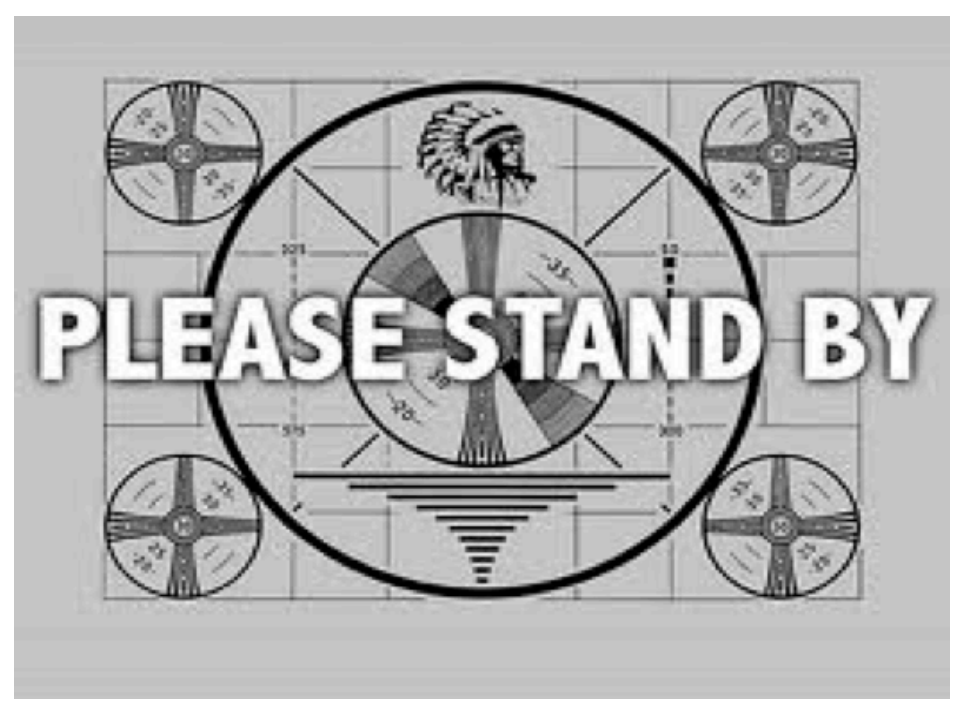

Figure 11. The image in front of the rape 
As written about earlier in rehearsal the group approached these scenes very carefully- making sure that there were others present- offered in support to the actor portraying Joan. The workshop performance was really blessed with her entering so generously into this 'world'. She was quite nervous about the scenes. However she displayed a real sense of courage and commitment in her willingness to engage with it as well. Still rehearsals were proceeding very slowly as she approached the material. Then in one rehearsal talk arose about how the camera affects what it is that the audience is allowed to see, how the camera has a way of distancing the actors from the audience and in a way that this paralleled the affect that arises from the Puppet booth- after all the figures are all approximately the same size. At some point the offer arrived from the actors of what would happen if we were to not allow the audience to see anything. They would still be able to hear everything. This was very intriguing since it was in opposition to what had been scripted. However, such moments are to be explored and if successful a script can be adapted, one of the benefits of having writer and director the same person.

One of the problems of turning off the camera, however in effect is that while the voices could be heard there was a chance that the audience might worry that a technical hitch was happening, preventing them from seeing the scene. This could result in them being distracted from the intention experience. This problem was solved by the television card, which said PLEASE STAND BY- 
MA Thesis: The Role of Misrule in the practice of Performance

clearly the camera is still operating yet we are still, in effect, prevented from seeing the rape. This forces the audiences imagination to fill in the blank space more directly- and with less interference.

Important also is the reading they can take from this card- which appears quite a lot in sixties dramas, where the threat of atomic attack means the TV goes off and people are advised to "duck and cover". If they are sufficiently armed with cultural baggage to pick up this intertext then the awfulness of the scene behind it is underlined. As with all intertexts it does not require interpretation but offers enrichment to those who recognise it. Those who do not have prior experience are still affected by this quite rational request, set against the sounds coming from behind it- the sound of which becomes that much more awful as their imagination is engaged. It was a deliberate choice to deepen this moment in response to the 'happy accident' that arose out of the rehearsal process.

\section{Circling the Question of Misrule}

Here is the difficult phase of the argument. In setting up the system of the rehearsal room in the way that I did, was there sufficient order and chaos to produce conditions that might manifest a spontaneous creative moment? Was the offer from the actors a moment of misrule? Did the decision to say yes to this offer, change the intention of the scene or lead, through the use of the TV card, to an enrichment of the experience that the audience had. I believe so.

Meaningful theater experiences do shine light in the dark places of the soul. To engage catharsis it is necessary to be sensitive to where the 
dark places are to be found at any particular moment. And this demands sensitivity to context.

(Bogart, 2007: 11)

Anne Bogart has offered me insight into process in her writings on both acting and directing. She very neatly places what I call misrule as an opportunity that arises from preparation. She makes it clear that all of the information and work which is done before and around rehearsals informs the possibilities that will arise when you need them- solutions arising from the context of the project you are engaged with. She suggests, in fact, that practitioners should celebrate accidents and quotes Robert Altman "On the film set I create the circumstances in which these accidents can happen" (2007:48)

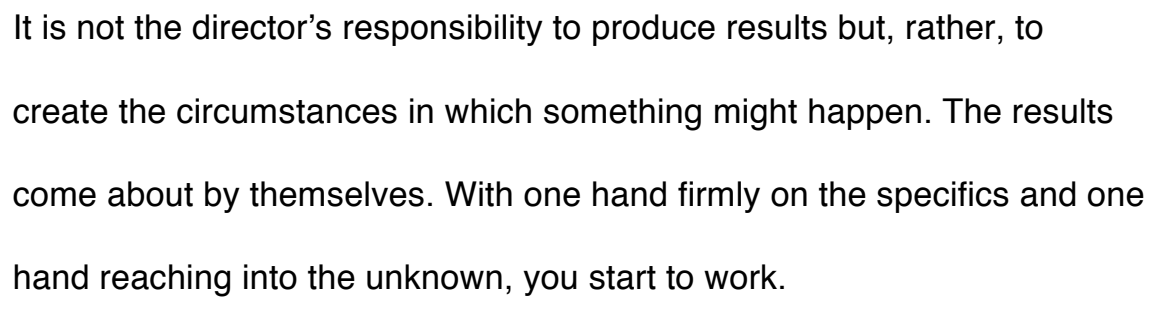

(Bogart, 2001: 124)

In The Viewpoints Book she addresses the framework within which creativity can be enhanced through this step beyond. 'Viewpoints' offers a system by which a company may enter into a formal style of improvisation, thus opening the dialectic of the rehearsal room. Dialectic in this sense is a search for the creative moment, through collaboration, community and through reflection. Such collaboration establishes a formality that can expose the moments of inspiration that Lewis Hyde identifies as being the province of the Trickster, manifesting its presence into the room. 
MA Thesis: The Role of Misrule in the practice of Performance

Similarly Bella Merlin makes it clear that while Stanislavsky developed a system it was never closed; he was constantly in a process of developing. She says, "Stanislavsky never intended his 'system' to be gospel. If your process ain't broken, there's no need to fix it. If the Muse descends upon you, celebrate that visitation, and don't overlay it with conscious intervention" (2007:12). Merlin continues to talk about other practitioners' definition of this moment; David Mamet's “terrifying unforeseen”, Michael Chekov's "quality of ease" (darkest tragedy with lightness of touch), Jerzy Grotowski’s "via negative" (elimination of blocks between inner impulse and outer expression) (2007:13). She seems to be suggesting that strict adherence to any path might be constraining the creative moment and require the practitioner to consider how what they wish to accomplish might be enlivened by being open to the misrulic moment.

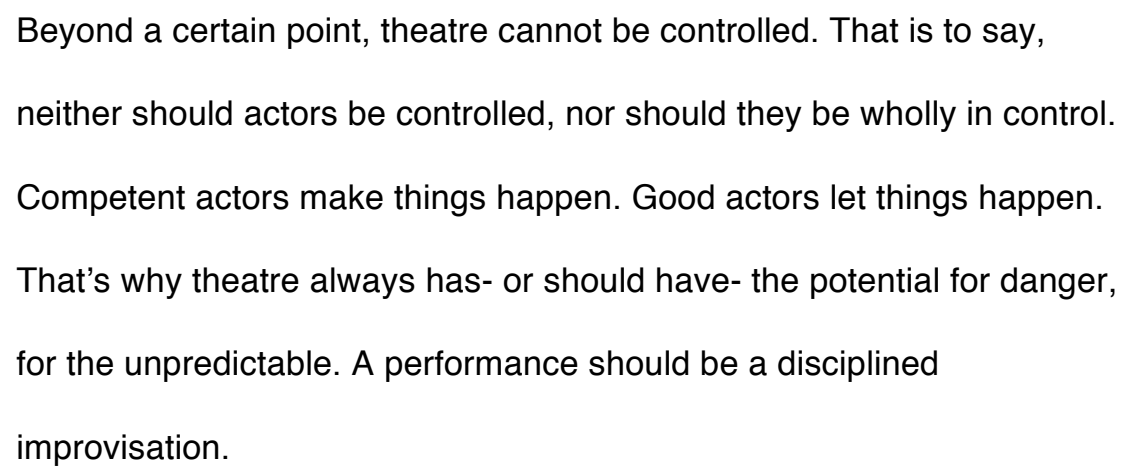

(Alfreds, 2007:344)

Mike Alfreds makes this point at the end of his book, which is quite actorcentric and provides a very tight set of tools or system for them. He too, however, clearly understands that any performance is spiced up with a little misrule. Alison Hodge in her examination of actor training strengthens this position by making it clear that a 'system' has been rather superseded by practitioners referring to a set of first principles arising out of their own 
particular contexts. She suggests that such first principles are transcending their origins and forming a sort of matrix of contemporary actor training (2010:xxv). She cites Copeau, Brecht, Strasberg and Mnouchkine as each having principles that demand attending to, but not constraint by. So whether it is through seeking the 'dramatic principle in oneself', observing and 'interrogating the social forces at play', creating out of himself by an 'appeal to the unconscious and the subconscious' or by finding a 'commitment to collective and community' the practitioner is seeking to bring together the forces of creativity (Hodge, 2010:xxv). Chris Baldwin and Tina Bicât argue that in devised theatre the baseline of a text may not exist. In which case the company is forced to seek a new way of interacting and sharing "Everybody involved in a devising project needs not only to be conscious of their artistic brief and responsibilities, but also sensitive to the dynamics of intense collaborative group work" (Bicât, 2002:7). They argue that devised work depends heavily upon ideas and chance discoveries (Bicât, 2002:9). Within their book lie a number of strategies for managing the process of devising and improvising.

There is an important difference between improvisation as a tool of the rehearsal room and its use upon the stage. Improvisation is like a loaded gun, quite safe if used judiciously and carefully. Improvisation in and of itself can be used as performance but often this does not lead to the depth of significance and meaning that is required by storyteller and audience. As a tool it has 
MA Thesis: The Role of Misrule in the practice of Performance

enormous usefulness however. In the rehearsal room it allows a number of situations to be explored. It can provide a way of looking outside the text at the relationships between the characters. It can provide opportunity to explore the space and the movement of the text and sometimes highlight the shortcomings of the written text. It is also a tool where failure is allowed and encouraged because of the things that can be experienced and learned. It encourages that sense of spontaneity that is so important during performance and allows actors to remain fresh. It is great for building trust and community amongst the cast.

However it also has a dark side. The problem with improvisation, as hinted at above, is one of order and control. Without a strong vision or system improvisation can become superficial and veer off into unknown and, largely, unusable material. Baldwin and Bicât leaven their invitation to improvise with the following caveat:

The prolific imaginations of the company, if well managed and focused, can be transformed from chaos into rich, elegant and often deeply resonant productions and performances for an audience.

(Bicât, \& Baldwin 2002:9)

The key here is management. If a group is using a written text then it will form a focus and a source to come back to even if it is a work in progress, as Saint Punch was. All of the work in the rehearsal room was structured towards examining and mining the text for the moments onstage where the audience would be invited to interrogate their own ideas about humour, violence and storytelling. If the original idea was the cruelty of putting the violence right out in front of them then the idea of removing it is radical to the intention but solves a difficulty and enhances the moment because it engages the audience to Gregor Cameron 198272670 
work. This process is what I call misrule, the moment when the trickster enters the carnivalic space and offers a new solution, a choice to the creative process.

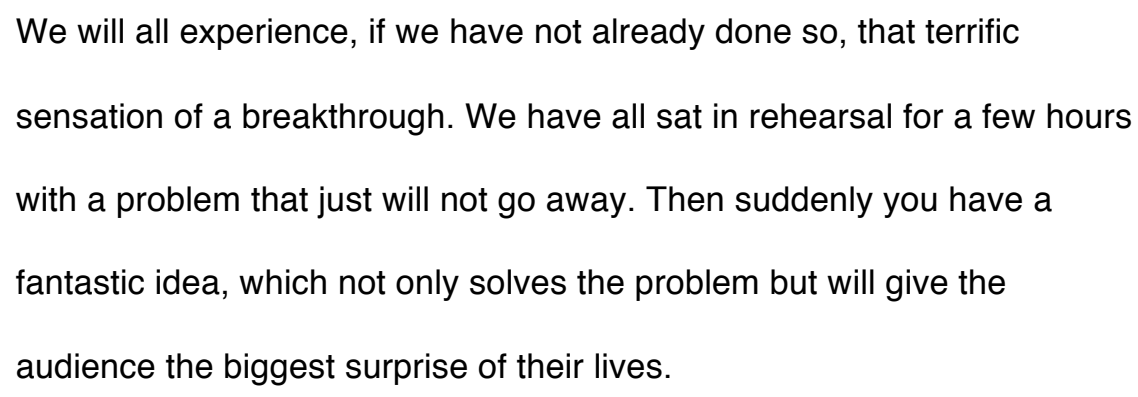

(Bicât, \& Baldwin 2002:151)

Judith Weston, writing about directing actors in film, offers the problem of the obligation- particularly the obligation to be right. The struggle of the actor already out there on a public space, albeit stage or screen, is enormous. To make choices and have those choices appear fresh places great burden upon their shoulders. Weston suggests that the director's role be one of allowing them to be wrong, in essence to seek to be free from obligation (Weston, 1996:68). Then in the moment the actor can use what comes up rather than feel they must suppress or try to ignore the moment- both of which will lead to a poorer performance. Weston also suggests that freedom allows humour. "A performance without freedom is a humorless one. Anytime in real life that people are loose and free, humor is bound to bubble up. Nothing is less entertaining than an actor who is straining to be funny" (Weston, 1996:69)

Of course the other side of this is that the director or dramaturge must be the managing power. In a sense they must be the ordering agent as well as the 
MA Thesis: The Role of Misrule in the practice of Performance

trickster. It is their role to take the offers given up during rehearsal or

improvisation and to compose them into the finished product. This composition is the process of editing out or taking advantage of the ideas and opportunities that arises within the rehearsal period. It seems to me to be quite a carnivalic process, as the interrogation of the status quo needs this editorial function to make change or to sustain the way things are. Change need not be revolutionary unless there has been a sustained period of non-reflexivity. In fact change, as Deleuze suggests is perhaps the only natural state, 'becoming', even if it is not a state most of us, often more comfortable with being, wish to acknowledge.

This is a key point within the problem as it struggles between intentionality and the spontaneous moment of performance. Composition is the final step before the performed moment. But even as it is composed it is unfinished. It is ephemeral because the next time a piece of theatre is performed it may be subtly different. If a different group chooses to perform a text it will almost certainly be different. Composition arises from the choices made by the company or through the vision of a director or dramaturge. In Saint Punch a number of ideas were developed, and either used, or let go. The Rehearsal room became a place where the best parts were allowed air to breathe and subsequently was available to the audience but there was also an amount of material that was not going in the right direction or which were not helping the overall impact of the text and thus were left behind. These decisions were mine -both good and bad decisions and it is very gratifying to look back and be able to say that I am proud of the work. I temper this with an acute 
awareness of some of the things which have provided the best learning, the things that did not work- most of which were not intentional and were an important part of my learning curve.

\section{Sacred/ Profane}

In his book, The Moving Body, Jacques Lecoq offers the Bouffon as a form for actor training. His philosophy, arising out of the form and function of the body, suggests that investigating the world through the three Bouffon charactersmystery, the grotesque and the fantastic- can lead his students, and by implication their performances, into the realm of the carnivalesque. He expresses this by talking of the Kings fool's license. He suggests that this gives the Bouffon permission "to express truth in all its forms" (Lecoq, $2002: 118)$. He goes on to talk about the power of laughter, how those who are willing to laugh at even the most sacred of things were able to enter a space in which the mystery of things could be interrogated.

Bouffons deal essentially with the social dimension of human relations, showing up their absurdities. They also deal with hierarchies of power and its reversal.

(Lecoq, 2002:119)

Lecoq's project is rooted deeply within the twentieth century and thus his Bouffons are part of the conversation between the spirit and reason. His mystery gang, as he calls them, are connected to the spiritual, his fantastic gang reflect the scientific and the grotesques deal with power and hierarchy. It does not seem much of a stretch to see the carnivalesque made manifest 
MA Thesis: The Role of Misrule in the practice of Performance

here. Tom McCrory, a pupil in the Lecoq School, points this out very clearly and indicates how each of the people entering into the process of rehearsal is similarly seeking to illuminate the sacred by exploring the profane. This is the project of the Bouffon.

Bouffons enjoy themselves, for their whole life is spent having fun imitating aspects of human life. Their great delight is to make war, fight, tear out each other's guts. However, their war games never follow the logical chronology of a story that unfolds. They bring a special style of composition: they so enjoy killing one another that with each killing they want to start again. So they indulge in repeated mutual massacres just for the fun of it.

(Lecoq, 2002:118)

This play, so reminiscent of childhood, is at the core of what Lecoq says is the second year of training for his students. This is deliberate. Lecoq insists that this liminal state allows for experimentation to include both the failures and the successes- the failed choices to inform the development of the successes that will be composed into performance. This is such a misrulic system- it foregrounds play and allows for a great deal of creativity. In an industry where money is the motivator this would be an anathema to those seeking to reduce risk. In this space composition overwhelms play, perhaps to its own detriment. Lecoq finishes his second year by inviting his students to find their own clown. This is highly individual work but still about the space the performer enters, it is still about the dialectic between performer and spectator, one leading the other and, in turn, are themselves led.

In this way the dialogue whether expressed as movement and mime or through inviting the audience to watch a life's narrative played out before them, Gregor Cameron 198272670 
is all about seeking something beyond ourselves, even as we exist knee-deep in muck. It is about seeking the sacred through the profane, the grotesque body offering us insight by doing or saying that which we cannot.

Saint Punch offered up this challenge, to engage in what it means to see violence so mediated it becomes the subject of humour. For this is what it is about, suggesting that Gilles de Rais' excesses are not so different from those of either Bluebeard or Mr. Punch. It is not at all plain whether this intention was able to bear fruit. The audience, while invited to reflect, may not have left the theatre with these thoughts clearly in their heads. However it would be true to say that by being exposed to both entertainment and the profane performance of violence they were at least provided with the opportunity for reflection. This brings up a very interesting question about what is it that the artist through their art is supposed to expect of demand of their audience. If the artistic moment is dialectic, then nothing is mandated but if the art is to take a transformative position then it is expected to propose change within the space of the carnivalesque.

In consideration of the role of the trickster, Lewis Hyde suggests that the artist's role is to linger in the liminal, the border, the joint. He suggests that the artist is cast into the space of the trickster able to see how things are but at the same time offering a glimpse across the doorway into what may be. In a sense he sees the trickster in a prophetic role, not the fortuneteller but rather as 
MA Thesis: The Role of Misrule in the practice of Performance someone who in witnessing the present offers some account of where the future might be. Clearly sitting between the sacred 'illusion and the profane "reality" (Hyde, 2008:300). Thus the artist in seeing the real but opening up the possibility invites their spectators to escape the mundane and to fly beyond the horizon.

There have been a number of comments from the audience attending Saint Punch that anecdotally suggest that while an entertaining play was experienced, it stayed with them after they left the theatre and some have spoken of their need to consider what it was that was put in front of them. It may be that at least for some people it completed what was the thematic intention; while for others they just had an intriguing night at the theatre, which may have been enjoyable or not depending on their mood. And this then raises a question about what is the artist's responsibility? The Trickster and the carnivalesque are all about opportunity, but they do not mandate participation. The artist offers and the dialectic allows the spectators to be responsible for their own willing activity within the liminal space. It does not mean you can not make the leading obvious but, if the spectators participation demands some work on their part, then it is possible the reward may be greater and the change in the borders of the mundane more stable. As has been discussed before radical change is not the end intention of either the carnivalesque or the trickster, but rather that the status quo grow to encompass that which is different. That, in Deleuze's sense, the becoming moves on, never satisfied just to be, seeking to defeat the static, motionless indifference of the stationary moment. 
Saint Punch, then, sought to engage this idea of mediation, in particular the mediation of violence, and challenge the audience's attitude to their own response to it. As Gilles picks up the girl, throws her against the table, parts her legs and thrusts, we hear the crying baby with Punch singing just prior to the baby being flung out onto the stage and as Bluebeard chucks his wife around, there is a moment where the spectators should pause and take a breath as the play begins to loosen the pins of laughter and dread in equal measure. The audience must respond to their own culpability in watching this horrendous group of violent offenders. Their position on this their own affair, it is not the art's responsibility to tell them how they should respond, only to try and elicit a response. Thus it is, for both the carnivalesque and the trickster, the invitation and the opportunity is there, to be taken up or not. In seeing the grotesque and the profane before them they are granted access to a sacred truth that they might discover, but it is no individuals single vision, and not within the artist's ability to proscribe- they have to 'become' on their own. 
MA Thesis: The Role of Misrule in the practice of Performance

\title{
Conclusion
}

\begin{abstract}
As Joseph Campbell has said: "Where you stumble, there you shall find your treasure." We invite the stumbling. We hope maybe to have indicated a path but not cleared it, leaving you to work through the most thorny areas.
\end{abstract}

(Bogart and Landau, 2005:xi)

This thesis began with a challenge that the objects of culture, and perhaps, cultural theory, should not just make statements about what it observes but also should be seen as calls to 'do' something, to redraw the borders of ourselves and our lives. In order to do this I have explored what Bakhtin defined as the carnival, harking back to the spectacle and ritual that offered the medieval mind opportunity to take a couple of days to dream about how things might be. Bakhtin's theory surrounding the carnivalesque is a very attractive frame for the work that goes on in the theatre, even though he located it in the novel. Others have been left to carry on his project in how it might apply to objects and situations outside, such as the theatrical spectacle. However, we should be reminded that the carnival itself can be both constative and performative in that it can either support the status quo, or work to interrogate it and offer it's redrawing.

It is important to see the carnivalesque as a frame, a function rather than a lens or a particular reading of a work. It facilitates but does not in itself colour the product of the theatre. There are plenty of more political movements that can be drawn into the carnivalesque space that can and will encourage particular readings of works, think feminist or post-colonial lenses for example. 
If it does become an agent it is, perhaps, through the character of the trickster. This personification as agency can and will provoke action and therefore becomes integral to the reading of the event.

Saint Punch, which can be read as a critique on the mediatization of violence, is a play in which the frame of the carnival is consciously used. There are also very clear motifs of the Dark Clown in the character of Mr. Punch. He is a reflection of both Bluebeard and Gilles De Rais. In a way it is this permission to play out the politic message that interests me. It is this function that makes theatre and performance central to how I process my world. I want a show to entertain and educate me.

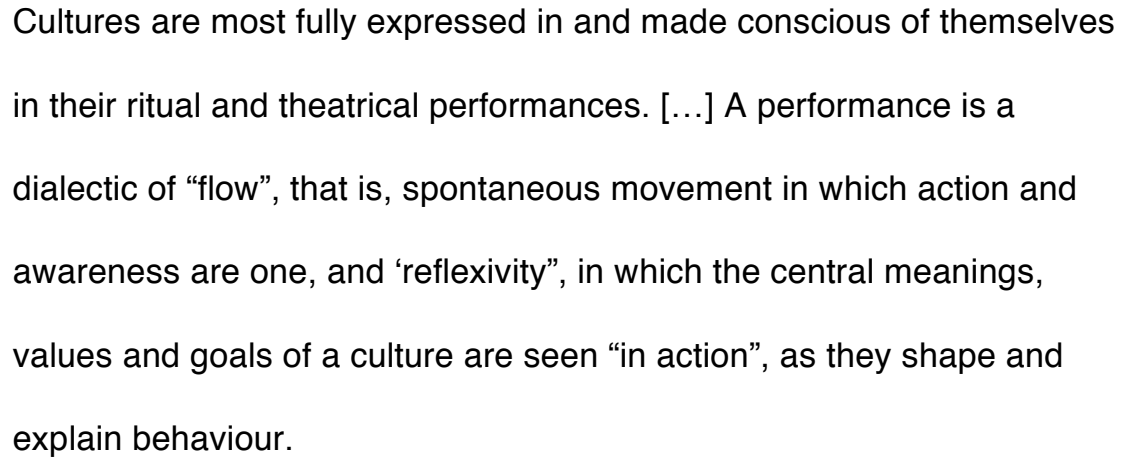

(Victor Turner, cited in Schechner, 2006:19)

In the process of offering an exegesis a number of reflections of Schechner's points appear. Firstly using a traditional story such as Bluebeard and the traditional performance that is Punch and Judy clearly offers entertainment. While much of the show is Grand Guignol inspired the point is made that by looking at the profane is simply a way of inviting the audience to consider the sacred, a beautiful thing. Saint Punch in suggesting that the main character of 
MA Thesis: The Role of Misrule in the practice of Performance

each story is, subject to mediation, essentially the same character, it seeks to mark and ring the changes in identity through history and mediation. With its beginnings, middle and end of process so clearly owing much to cast, crew, audience, tradition and mentorship a community is acknowledged- it takes a village to bring up a [child]? It is the hope of the players/ author that, through consideration of what we are still tolerant of in our 'entertainment', there is an opportunity to heal our society of its (de)regulation of violence in all its many manifestations. That this very process of transparent mediation can offer the audience conscious understanding of what they can learn about their own behaviours. This arises out of the direct observation of both the profane and the sacred. At least that is the intention of the show. Schechner's seven functions of performance also support this idea (Schechner, 2006:46).

On the other hand there are also questions around how clear and/or successful these intentions were. However, here the words of Lewis Hyde become quite potent. Hyde suggests that the traditional culture hero, such as Hermes, Loki, Maui and Monkey do not demand from the humans, whose lives they enter, should just take up the opportunities they offer. Hyde makes the point that the trickster is not about mandating a response in the way that a system might. Rather, the trickster, a liminal figure, hangs out on the border, in the doorway, or in the joints, facilitating the travelers' traverse of these points. Hyde likens the role of the artist to the trickster's disruptive imagination- that art itself holds no power other than what we give it. The artist offers the art but the spectator must be willing to interact with it. It is not the artists, as it is not the trickster's, responsibility to mandate what reaction there is to any action 
that they enter into. It is a project of thinking that art invites the spectator into and what they gather there and take away with them is their own responsibility.

As part of this, the thesis offers the art itself, in the form of a video recording of the show on two different nights and some ancillary extras on a DVD, along with the performance script. In part this is to provide access to the art that is central to this project but also to take a measure of where this project began over a decade ago and where it has ended up as performance.

This is where the question of misrule arises. I have used this term to look at how this element entered the process of bringing Saint Punch to the stage. Undoubtedly the preparation around the context of the historical and fictional worlds of the stories in Saint Punch provided a framework, which any negotiation of meaning might be found. I have written about the second rape as a defining moment. The momentary 'misrulic' offer on the rehearsal floor was such a wonderful opportunity. Acknowledging the 'happy accident' and accepting that what you hide from view can be more affecting than what you show, exposed meaning within the performed text that was not implicit in the written script. Therefore I would argue that misrule supported the moment I am highlighting in my play rather than leading to more difficulty. Change and 'becoming' are infused into the performed play by the attitude of both being prepared and yet open to the opportunities of the rehearsal floor. By taking an attitude of acceptance to 
MA Thesis: The Role of Misrule in the practice of Performance

what could happen, it allowed what did happen to bear significant fruit in the final performance.

The carnival and the trickster are the harbingers of misrule. By harnessing their energies and opportunities the artist encounters an otherness that expands his experience of the world. It is this he offers to the world. The world in turn then decides what to do with the offer. The PLEASE STAND BY card is read by the audience informed by their previous cultural encounters, whether they be broken TV signals or precursors to the end of the sixties world. It is not the shows responsibility to make this sign clear to them; they must do the work themselves as part of a community that endeavours together.

This engagement with the trickster is an ongoing one and this work offers the Doctor as an example. By citing the Doctor and his place in the cultural literacy of those who know him an offer is made to consider the trickster as a continuing cultural hero and still a part of making our culture who it is long after its mythical formation might be aid to be long dead and buried. By using the Doctor as an exemplar it is hoped that one point is underlined- as Hyde suggests using the Hermetic Hymn as an examplethat it is not the tricksters role to destroy the native system but rather to redraw its borders. That the Doctor/Trickster is travelling both "in the light taking things apart and back into the dark to stitch them back together again" (Hyde, 2008:309). In this way it is hoped that the reader will 
engage in the frame of the sacred/profane nature of the carnival and its chief player, the trickster.

There are still questions to engage with, of course. This thesis is not exhaustive on the topic of the cultural significance of the trickster or of the ongoing project of Bakhtin's Carnival. Neither does it judge the effectiveness of the theme of the mediation of violence that Saint Punch indicates. Instead it offers to entertain the idea of a community in which an artist points to something that they hope will have meaning to its spectators. It is offered without expectation, but in the spirit of the trickster, is a doorway towards a new way of perceiving the world. It asks a question to which there can only be an ongoing answer, just as culture can only be an ongoing definition.

Having said that, this thesis does engage with the object, Saint Punch. Hopefully by acknowledging the subjectivity of the artist, but also bringing to it a more formal eye, the performance, within its frame, is adequately defined and described. It is the subject of this thesis because of its conscious carnivalesque frame but also because that consciousness has enabled a particular element of the creative process to be named as misrule. If misrule is not simply an accident but actually an identifiable element that has been encountered by other practitioners, then this thesis has achieved its end. If not, then perhaps misrule belongs to the dream, a weak and idle theme. It is this 
MA Thesis: The Role of Misrule in the practice of Performance

theme that gently allows systems to remain open to the creative moment-

echoing Altman, Kiwi Director Rob Sarkies has admitted that if his cast and crew become too happy he is all too willing to throw a little 'wake up call' their way $^{42}$. By drawing these elements and frames together we seek to restore to the community it's ability to see beyond itself. I believe it is a need that artists acknowledge and seek in disrupting the creative imagination.

And this is where I come stumbling in. By choosing to use a script I stumbled through the writing of, by stumbling through the experience of directing and by stumbling along with a group of strangers to the Laboratory presentation of this performance, I have become immersed in Joseph Campbell's stumble. The treasure I have found not only has bolstered my confidence and my experience but has also proved to myself the resiliency and strength there is in the moment of stumbling that I identify as misrule.

${ }^{42}$ Comments made during a three-weekend workshop held by Sarkies in Wellington in 2010. Author was in attendance at the Film School venue. see http://www.imdb.com/name/nm0765291/ accessed 28/2/12 


\section{Works Cited.}

Alfreds, Mike. Different Every Night: Freeing the Actor. London/GB: NICK HERN BOOKS, 2007. Print.

Alrutz, M., J. Listengarten, and V. Wood. Playing with Theory in Theatre Practice. Palgrave Macmillan, 2011. Print.

Attwood, Feona. "Weird Lullaby: Jane Campion's "the Piano"." Feminist Review.58 (1998): 85-101. Print.

Babcock-Abrahams, Barbara. "A Tolerated Margin of Mess": The Trickster and His Tales Reconsidered." Journal of the Folklore Institute 11.3 (1975): 147-86. Print.

Bicât, T., and C. Baldwin. Devised and Collaborative Theatre: A Practical Guide. Crowood, 2002. Print.

Bogart, Anne. A Director Prepares : Seven Essays on Art and Theatre. London; New York: Routledge, 2001. Print.

Bogart, Anne, and Tina Landau. The Viewpoints Book: A Practical Guide to Viewpoints and Composition. 1st Ed. New York St. Paul, MN: Theatre Communications Group; Distributed by Consortium Book Sales and Distribution, 2005. Print.

Bogart, Anne. And Then, You Act: Making Art in an Unpredictable World. New York: Routledge, 2007. Print. 
MA Thesis: The Role of Misrule in the practice of Performance

Bolton, Gavin. "Changes in Thinking About Drama in Education." Theory into Practice 24.3 (1985): 151-57. Print.

Brecht, Bertolt, and John Willett. Brecht on Theatre: The Development of an Aesthetic. London: Eyre Methuen, 1978. Print.

Bristol, Michael D. "Carnival and the Institutions of Theater in Elizabethan England." ELH 50.4 (1983): 637-54.

Bristol, Michael D. Carnival and Theater: Plebeian Culture and the Structure of Authority in Renaissance England. London: Methuen, 1985.

Britton, P. D. Tardisbound: Navigating the Universes of Doctor Who. I. B. Tauris, 2011. Print.

Carlson, Marvin A. Performance: A Critical Introduction. 2nd Ed. New York: Routledge, 2004. Print.

Carter, A. The Bloody Chamber. Harper \& Row, 1979. Print.

Charles, Alec. "The Crack of Doom: The Uncanny Echoes of Steven Moffat's "Doctor Who"." Science fiction film and television 4.1 (2011): 123. Print.

Charles, David. "A New Paradigm of Popular Play: Playback as Bakhtinian Novelistic Theatre."_(2004): 19 pp. 24/11/11

Web<http://www.pdfdownload.org/pdf2html/view_online.php?url=http\%3A\%2F\%2Fwww.playbacktheatre.or g\%2Fwp-content\%2Fuploads\%2F2010\%2F04\%2FCharles-ANewParadigmOfPopularPlayPlayback.pdf>.

Chumo, Peter N. "Keys to the Imagination: Jane Campion's the Piano." Literature/Film Quarterly 25.3 (1997): 173-6. ProQuest Central; ProQuest Science Journals. Web. 4 Dec. 2011.

Clarke, Arthur C. The City and the Stars. VGSF, 1956. Print. 
Cleary, Farrell. "Baxter's Plays: The Search for Life before Death." Journal of New Zealand Literature: JNZL.13 (1995): 121-32. Print.

Crone, Rosalind. "Mr. and Mrs. Punch in Nineteenth-Century England." The Historical Journal 49.04 (2006): 1055-82. Print.

Danow, David. The Spirit of Carnival: Magical Realism and the Grotesque. Pbk ed. Kentucky, USA: University Press of Kentucky, 2004. Print.

Edgar, Andrew, and Peter R. Sedgwick. Key Concepts in Cultural Theory. Key Concepts Series. London; New York: Routledge, 1999. Print.

Fortier, Mark. Theory/Theatre: An Introduction. 2nd ed. London; New York: Routledge, 2002. Print.

Franks, Anton and Ken Jones. "Lessons from Brecht: A Brechtian Approach to Drama, Texts and Education [1]." Research in Drama Education 4.2 (1999): 181-201. Print.

Freshwater, Helen. "Sex, Violence and Censorship: London's Grand Guignol and the Negotiation of the Limit." Theatre Research International 32.03 (2007): 247-62. Print.

Haberer, Adolphe. "Intertextuality in Theory and Practice." LITERATÛRA 49.5 (2007): 54-67. Print.

Hand, R. J., and M. Wilson. London's Grand Guignol and the Theatre of Horror. University of Exeter Press, 2007. Print. 
MA Thesis: The Role of Misrule in the practice of Performance

Heathcote, D., L. Johnson, and C. O'Neill. Collected Writings on

Education and Drama. Northwestern University Press, 1991. Print.

Hills, Matt. How to Do Things with Cultural Theory. London: Hodder Education, 2005. Print.

Hills, Matt. Triumph of a Time Lord : Regenerating Doctor Who in the Twenty-First Century. London; New York: I.B. Tauris: Distributed in the United States by Palgrave Macmillan, 2010

Hodge, Alison. Actor Training. 2nd ed. London; New York, NY: Routledge, 2010. Print.

Hyde, L. Trickster Makes This World. Canongate Books Ltd., 2008. Print.

Idle, Eric. The Road to Mars: A Post-Modern Novel. 1st Ed. New York: Pantheon Books, 1999. Print.

Jenkins, Henry. Textual Poachers: Television Fans \& Participatory Culture. Studies in Culture and Communication. New York: Routledge, 1992. Print.

Knowles, Ronald Shakespeare and Carnival: After Bakhtin. Basingstoke, Hampshire: Macmillan Press; New York: St. Martin's Press, 1998. Print.

Koepping, Klaus-Peter. "Absurdity and Hidden Truth: Cunning Intelligence and Grotesque Body Images as Manifestations of the Trickster." History of Religions 24.3 (1985): 191-214. Print.

Lecoq, J., et al. The Moving Body: Teaching Creative Theatre. Routledge, 2002. Print.

Liddo, A. D. Alan Moore: Comics as Performance, Fiction as Scalpel. University Press of Mississippi, 2009. Print. 
Lokke, Kari E. "Bluebeard" and "the Bloody Chamber": The Grotesque of Self-Parody and Self-Assertion. Frontiers: A Journal of Women Studies 10.1 (1988): 7-12. Print.

May, Todd. Gilles Deleuze : An Introduction. New York: Cambridge University Press, 2005. Print.

McKee, Alan. "Is Doctor Who Political?" European Journal of Cultural Studies 7.2 (2004): 201-17. Print.

Merlin, Bella. The Complete Stanislavsky Toolkit. London: Nick Hern Books, 2007.

Morris, Barbra S. "Why Is George So Funny? Television Comedy, Trickster Heroism, and Cultural Studies." The English Journal 88.4 (1999): 47-52. Print.

Nichols, Nina daVinci. "The Arlecchino and Three English Tinkers." Comparative Drama 36.1-2 (2002): 145-85. Print.

Owen, Rachael and Anna Sweeting. Hoodie or Goodie? The Link between Violent Victimisation and Offending in Young People. Victim Support: Victim Support, 2007. Print.

Pickering, Kenneth, and Mark Woolgar. Theatre Studies. Houndmills; New York: Palgrave Macmillan, 2009.

Pickering, Kenneth. Key Concepts in Drama and Performance. Palgrave Key Concepts. New York: Palgrave Macmillan, 2005. 
MA Thesis: The Role of Misrule in the practice of Performance

Schechner, Richard. Performance Studies: An Introduction. 2 Ed. New York: Routledge, 2006. Print.

Schirato, T., and S. Yell. Communication and Culture: An Introduction. Sage Publications, 2000. Print.

Shakespeare, W., et al. A New Variorum Edition of Shakespeare. J.B. Lippincott \& co., 1955. Print.

Sheets, Robin Ann. "Pornography, Fairy Tales, and Feminism: Angela Carter's "the Bloody Chamber". " Journal of the History of Sexuality 1.4 (1991): 633-57. Print.

Speidel, E. "Brecht's "Puntila": A Marxist Comedy." The Modern Language Review 65.2 (1970): 319-32. Print.

Stam, Robert. Subversive Pleasures: Bakhtin, Cultural Criticism, and Film. Baltimore: Johns Hopkins University Press, 1989.

Tatar, M. Secrets Beyond the Door: The Story of Bluebeard and His Wives. Princeton University Press, 2004. Print.

Thompson, S. Leigh. "Essay: Theatre of Change (About Legislative Theatre) I the Forum Project". <http://theforumproject.org/whatisto/whatis-theatre-of-the-oppressed/essay-theatreofchange4/>.

Vecsey, Christopher. "The Exception Who Proves the Rules: Ananse the Akan Trickster." Journal of Religion in Africa 12.3 (1981): 161-77. Print.

Vice, Sue. Introducing Bakhtin. Manchester: Manchester University Press, Distributed exclusively in the USA by St. Martin's Press, 1997.

Webb, Jen, and Tony Schirato. "Bourdieu's Concept of Reflexivity as Metaliteracy."Cultural Studies 17.3/4 (2003): 539-39. Print. 
Weston, Judith. Directing Actors: Creating Memorable Performances for Film and Television. Studio City, CA: M. Wiese Productions, 1996. Print.

Wilson, Diane E. Buffy Vs. Bakhtin: Carnival and Dialogism in the Buffyverse. SC2: the Slayage Conference on the Whedonverses. 2006. Available online. 


\section{Appendix One}

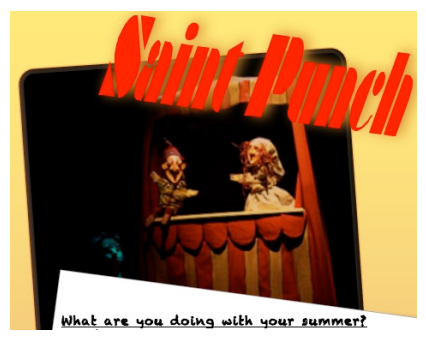

FatCircus, Workshop Number One.

When: Saturday $29^{\text {th }}$ of January 2011 from 10 to $6 \mathrm{pm}$

Where: 93 Kelburn Parade, the Theatre Programme of Victoria University of Wellington. In this first workshop, I want to focus an eye on the ideas of fear and frivolity, the mediation of the extreme, and the subversive element of the theatre. These elements in some way arise from my research into the Carnivalesque and Misrule. I am focusing on how misrule, rather than arising from breaking of the rules, manages to acknowledge and to interrogate the rules and traditions of the theatre and of the world beyond. Mikhail Bakhtin and Gilles Deleuze have been key thinkers in this process and I acknowledge theatre writings by Stanislavsky, LeCoq, Mike Alfreds, Ann Bogart and Judith Weston. I also think that without an element of misrule it becomes difficult to be creative.

Using some exercises to ease us into the mode of misrule and then moving into a short storytelling exercise I wish to examine how these elements might inform a methodology of rehearsal and vision. This is a beginning for me with this work and as such is necessarily not as deep as if a company might spend considerable time developing a voice out of this work. It is therefore important that the people attending bring their own experiences, their own eyes and creative voice to work in the spirit of the carnival.

However, what people can bring is not as important as their willingness to talk about and put a creative exercise up on its feet.

The work that comes out of this will inform the activities that will be present a fortnight later in the second workshop where the text of Saint Punch will be introduced. My intention is to bring together a number of people for the first workshop- some of whom may not be available for the performances and rehearsals of Saint Punch- however for me it would be useful to have, in addition those who are interested taking this trip with me, coming to the first of these workshops before we begin rehearsals.

Saint Punch will be rehearsed for 9 weeks and performed at 93 Kelburn Parade prior to Easter. The commitment required for this will be one weeknight rehearsal and one weekend day rehearsal for all performers.

So if you are interested in joining us (and here I acknowledge those who with patience have already indicated their interest) or can pass this on to someone who may wish to contribute, please send me an email at Gregor@fatcircus.co.nz 


\section{Appendix Two}

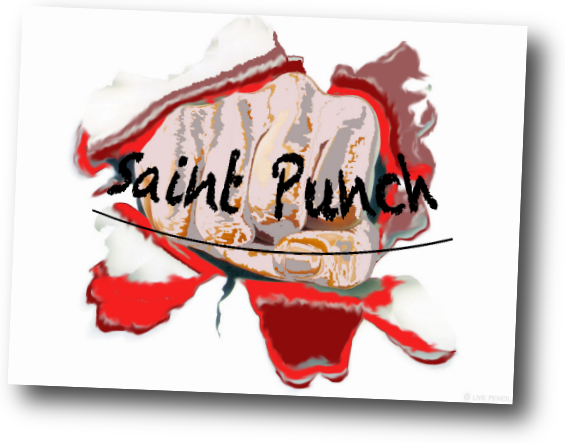

\section{Programme detail}

A story begins at the beginning, that much is obvious. A journey, a becoming. To just be, is to be trapped in a character unable to change.

Our lives, however, are always caught within an act of becoming. Even in death our lives are given over to the tapestry of history, to be interpreted and used in ways we might never have thought of. Saint Punch is such to me, one story told in three versions. Becoming something else, used by others for something other than our own intentions.

In this world of mediated fame and infamy it becomes all the more important that we stop and consider what these stories represent. I am caught up in Bakhtin's notion of Carnival. It seems to fit so nicely around the ritual of theatre and requires us to consider the mediation of our stories to exist, to become. From Bakhtin we might perceive that by entering the theatre we cross the borders into the carnival. Inside we expect to see wonders, and grotesques, to explore danger and to see the world as we know turned upside down. Thus came about the story of Gilles de Rais and Joan of Arc, of Bluebeard and Judith, and Punch \& Judy. Stories dissimilar yet connected.

This play has haunted me for a number of years, its voices crying to be realised. The opportunity to place this text central to my work here at Victoria was of immense value and I must thank John Downie for his constant provocation over twenty odd years which has brought me to this point. I also acknowledge the support of colleagues all over the School of English, Film, Theatre, and Media Studies. I also appreciate the help and support of my mentors-you know who you are. Of course there are also the stalwarts of the university, our general staff who make all things possible. 
Finally an ode to my cast and crew, who have helped me make this one of the most pleasurable times of my life, thank you one and all. I hope you enjoy the show.

\section{Cast of Characters}

Thomas Pepperell:

Emma Smith:

Rosie Tapsell:

Des Morgan:

Audrey Martin:

Patrick Coelho:

Maria Becerro Casero:

Piotr Wolodzko:

Martin Quicke:

\author{
Mr. Punch \\ Judy/ Ghost/ Crocodile/ Inquisitor \\ Joan D'Arc/ Esmerelda \\ Gilles de Rais \\ Judith \\ Bluebeard \\ Clara/Some soldiers \\ Joey//Beadle/Policeman \\ The Professor/ Poitou/ Prelati/ La Hire/ \\ Publican/ Jack Ketch
}

\section{Crew.}

Gregor Cameron:

Rosanagh Kynoch:

Shannon Friday, Courtney Leggett,

Kate Norquay, Bop Murdoch:

Stephen Keen, Andy Friedland:

Welding

Andy Friedland:

Operator

Des Morgan:

construction

Patricia Hetherington:

operation

Elliot Lim:

compositing.

By grace of cast and crew:

Stage crew and others:

\author{
Director/Producer \\ Stage Manager
}

Staging

Studio Construction \&

Lighting Advice \&

Mini-set \& Props

Sound design \&

Video design and Live

Costuming and Masks

Set Construction

\section{Music \\ Punch \& Judy Man-Fraser Hines \\ In for the Kill-Damien Brell \\ Hell-bound Train-Victoria Police Pipe Band}

Acknowledgements.

John Downie, Alex Funke, Paul Wolffram, Jim Davenport, William Franco, Tom

McCrory, Bernard Blackburn, Damien Brell, Horst Sarubin, Kerry Glamsch,

Chris Ryan, Ralph Johnson, Dawa Devereaux, ICW Productions, Shane

Roberts, Roc Travers, Sean Redmond, Doug Van Belle, Matthew Wagner,

Claire O'Loughlin, Family \& Friends always, The Wisebuys on Dixon shop.

Various histories of Gilles De Rais and Joan of Arc. Most particularly The Saint and the Devil

by Frances Winwar, 1948.

The Folk tradition and tale of Bluebeard. With awareness of Angela Carter

A Punch and Judy Script as it first appeared in London Labour and the London Poor by Henry Mayhew, published in 1851

I appreciate that these three sources gave up major inspiration to the above work, which is somewhat truthful. However take care as any truth found herein is completely coincidental and not the intention of the author 


\section{Appendix Three}

\section{Barbara Babcock-Abrahams list of Trickster characteristics:}

\section{In almost all cases, and to a greater or lesser degree, tricksters}

1. exhibit an independence from and an ignoring of temporal and spatial boundaries;

2. tend to inhabit crossroads, open public places (especially the marketplace), doorways, and thresholds. In one way or another they are usually situated between the social cosmos and the other world or chaos;

3. are frequently involved in scatological and coprophagous episodes which may be creative, destructive, or simply amusing;

4. may, similarly, in their deeds and character, partake of the attributes of Trickster-

Transformer-Culture Hero;

5. frequently exhibit some mental and/or physical abnormality, especially exaggerated sexual characteristics;

6. have an enormous libido without procreative outcome;

7. have an ability to disperse and to disguise themselves and a tendency to be multiform and ambiguous, single or multiple;

8. often have a two-fold physical nature and/or a "double" and are associated with mirrors.

Most noticeably, the trickster tends to be of uncertain sexual status;

9. follow the "principle of motley" in dress;

10. are often indeterminant (in physical stature) and may be portrayed as both young and old, as perpetually young or perpetually aged;

11. exhibit an human/animal dualism and may appear as a human with animal characteristics or vice versa; (even in those tales where the trickster is explicitly identified as an animal, he is anthropomorphically described and referred to in personal pronouns);

12. are generally amoral and asocial - aggressive, vindictive, vain, defiant of authority, etc.;

13. despite their endless propensity to copulate, find their most abiding form of relationship with the feminine in a mother or grandmother bond;

14. in keeping with their creative/destructive dualism, tricksters tend to be ambiguously situated between life and death, and good and evil, as is summed up in the combined black and white symbolism frequently associated with them;

15. are often ascribed to roles (i.e., other than tricky behavior) in which an individual normally has privileged freedom from some of the demands of the social code;

16. in all their behavior, tend to express a concomitant breakdown of the distinction between reality and reflection ${ }^{43}$.

From Babcock-Abrahams, Barbara. "A Tolerated Margin of Mess": The Trickster and His Tales Reconsidered." Page 159-160

\footnotetext{
43 See Laura Makarius, "Ritual Clowns and Symbolic Behavior," Diogenes no. 69 (1970): 66, for a related list of characteristics she sees as common to both clown and trickster. Cf. Turner, "Myth and Symbol," p. 578.
} 


\section{Appendix Four}

\section{Specific Influences}

Here is a told original version of the Anansi story that Neil Gaiman used and I adapted for use with Mr Punch.

\section{Anansi kills his Grandmother.}

William Cooper, Mandeville.

Anansi an' Tiger were travelling. Anansi kill him old grandmother, him put him into a little handcart was shoving him t'ru de town. After him catch to a shop jes' like out here, de shopkeeper was a very hasty-temper man; an' went in de shop an' call fe some whiskey an' give it to one of de shopkeeper carry it to his grandmother. An' said he mus' go up to de han'cart an' call twice. An' de ol' lady did not hear. So Anansi said to de shop-keeper him mus' holla out to de ol' lady; him sleeping. So de ol' lady didn't hear, he fire de glass in de ol' lady face, an' de ol' lady fell right over. Then the shop-keeper get so frighten he cry out to Anansi, say Anansi mustn't mek no alarm in de town; he will give him a bushel of money to mek him keep quiet.

So dem was going along an' borrow a quart can from Tiger an' was measuring dis money. Tiger said, "Where you get all dat money?" Anansi say, "I kill my ol' grandmother." Tiger, him went home an' kill his grandmother an' put her up in a little hand-cart an' was goin' along t'ru de town hollerin' out to all de people, "Who want a dead body to buy?" So Anansi said to Tiger he shouldn't do anyt'ing like dat; too foolish! ${ }^{44}$

"First they came..." is a famous statement attributed to pastor Martin Niemöller (1892-1984) about the inactivity of German intellectuals following the Nazi rise to power and the purging of their chosen targets, group after group. The text of the quotation is usually presented roughly as follows:

First they came for the communists,

and I didn't speak out because I wasn't a communist.

Then they came for the trade unionists,

and I didn't speak out because I wasn't a trade unionist.

Then they came for the Jews,

and I didn't speak out because I wasn't a Jew.

Then they came for the Catholics,

and I didn't speak out because I was Protestant.

Then they came for me

and there was no one left to speak out for me.

Martin Niemöller was a German pastor and theologian born in Lippstadt, Germany, in 1892. Niemöller was an anti-Communist and supported Hitler's rise to power at first. But when Hitler insisted on the supremacy of the state over religion, Niemöller became disillusioned. He became the leader of a group of German clergymen opposed to Hitler. He was imprisoned in Sachsenhausen concentration camp ${ }^{45}$

\footnotetext{
${ }^{44}$ aren.org/prison/documents/African/14/14.pdf accessed 18/9/1

45 http://en.wikipedia.org/wiki/First_they_came... Accessed 22/1/12
} 